Check for updates

Cite this: Phys. Chem. Chem. Phys., 2020, 22, 10189

Received 23rd December 2019 Accepted 20th April 2020

DOI: $10.1039 / \mathrm{c} 9 \mathrm{cp} 06924 \mathrm{k}$

rsc.li/pccp

\section{Evaluation of bismuth-based dispersion energy donors - synthesis, structure and theoretical study of 2-biphenylbismuth(III) derivatives $\dagger$}

\author{
Ana-Maria Fritzsche, ${ }^{\text {ab }}$ Sebastian Scholz, ${ }^{a}$ Matgorzata Krasowska, ${ }^{c}$ \\ Kalishankar Bhattacharyya, (D) ${ }^{c}$ Ana Maria Toma, ${ }^{\text {ad }}$ Cristian Silvestru, ${ }^{d}$ \\ Marcus Korb, (D) ef Tobias Rüffer, (D) ${ }^{\text {e }}$ Heinrich Lang, (D) ${ }^{\text {be }}$ Alexander A. Auer (D) *c \\ and Michael Mehring (D) *ab
}

\begin{abstract}
A series of 2-biphenyl bismuth(II) compounds of the type (2- $\left.\mathrm{PhC}_{6} \mathrm{H}_{4}\right)_{3-n} \mathrm{BiX}_{n}[n=0$ (1); $n=1, \mathrm{X}=\mathrm{Cl}(\mathbf{2})$, $\mathrm{Br}$ (3), I (4), $\mathrm{Me}(5) ; n=2, X=\mathrm{Cl}(\mathbf{6}), \mathrm{Br}(\mathbf{7}), \mathrm{I}(\mathbf{8})]$ has been synthesized and analyzed with focus on intramolecular London dispersion interactions. The library of the compounds was set up in order to investigate the $\mathrm{Bi} \cdots \pi$ arene interaction by systematic variation of $X$. The structural analysis in the solid state revealed that the triarylbismuth(III) compound 1 shows an encapsulation of the metal atom but the distances between the bismuth atom and the phenyl centroids amount to values close to or larger than $4.0 \AA$, which is considered to be a rather week dispersion interaction. In the case of monomeric diorganobismuth(III) compounds 2-5 the moderate crowding effectively hinders the formation of intermolecular donor-acceptor interactions, but allows for intramolecular dispersion-type interactions with the 2-biphenyl ligand. In contrast, the structures of the monoorganobismuth compounds $\mathbf{6 - 8}$ show the formation of $\mathrm{Bi}-\mathrm{X}$...Bi donor-acceptor bonds leading to the formation of $1 \mathrm{D}$ ribbons in the solid state. These coordination bonds are accompanied by intermolecular dispersion interactions with $\mathrm{Bi}$...Ph $\mathrm{Ph}_{\text {centroid }}$ distances < $4.0 \AA$. In solution the diorganobismuth(II) halides 2-4 show a broadening of their NMR signals $\left(\mathrm{H}-8, \mathrm{H}-\mathrm{8}^{\prime}\right.$ and $\mathrm{H}-9, \mathrm{H}-9^{\prime}$ protons of the 2-biphenyl ligand), which is a result of dynamic processes including ligand rotation. For further elucidation of these processes compounds 2, 4 and $\mathbf{7}$ were studied by temperature-dependent NMR spectroscopy. Electronic structure calculations at the density functional theory and DLPNO-coupled cluster level of theory were applied to investigate and quantify the intramolecular London dispersion interactions, in an attempt to distinguish between basic intramolecular interactions and packing effects and to shed light on the dynamic behavior in solution.
\end{abstract}

\section{Introduction}

Over the past several years, London dispersion interaction of main group elements has witnessed increasing interest both experimentally ${ }^{1-9}$ and theoretically, ${ }^{10-16}$ and was demonstrated to be relevant in the field of organometallic chemistry with regard to structure and properties even of small molecules. In recent reports it is discussed that weak dispersion interactions of the type metal $\cdots \pi$ arene contribute significantly to the assembling processes of molecular units in supramolecular structures,

\footnotetext{
${ }^{a}$ Technische Universität Chemnitz, Fakultät für Naturwissenschaften, Institut für Chemie, Professur Koordinationschemie, 09107 Chemnitz, Germany. E-mail: michael.mehring@chemie.tu-chemnitz.de

${ }^{b}$ Center for Materials, Architectures and Integration of Nanomembranes (MAIN), Rosenbergstr. 6, 09126 Chemnitz, Germany

${ }^{c}$ Max-Planck-Institut für Kohlenforschung, Kaiser-Wilhelm-Platz 1, 45470 Mülheim an der Ruhr, Germany. E-mail: alexander.auer@kofo.mpg.de

${ }^{d}$ Babeș-Bolyai University, Faculty of Chemistry and Chemical Engineering, Department of Chemistry, Supramolecular Organic and Organometallic Chemistry Centre (SOOMCC), 11 Arany Janos, 400028 Cluj-Napoca, Romania

${ }^{e}$ Technische Universität Chemnitz, Fakultät für Naturwissenschaften, Institut für Chemie, Professur Anorganische Chemie, 09107 Chemnitz, Germany

${ }^{f}$ The University of Western Australia, Faculty of Science, School of Molecular Sciences, Crawley, Perth, WA 6009, Australia

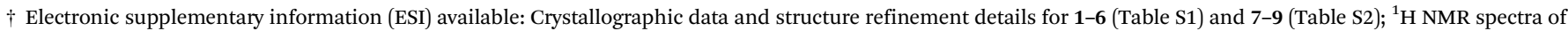

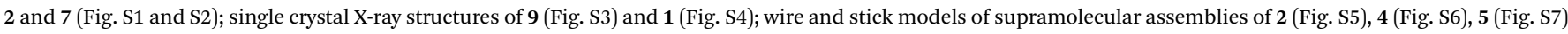

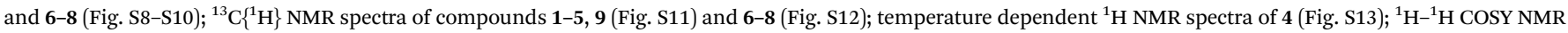

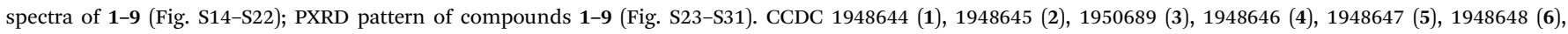
1950690 (7), 1948649 (8), 1948650 (9). For ESI and crystallographic data in CIF or other electronic format see DOI: 10.1039/c9cp06924k
} 


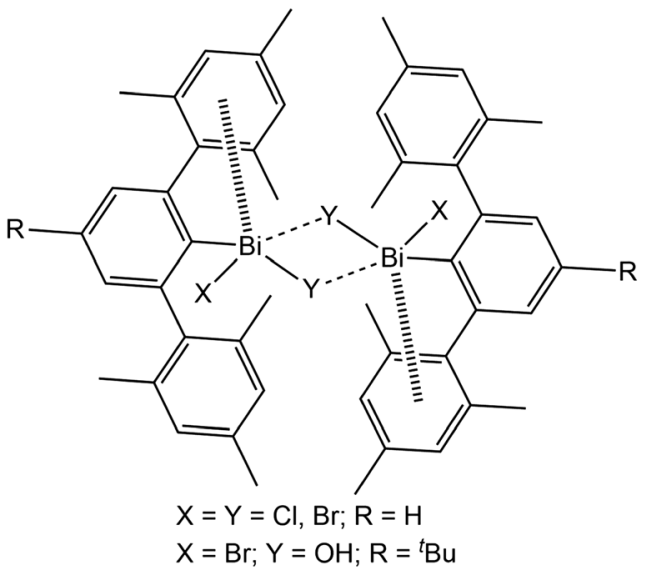

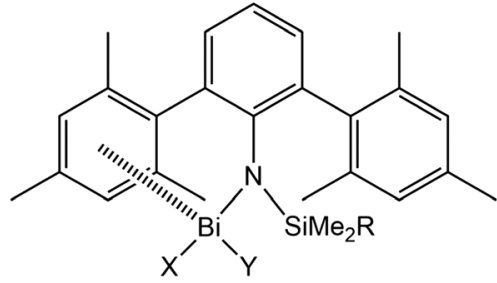

$$
\begin{aligned}
& X=Y=C l, I, N_{3} ; R=M e \\
& X=M e ; Y=C l, \text { OTf; } R=\text { OTf }
\end{aligned}
$$
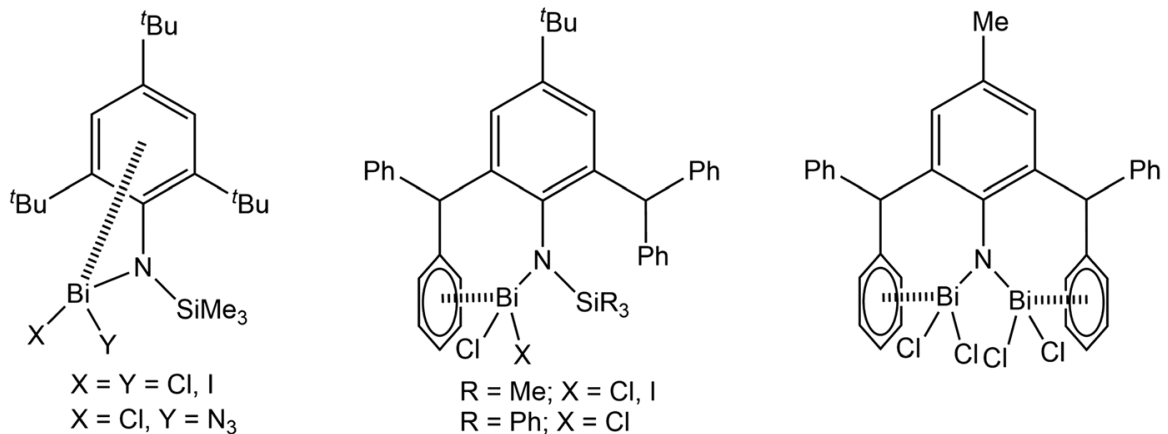

Scheme 1 Selected molecules showing intramolecular $\mathrm{Bi} \cdots \pi$ arene interactions with significant impact on structure and reactivity. ${ }^{24,27-32}$

which might open up new directions of dynamic structural evolution of supramolecular architectures. ${ }^{6-8}$ With regard to this and to build up a better understanding of the basic principles intermolecular, London dispersion interactions for diverse arylbismuth compounds have been studied in our research groups, ${ }^{16-22}$ and the effect on polymorphism and phase transition in compounds of the type $\mathrm{Ar}_{3} \mathrm{Bi}\left(\mathrm{Ar}=\mathrm{C}_{4} \mathrm{H}_{3} \mathrm{NMe}, \mathrm{C}_{4} \mathrm{H}_{3} \mathrm{O}, \mathrm{C}_{4} \mathrm{H}_{3} \mathrm{~S}, \mathrm{C}_{4} \mathrm{H}_{3} \mathrm{Se}\right)$ was demonstrated. ${ }^{18,21}$ In the last years, the importance of intramolecular $\mathrm{Bi} \cdots \pi$ arene interactions for the stabilisation of unusual organobismuth compounds, mainly bearing ligands of the terphenyl type, has been demonstrated by several other research groups (Scheme 1). ${ }^{23-32}$ Although it is now well accepted that dispersion interaction plays an important role in structure formation, there is still need for systematic investigations in order to determine the influence of e.g. the ligands $\mathrm{X}$ in organobismuth(III) compounds of the type $\mathrm{Ar}_{3-n} \mathrm{BiX}_{n}(n=0,1,2)$. A future aim is to make use of this type of interaction in supramolecular design strategies controlled by the strength and nature of the interaction of aryl ligands with bismuth and other heavy metals.

To reach this goal theoretical work is necessary in addition to experimental studies. So far, computational studies on pnictogen $\cdots \pi$ arene interactions address mainly intermolecular interactions, ${ }^{13,16,20,21,33}$ whereas only a limited number of studies on intramolecular interactions of this type is reported. ${ }^{25,29,32}$ For example, intermolecular pnictogen $\cdots \pi$ arene interaction were investigated earlier using computational methods (BP86D3/def2-TZVPD level of theory) by Frontera and coworkers on a series of systems involving different types of benzene derivatives and the heavier pnictogenes $\mathrm{ECl}_{3}(\mathrm{E}=\mathrm{As}, \mathrm{Sb}, \mathrm{Bi}) .{ }^{14,15}$ In a more recent paper we have investigated the intermolecular interaction between various compounds of the type $\operatorname{BiX}_{3}(\mathrm{X}=\mathrm{H}, \mathrm{Me}, \mathrm{Ph}$, $\mathrm{OH}, \mathrm{OMe}, \mathrm{F}, \mathrm{Cl}, \mathrm{Br}$ ) and $\mathrm{C}_{6} \mathrm{H}_{6}$ (Scheme 2, A). These studies have shown that the nature and strength of the dispersion interaction is strongly influenced by the ligand $\mathrm{X} \cdot{ }^{16,20}$ The higher the bismuth is polarized by $\mathrm{X}$, the stronger is the interaction and the shorter is the $\mathrm{Bi} \cdots \mathrm{Ph}_{\text {centroid }}$ distance. The calculations revealed a pure dispersive interaction for the methyl group, while the chlorine induces a significant donor-acceptor behaviour. This interplay between dispersion and donor-acceptor properties results from the $\left(\pi \rightarrow \sigma^{*}\right)$ charge transfer. Another study was focused on the $\mathrm{As}, \mathrm{Sb}$ and Bi adducts $\mathrm{EX}_{3} \cdots \mathrm{C}_{6} \mathrm{H}_{6}(\mathrm{X}=\mathrm{Me}, \mathrm{OMe}, \mathrm{Cl})$ (Scheme 2, B) and it was analysed how the dispersion interaction strength is altered by exchanging the pnictogen $\mathrm{E}$. The interaction energies calculated at the DLPNO-CCSD(T) level increase from As $<\mathrm{Sb}<\mathrm{Bi}$ and range from $-10 \mathrm{~kJ} \mathrm{~mol}^{-1}$ to $-40 \mathrm{~kJ} \mathrm{~mol}^{-1}$ for $\mathrm{ECl}_{3} \cdots \mathrm{C}_{6} \mathrm{H}_{6}(\mathrm{E}=\mathrm{As}, \mathrm{Sb}, \mathrm{Bi}) .{ }^{34}$ In a recent paper we have also discussed the interaction between $\mathrm{BiCl}_{3}$ and benzene derivatives with either one or three substituents being $\mathrm{R}=\mathrm{CF}_{3}, \mathrm{NO}_{2}, \mathrm{NH}_{2}, \mathrm{OH}$, $\mathrm{OCH}(\mathrm{O})$ (Scheme 2, C). The results show that the substituents of the arene have a significant influence on the interaction strength and structure of the formed adducts $\left(\right.$ e.g. $\left.\mathrm{BiCl}_{3} \cdots \mathrm{C}_{6} \mathrm{H}_{5} \mathrm{R}\right)$ and especially substituents that increase the electron density in the aromatic ring increase the strength of the donor-acceptor interaction and vice versa. ${ }^{35}$ The overall interaction energy might transcend $-70 \mathrm{~kJ} \mathrm{~mol}^{-1}$ in compounds of the type $\mathrm{BiCl}_{3} \cdots \mathrm{C}_{6} \mathrm{H}_{3} \mathrm{R}_{3}$. 


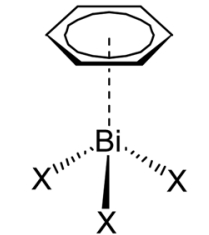

$$
\begin{gathered}
X=\underset{\mathrm{OMe}, \mathrm{F}, \mathrm{Cl}, \mathrm{Br}}{\mathrm{H}}, \\
\text { OM }
\end{gathered}
$$

A

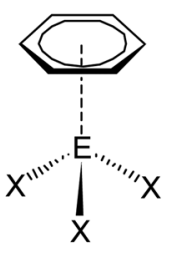

$\mathrm{E}=\mathrm{As}, \mathrm{Sb}, \mathrm{Bi}$

$\mathrm{X}=\mathrm{CH}_{3}, \mathrm{OMe}, \mathrm{Cl}$
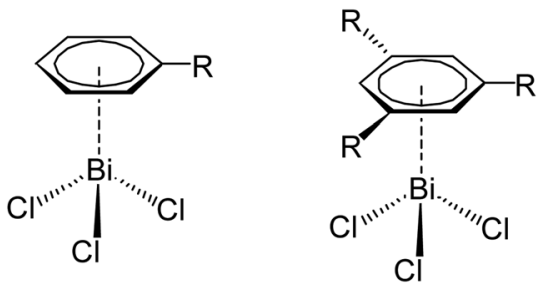

$\mathrm{R}=\mathrm{CF}_{3}, \mathrm{NO}_{2}, \mathrm{NH}_{2}, \mathrm{OH}, \mathrm{OCOH}$

Scheme 2 Different dispersion adducts of aromatic systems with trivalent heavy pnictogen compounds $\left(E_{3}\right) .{ }^{16,20,34,35}$

On the basis of our previous studies here the synthesis, characterization and the crystal structures of the arylbismuth(III) compounds $\left(2-\mathrm{PhC}_{6} \mathrm{H}_{4}\right)_{3-n} \mathrm{BiX}_{n}[n=0$ (1); $n=1, \mathrm{X}=\mathrm{Cl}(2), \mathrm{Br}(3)$, $\mathrm{I}(\mathbf{4}), \mathrm{Me}(5) ; n=2, \mathrm{X}=\mathrm{Cl}(\mathbf{6}), \mathrm{Br}(7), \mathrm{I}(\mathbf{8})]$ are reported (Scheme 3). They are composed of bismuth acting as DED (Dispersion Energy Donor) and 2-biphenyl as a rigid intramolecular ligand. The influence of the ligand $\mathrm{X}$ on the strength of the intramolecular bismuth $\cdots \pi$ arene interaction was analysed experimentally and by using electronic structure calculations.

\section{Results and discussion}

\section{Synthesis}

The first report on the synthesis of $\left(2-\mathrm{PhC}_{6} \mathrm{H}_{4}\right)_{3} \mathrm{Bi}$ dates back to 1936, based on the reaction of the Grignard reagent 2- $\mathrm{PhC}_{6} \mathrm{H}_{4} \mathrm{MgBr}$ and $\mathrm{BiCl}_{3}{ }^{36}$ Later on, the synthesis of the related derivatives of the lighter pnictogens, i.e. $\left(2-\mathrm{PhC}_{6} \mathrm{H}_{4}\right)_{3} \mathrm{E}(\mathrm{E}=\mathrm{P}$, As and $\mathrm{Sb}) \mathrm{using}$ the Wurtz-Fittig method, employing sodium was reported. ${ }^{37}$ However, neither the determination of the crystal structures

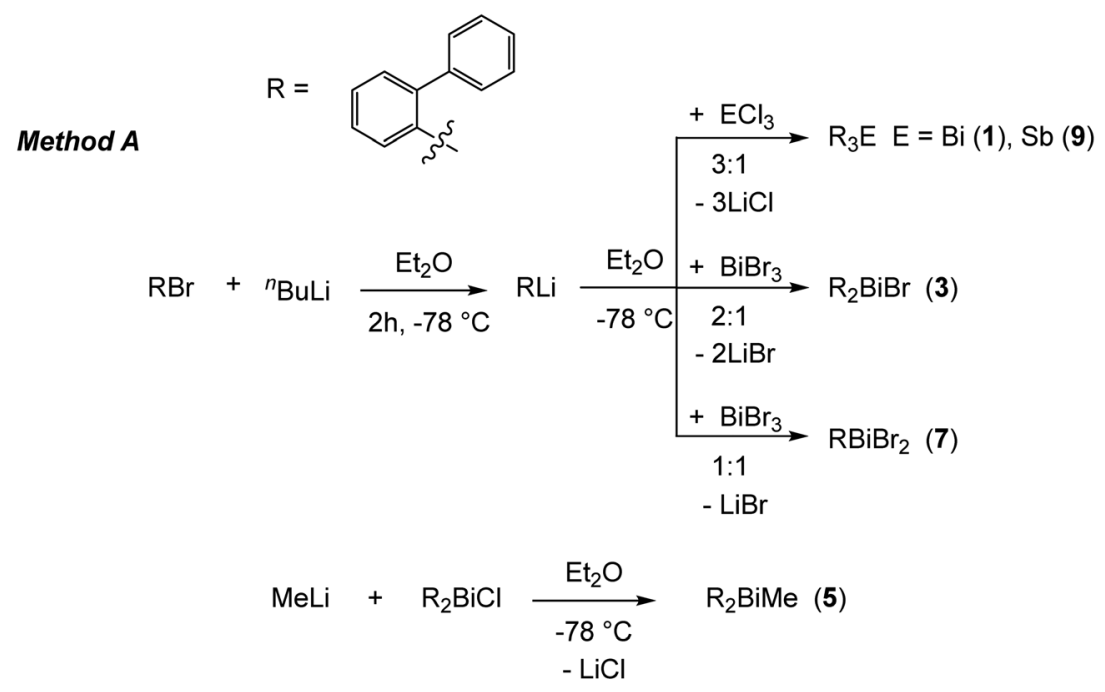

Method B

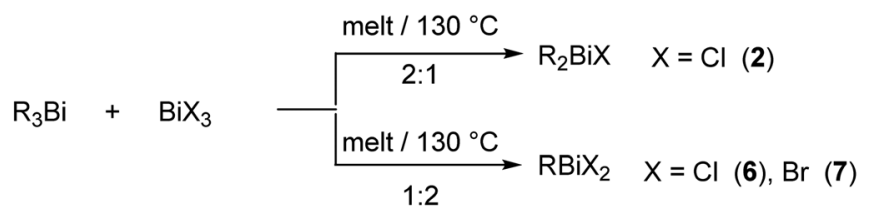

Method C

$$
\begin{aligned}
& \mathrm{R}_{2} \mathrm{BiBr}+\mathrm{Kl} \underset{\substack{1: 1 \\
-\mathrm{KBr}} \stackrel{\mathrm{EtOH}}{\longrightarrow}}{\stackrel{\mathrm{KB}}{\longrightarrow}} \mathrm{R} \text { Bil (4) } \\
& \mathrm{RBiBr}_{2}+\mathrm{KI} \underset{-2}{\stackrel{\mathrm{EtOH}}{1: 2}} \mathrm{RBil}_{2} \text { (8) }
\end{aligned}
$$

Scheme 3 Synthetic routes for the preparation of the organobismuth(III) compounds $\left(2-\mathrm{PhC}_{6} \mathrm{H}_{4}\right)_{3-n} \mathrm{BiX}_{n}(\mathbf{1}-\mathbf{8})$ and $\left(2-\mathrm{PhC}_{6} \mathrm{H}_{4}\right)_{3} \mathrm{Sb}(\mathbf{9})$. 
of these compounds nor of their halogen derivatives was published so far.

The compounds reported herein of the type $\left(2-\mathrm{PhC}_{6} \mathrm{H}_{4}\right)_{3-n} \mathrm{BiX}$ $[n=0 ;(1) ; n=1, \mathrm{X}=\mathrm{Cl}(2), \mathrm{Br}(3), \mathrm{Me}(5) ; n=2, \mathrm{X}=\mathrm{Cl}(6), \mathrm{Br}(7)]$ were prepared either via (i) salt elimination reactions between 2-biphenyllithium and $\mathrm{BiX}_{3}(\mathrm{X}=\mathrm{Cl}, \mathrm{Br}),(3: 1,2: 1$ and $1: 1$ molar ratio), or methyllithium and $\left(2-\mathrm{PhC}_{6} \mathrm{H}_{4}\right)_{2} \mathrm{BiCl}$ in $\mathrm{Et}_{2} \mathrm{O}$ solution, at $-78{ }^{\circ} \mathrm{C}$ (Method $\mathrm{A}$, Scheme 3), or (ii) solvent-free redistribution reactions between $\left(2-\mathrm{PhC}_{6} \mathrm{H}_{4}\right)_{3} \mathrm{Bi}$ and $\mathrm{BiX}_{3}$ (1:2 molar ratio) carried out at $130{ }^{\circ} \mathrm{C}$ (Method B, Scheme 3). The compounds were isolated as colorless crystalline solids in moderate to good yields. Treatment of the organobismuth(III) bromides in EtOH with KI gave, via halogen exchange reactions (Method $\mathrm{C}$, Scheme 3), the iodides $\left(2-\mathrm{PhC}_{6} \mathrm{H}_{4}\right)_{2} \mathrm{BiI}(4)$ and $\left(2-\mathrm{PhC}_{6} \mathrm{H}_{4}\right) \mathrm{BiI}_{2}$ (8) as yellow and orange solids in good yields. The compound $\left(2-\mathrm{PhC}_{6} \mathrm{H}_{4}\right)_{3} \mathrm{Sb}(9)$ was prepared using the same synthetic procedure as described for $\mathbf{1}$ and was obtained as a colorless solid (Scheme 3 ). The compounds 1-9 are soluble in common organic solvents, but the bismuth compounds are air and heat sensitive. In solution and in the solid state the compounds slowly decompose and hence must be stored under inert conditions. The stability of the organobismuth(III) halides was analysed by time dependent ${ }^{1}$ H NMR spectroscopy (see ESI, $\dagger$ Fig. S1 and S2). The compounds decompose in the course of five to six days via redistribution reactions finally leading to the formation of biphenyl.

\section{Molecular structures of the triarylpnictogen(III) compounds 1 and 9}

Single crystals suitable for X-ray diffraction analysis of $\mathbf{1}$ were grown from a $n$-hexane solution and the molecular structure is illustrated in Fig. 1. Selected bond lengths and angles are listed in the figure caption and the crystallographic data are given in Table S1 (ESI $\dagger$ ). Compound 1 crystallizes in the monoclinic space group $P 2_{1} / n$ and is isomorphous with $\left(2-\mathrm{PhC}_{6} \mathrm{H}_{4}\right)_{3} \mathrm{Sb}(\mathbf{9})$ (see the ESI, $\dagger$ Fig. S3). A detailed discussion of the crystal

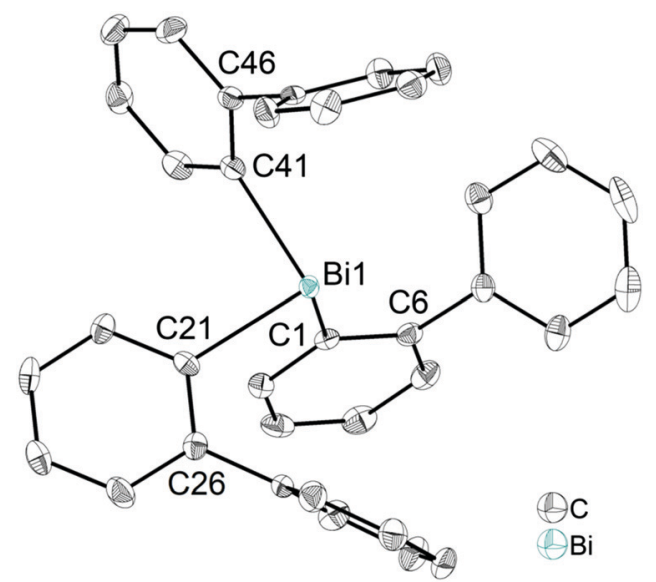

Fig. 1 Thermal ellipsoid model of $\left(2-\mathrm{PhC}_{6} \mathrm{H}_{4}\right)_{3} \mathrm{Bi}$ (1) at $50 \%$ probability level. Hydrogen atoms are omitted for clarity. Selected bond lengths $[\AA \AA]$ :

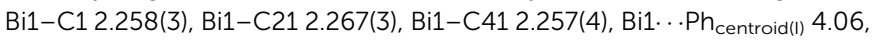
Bi1...Ph $\mathrm{Ph}_{\text {centroid(II) }} 4.04, \mathrm{Bi1} \ldots \mathrm{Ph}_{\text {centroid(III) }}$ 3.99. Selected bond angles $\left[^{\circ}\right]$ : C1-Bi1-C21 95.28(12), C1-Bi1-C41 96.04(12), C21-Bi1-C41 92.33(12), Bi1-C1-C6 118.1(2), Bi1-C21-C26 118.0(3), Bi1-C41-C46 117.0(2). structure of $\mathbf{9}$ is presented in the ESI. $\dagger$ The molecular structure of 1 shows a trigonal pyramidal geometry at the metal atom with average $\mathrm{C}-\mathrm{E}-\mathrm{C}$ bond angles of $94.6^{\circ}$ for 1 . The average values of the $\mathrm{Bi}-\mathrm{C}$ bond lengths of $2.261 \AA$ are within the ranges reported for other arylbismuthine derivatives, i.e. $\mathrm{Ph}_{3} \mathrm{Bi},{ }^{20,38,39}$ $\mathrm{Mes}_{3} \mathrm{Bi}^{40}$ and $(p \text {-tolyl })_{3} \mathrm{Bi}^{41}$

Compound 1 shows an encapsulation of the bismuth atom by the 2-biphenyl ligands (Bi $\cdots$ Ph $_{\text {centroid: }} 3.99 \AA$, $4.04 \AA$ and $4.06 \AA$ ), however, the $\mathrm{Bi} \cdot \mathrm{Ph}_{\text {centroid }}$ distances are found close to $4.0 \AA$, which can be considered as the limit of significant London dispersion interaction for these systems based on previous theoretical work. ${ }^{35}$ However, the structure of 1 revealed $1 \mathrm{D}$ ribbon-like structures (Fig. S4(i), ESI $\dagger$ ) which are formed via $\mathrm{C}-\mathrm{H} \cdots \mathrm{Ph}_{\text {centroid }}$ intermolecular contacts with a distance of $\mathrm{C} 24-\mathrm{H} 24 \cdots \mathrm{Ph}_{\text {centroid }}$ $2.55 \AA$ and an angle $\gamma=5.6^{\circ}$ between the ring normal and the vector between the ring centroid and the hydrogen atom. The $1 \mathrm{D}$ ribbons are further connected via the $\mathrm{C}-\mathrm{H} \cdots \mathrm{Ph}$ intermolecular contacts $\mathrm{C} 43-\mathrm{H} 43 \cdots \mathrm{Ph}_{\text {centroid }} 3.06 \AA\left(\gamma=10.3^{\circ}\right)$ to give a $2 \mathrm{D}$ network in the solid state (see the ESI, $\dagger$ Fig. S4(ii)).

\section{Molecular structures of the diarylbismuth halides 2-4 and the diarylmethylbismuthine 5}

Single crystals suitable for X-ray crystallography were isolated upon crystallization at ambient temperature from a $n$-hexane solution (for 2, 3), from a $\mathrm{CHCl}_{3}$ solution (for 4) and by slow diffusion of $\mathrm{Et}_{2} \mathrm{O}$ into $n$-pentane solution at $-28{ }^{\circ} \mathrm{C}$ (for 5 ). The molecular structures of the diarylbismuth(III) halides are depicted in figures $\mathbf{2 - 5}$, the selected bond lengths and angles are listed in the figure captions, and their crystallographic data are given in Table S1 (ESI $\dagger$ ). The compounds crystallize in the triclinic space group $P \overline{1}$ (2 and 4 ) and the monoclinic space groups $P 2_{1} / n$ (3) and $P 2_{1}(5)$. The asymmetric unit of 2 comprises two crystallographically independent molecules, denoted as $\mathbf{2 a}(\mathrm{Bi} 1)$ and $\mathbf{2 b}$ (Bi2). Related bond lengths and angles of $\mathbf{2 a}$ and $\mathbf{2 b}$ differ by up to $2 \%$, however, in the following we focus on data of 2a. All the compounds show monomeric structures in the solid state with intramolecular dispersion interactions of the type $\mathrm{Bi} \cdots \pi$ arene. The corresponding $\mathrm{Bi} \cdots \mathrm{Ph}_{\text {centroid }}$ distances are Bi1 $\cdots \mathrm{Ph}_{\text {centroid(I) }} 3.92 \AA$ (2a, Fig. 2(i)), Bi1 $\cdots \mathrm{Ph}_{\text {centroid(I) }}$ $3.82 \AA$ (3, Fig. 3(i)) and for 4 Bi1 $\cdots$ Ph $_{\text {centroid(I) }} 3.89 \AA$ and Bi1 . . Ph centroid(II) $3.98 \AA$ (Fig. 4(i)). The angle $\gamma^{\prime}$, which is defined as the angle between the ring normal and the vector between the ring centroid and the bismuth atom, amounts to $46.5^{\circ}$. At least one of the Bi-C-C angles for 2a (Bi1-C13-C18 116.3(2) $)^{\circ}$, 3 (Bi1-C13-C18 114.6(3) $)^{\circ}$ and 4 (Bi1-C1-C6 116.2(8) ${ }^{\circ}$, Bi1-C13$\left.\mathrm{C} 18117.4(8)^{\circ}\right)$ is slightly compressed in comparison to the triorganobismuthine $\mathbf{1}$. This is indicative for a dispersion interaction between bismuth and one phenyl moiety in 2-4.

Due to the $\mathrm{Bi} \cdots \pi$ arene interactions the geometry at the bismuth atoms is best described as distorted pseudo-trigonal bipyramidal with the $\mathrm{Ph}_{\text {centroid }}$ trans to the halogen atom

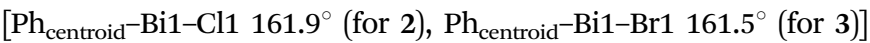
and the carbon atoms placed in the equatorial positions [C1-Bi1-C13 93.30(12) ${ }^{\circ}, \mathrm{C} 1-\mathrm{Bi1}-\mathrm{Cl} 1$ 89.64(8) ${ }^{\circ}, \mathrm{C} 13-\mathrm{Bi} 1-\mathrm{Cl} 1$ 92.89(9) ${ }^{\circ} \quad$ (for 2a), C1-Bi1-C13 96.09(17) ${ }^{\circ}, \quad$ C1-Bi1-Br1 92.33(14) ${ }^{\circ}$, C13-Bi1-Br1 93.63(14) ${ }^{\circ}$ (for 3)]. 

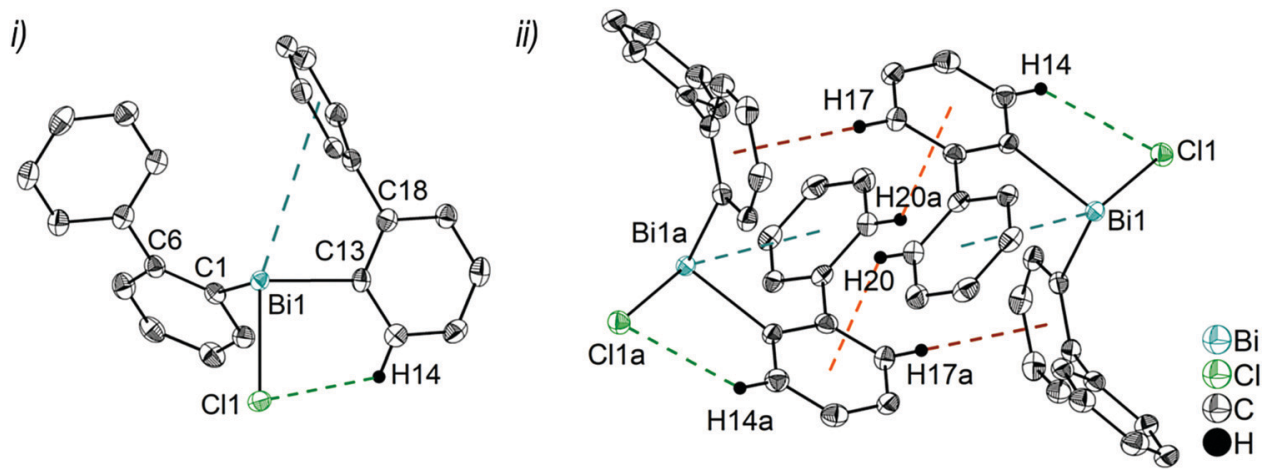

Fig. 2 Thermal ellipsoid model of $\left(2-\mathrm{PhC}_{6} \mathrm{H}_{4}\right)_{2} \mathrm{BiCl}(\mathbf{2})$ at $50 \%$ probability level showing: (i) the molecular structure of 2 a. Hydrogen atoms are omitted for clarity, except those involved showing intra- or intermolecular contacts. Selected bond lengths [Å]: Bi1-C1 2.264(3), Bi1-C13 2.263(3), Bi1-Cl1 2.519(1), Bi1 ...Ph centroid(I) $^{3.92}\left(\gamma^{\prime}=46.5^{\circ}\right), \mathrm{Bi1} \ldots \mathrm{Ph}_{\text {centroid(II) }} 4.26, \mathrm{H} 14 \ldots \mathrm{Cl1}$ 2.81. Selected bond angles [ [ ]: C1-Bi1-C13 93.30(12), C1-Bi1-Cl1 89.64(8), C13-Bi1-Cl1 92.89(9), Bi1-C1-C6 120.8(2), Bi1-C13-C18 116.2(2). (ii) Dimer association: C17-H17 $\ldots \mathrm{Ph}_{\text {centroid }} 2.73 \AA\left(\gamma=2.9^{\circ}\right), \mathrm{C} 20-\mathrm{H} 20 \ldots \mathrm{Ph}$ centroid $2.93 \AA$ $\left(\gamma=6.8^{\circ}\right)$. Symmetry transformations: $a=1-x,-y, 1-z$.
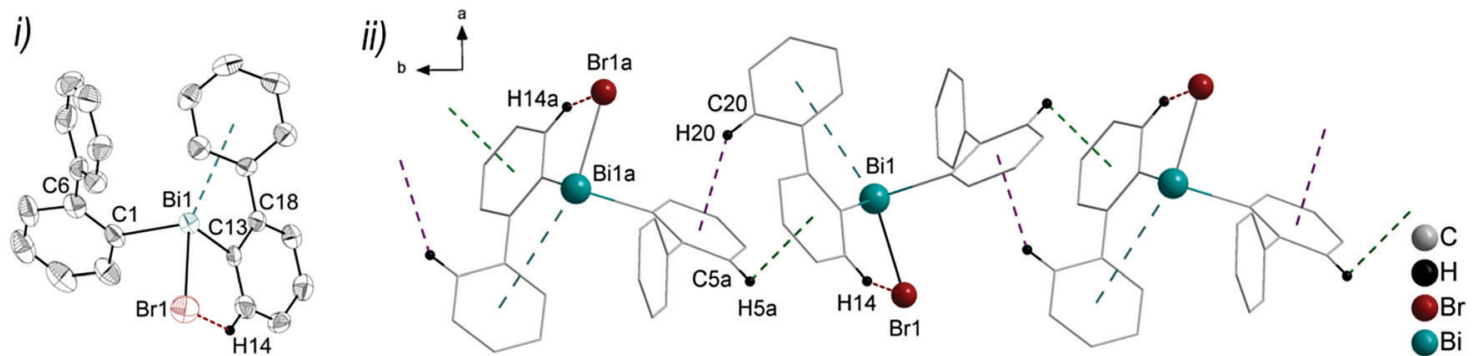

Fig. 3 (i) Thermal ellipsoid model of $\left(2-\mathrm{PhC}_{6} \mathrm{H}_{4}\right)_{2} \mathrm{BiBr}(3)$ at $60 \%$ probability level. Hydrogen atoms are omitted for clarity, except those involved showing intra- or intermolecular contacts. Selected bond lengths [Å]: Bi1-C1 2.240(5), Bi1-C13 2.252(5), Bi1-Br1 2.655(7), Bi1 . P Ph centroid(I) 3.82 ( $\gamma^{\prime}=43.4^{\circ}$ ),

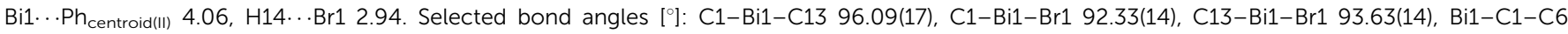
118.8(3), Bi1-C13-C18 114.6(3). (ii) Wire and stick model of $1 \mathrm{D}$ ribbons (view along the $\mathrm{C}$-axis): $\mathrm{C} 20-\mathrm{H} 20 \ldots \mathrm{Ph}_{\mathrm{centroid}} 2.94 \AA\left(\gamma=12.6^{\circ}\right.$ ), $\mathrm{C} 5 \mathrm{a}-\mathrm{H} 5 \mathrm{a}_{\text {arene }} \cdots \mathrm{Ph}_{\text {centroid }} 3.07 \AA\left(\gamma=14.5^{\circ}\right)$. Symmetry transformations: $a=-1+x, 1+y, z$.
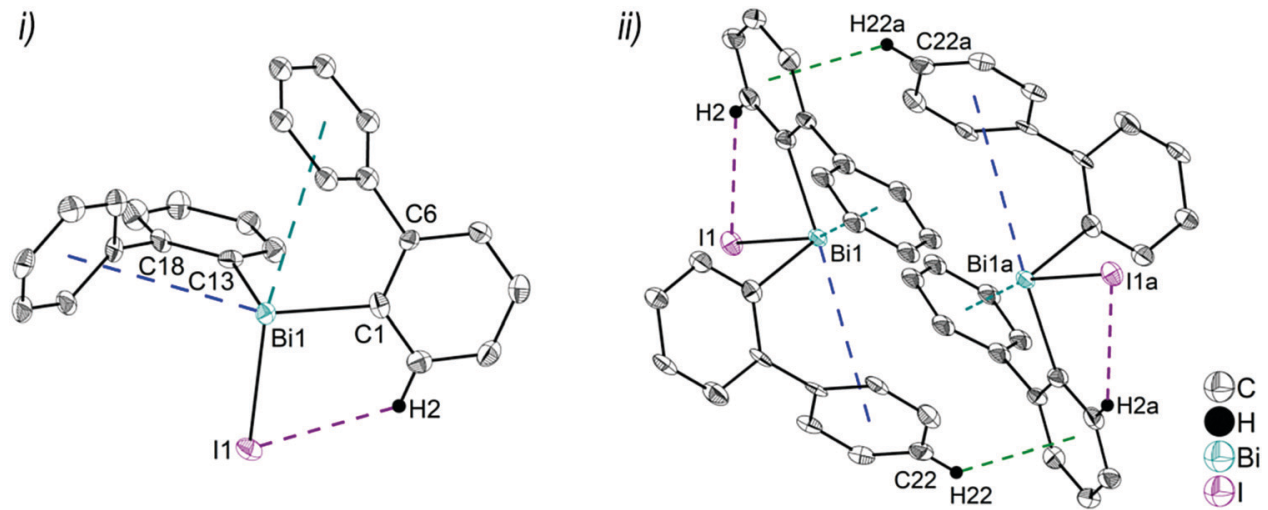

Fig. 4 Thermal ellipsoid model of $\left(2-\mathrm{PhC}_{6} \mathrm{H}_{4}\right)_{2} \mathrm{Bil}(\mathbf{4})$ at $50 \%$ probability level showing: (i) the molecular structure of 4 . Hydrogen atoms are omitted for clarity, except those involved showing intra- or intermolecular contacts. Selected bond lengths [Å]: Bi1-C1 2.264(11), Bi1-C13 2.248(11), Bi1-I1 2.8829(8), Bi1 ...Ph $\mathrm{Ph}_{\text {centroid(I) }} 3.89\left(\gamma^{\prime}=48.5^{\circ}\right), \mathrm{Bi1} \ldots \mathrm{Ph}_{\text {centroid(II) }} 3.98\left(\gamma^{\prime}=39.9^{\circ}\right), \mathrm{C} 2-\mathrm{H} 2 \ldots \mid$ I1 3.05. Selected bond angles [ ${ }^{\circ}$ : C1-Bi1-C13 94.9(4), C1-Bi1-I1 94.7(3), C13-Bi1-I1 93.9(3), Bi1-C1-C6 116.2(8), Bi1-C13-C18 117.4(8). (ii) Dimer association: C22-H22 ‥Ph centroid $2.77 \AA\left(\gamma=6.7^{\circ}\right)$. Symmetry transformations: $a=1-x, 1-y, 1-z$.

Intramolecular $\mathrm{Bi}$..Ph contacts in 4 lead to a distorted square pyramidal coordination geometry at the bismuth atom, with the carbon atom C13 of one 2-biphenyl ligand placed in the axial positions. The basal plane of the square pyramid is described by the two $\mathrm{Ph}_{\text {centroid }}$ ligands, the iodide atom and the carbon atom $\mathrm{C} 1$ of the second aryl ligand. This is supported by the bond angles C1-Bi1-C13 of $94.9(4)^{\circ}, \mathrm{C} 13-\mathrm{Bi1}-\mathrm{I} 1$ of $93.9(3)^{\circ}$, C13-Bi1- $\mathrm{Ph}_{\text {centroid(I) }}$ of $72.9^{\circ}, \mathrm{C} 13-\mathrm{Bi1}-\mathrm{Ph}_{\text {centroid(II) }}$ of $69.2^{\circ}$, 
$\mathrm{Ph}_{\text {centroid(I) }}-\mathrm{Bi1}-\mathrm{I} 1$ of $158.8^{\circ}$ and $\mathrm{Ph}_{\text {centroid(II) }}$-Bi1-C1 of $158.6^{\circ}$. Compounds 2a and $\mathbf{4}$ both form centrosymmetric dimers via two different $\mathrm{C}-\mathrm{H} \cdots \mathrm{Ph}$ intermolecular contacts for $\mathbf{2 a}(\mathrm{C} 17 \mathrm{~b}-$ $\mathrm{H} 17 \mathrm{~b}_{\text {arene }} \cdots \mathrm{Ph}_{\text {centroid }} 2.73 \AA\left(\gamma=2.9^{\circ}\right)$, C20b-H20b $\mathrm{b}_{\text {arene }} \cdots \mathrm{Ph}_{\text {centroid }}$ $2.93 \AA$, $\gamma=6.8^{\circ}$, Fig. 2(ii)) and for $4\left(\mathrm{C} 22-\mathrm{H} 22_{\text {arene }} \cdots \mathrm{Ph}_{\text {centroid }}\right.$ $2.77 \AA, \gamma=6.7^{\circ}$, see Fig. 4(ii)). Moreover, the dimers in 2a are connected via two additional intermolecular $\mathrm{Cl} \cdots \mathrm{H}$ contacts, $\mathrm{Cl} 2 \mathrm{a} \cdots \mathrm{H} 5 \mathrm{c} 2.75 \AA$ and Cl1b..H21e $2.86 \AA$, which results in the formation of a $2 \mathrm{D}$ network in the solid state (Fig. S5, ESI $\dagger$ ). In 4 the dimeric associates are connected via $\mathrm{C}-\mathrm{H} \cdots \mathrm{Ph}_{\text {centroid }}$ intermolecular contacts with $\mathrm{C} 10-\mathrm{H} 10_{\text {arene }} \cdot \mathrm{Ph}_{\text {centroid }}$ distances of $2.81 \AA\left(\gamma=10.7^{\circ}\right)$ leading to the formation of $1 \mathrm{D}$ ribbon-like structures (view along the $a$-axis, Fig. S6, ESI $\dagger$ ). Noteworthy, compound 3 also forms a 1D ribbon (view along the $c$-axis) in the solid state via two different $\mathrm{C}-\mathrm{H} \cdots \mathrm{Ph}_{\text {centroid }}$ intermolecular contacts with $\mathrm{C} 20-\mathrm{H} 20 \cdots \mathrm{Ph}_{\text {centroid }} 2.94 \AA\left(\gamma=12.6^{\circ}\right)$, C5aH5a $\cdots$ Ph $_{\text {centroid }} 3.07 \AA\left(\gamma=14.5^{\circ}\right)$ (Fig. 3(ii)).

In addition the molecules of the monohalides $\mathbf{2 a - 4}$ reveal the presence of intramolecular $\mathrm{C}-\mathrm{H} \cdots$ halogen contacts, with

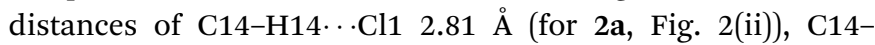
$\mathrm{H} 14 \cdots \mathrm{Br} 12.94 \AA$ (for 3, Fig. 3(i)) and $\mathrm{C} 2-\mathrm{H} 2 \cdots \mathrm{I} 13.05 \AA$ (for 4, Fig. 4(i)), which are shorter than the sum of the van der Waals radii of the corresponding atoms $\left(\sum r_{\mathrm{vdw}}(\mathrm{H}, \mathrm{Cl})=\right.$ $3.02 \AA, \sum r_{\mathrm{vdw}}(\mathrm{H}, \mathrm{Br})=3.06 \AA$ and $\left.\sum r_{\mathrm{vdw}}(\mathrm{H}, \mathrm{I})=3.24 \AA\right) .{ }^{42}$ Due to these intramolecular $\mathrm{C}-\mathrm{X} \cdot \mathrm{H}$ interactions, the molecules are arranged in such a way that the halogen atom is placed closer to a 2-biphenyl ligand of the same molecular unit than to the bismuth atom of the neighbouring molecule.

The heteroleptic triorganobismuth(III) compound 5 crystallises in the space group $P 2_{1}$ with two crystallographically independent molecules. Both molecules adopt a distorted trigonal pyramidal geometry at the bismuth atom with average $\mathrm{C}-\mathrm{Bi}-\mathrm{C}$ bond angles of $93.0^{\circ}$ (5a and 5b) (Fig. 5). In 5a the $\mathrm{Bi} \cdot \mathrm{Ph}_{\text {centroid }}$ distances are $4.11 \AA$ and $4.19 \AA$, and $4.10 \AA$ and $4.24 \AA$ in $5 \mathrm{~b}$. The $\mathrm{Bi}-\mathrm{C}-\mathrm{C}$ angles are close to $120^{\circ}$ [5a: Bi1-C14-C19 120.8(12) and Bi1-C2-C7 $121.0(12)^{\circ}$; 5a: Bi2-C44-C49 122.5(12) ${ }^{\circ}$ and Bi1-C32-C37 120.1(13) $)^{\circ}$, and thus not indicative for a significant intramolecular interaction between bismuth and the phenyl groups. Intermolecular $\mathrm{Bi} \cdots \mathrm{Ph}_{\text {centroid }}$ contacts are neither found (Fig. S7, ESI $\dagger$ ).

Analysis of the crystal structures of 2-5 reveals that the moderate crowding at the bismuth atom hinders strong intermolecular donor-acceptor interactions and that weak $\mathrm{C}-\mathrm{H} \cdots \pi$ arene interactions determine the crystal packing. Intramolecular $\mathrm{Bi} \cdot \mathrm{Ph}$ contacts are observed in the range 3.82-4.31 $\AA$ for the monomers, with the $\mathrm{Bi} \cdot \mathrm{Ph}_{\text {centroid }}$ distances following the order $3<4<2<5$ (Fig. 6). It might be concluded, that these interactions hinder free rotation of the biphenyl ligands, but the $\mathrm{H} \cdots \mathrm{X}$ contacts might also contribute to the stabilization of rotational isomers. For the diorganobismuth halides $\mathbf{2 - 4}$, the $\mathrm{Bi}-\mathrm{C}-\mathrm{C}$ bond angles are significantly compressed (deviation from ideal angle of $120^{\circ}$ ), while for 5 the $\mathrm{Bi}-\mathrm{C}-\mathrm{C}$ bond angles are close to $120^{\circ}$. This implies that in the organobismuth(III) halides the bismuth $\cdots \pi$ arene interaction is significantly more attractive in comparison to the triorganobismuth(III) compound 5. However, the trend for the $\mathrm{Bi} \cdot \cdots \mathrm{Ph}_{\text {centroid }}$ distance does not follow the trend predicted for the interaction between bismuth halides and a $\pi$

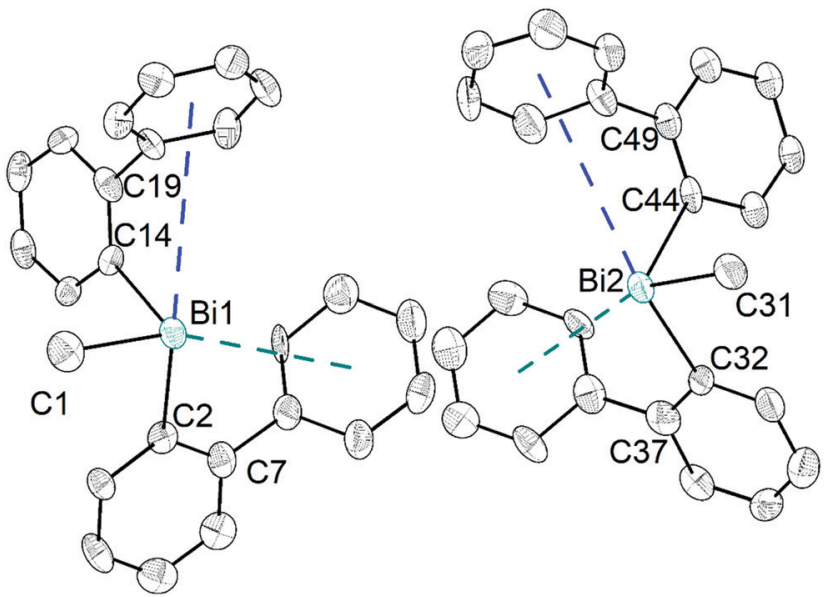

Fig. 5 Thermal ellipsoid model of $\left(2-\mathrm{PhC}_{6} \mathrm{H}_{4}\right)_{2} \mathrm{BiMe}(\mathbf{5})$ at $30 \%$ probability level. Hydrogen atoms are omitted for clarity. Selected bond lengths $[\AA \AA]$ : 5 a (left): Bi1-C1 2.25(2), Bi1-C2 2.263(18), Bi1-C14 2.249(14), Bi1 ...Ph centroid(I) 4.11 and $\mathrm{Bi1} \ldots \mathrm{Ph}_{\text {centroid(II) }}$ 4.19. Selected bond angles [ $\left.{ }^{\circ}\right]$ : $\mathrm{C} 1-\mathrm{Bi} 1-\mathrm{C} 2$ 95.0(7), C1-Bi1-C14 89.7(6), C2-Bi1-C14 94.4(6), Bi1-C2-C7 120.8(12), Bi1-C14-C19 121.0(12). 5b (right): Bi2-C31 2.23(2), Bi2-C32 2.285(17),

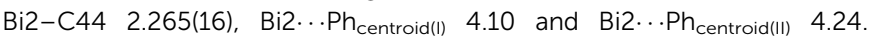
Selected bond angles [']: C31-Bi2-C32 95.6(7), C31-Bi2-C44 88.9(6), C32-Bi2-C44 94.5(6), Bi2-C32-C37 120.1(13), Bi2-C44-C49 122.5(12).

arene ligand. This suggests that packing effects in the crystal interfere with the weak intramolecular interaction. In order to assess, quantify and rationalize these results, an electronic structure calculations on the isolated molecular species was carried out, which will be discussed in a following section.

\section{Crystal structures of the arylbismuth(III) dihalides 6-8}

Colorless, light yellow and orange single crystals suitable for $\mathrm{X}$-ray crystallography were isolated upon crystallization by slow diffusion of $n$-pentane into $\mathrm{Et}_{2} \mathrm{O}$ solution at $-28{ }^{\circ} \mathrm{C}$ (for 6), at ambient temperature by slow diffusion of $n$-hexane into $\mathrm{CHCl}_{3}$ solution (for 7) and from a $\mathrm{CH}_{2} \mathrm{Cl}_{2}$ solution at ambient temperature (for 8), respectively. The molecular structures of the arylbismuth(III) dihalides $\mathbf{6 - 8}$ are depicted in figures $\mathbf{7 - 9}$, the selected bond lengths and angles are listed in the figure captions and their crystallographic data are given in Tables S1 and S2 (ESI $\dagger)$. The compounds crystallize in the orthorhombic space group $P 2_{1} 2_{1} 2_{1}$ (for 6), the monoclinic space group $P 2_{1} / c$ (for 7 ) and triclinic space group $P \overline{1}$ (for 8 ) respectively. Compound 7 shows a disorder of the 2-biphenyl group with an occupancy ratio of 0.59:0.41. Thus, the supramolecular structures are shown and discussed only for the molecule that shows the higher occupancy for the aryl ring. The asymmetric units of 6 and 7 comprise one molecule of $\left(2-\mathrm{PhC}_{6} \mathrm{H}_{4}\right) \mathrm{BiX}_{2}$, with Bi1-C1, Bi-X1 and $\mathrm{Bi}-\mathrm{X} 2$ bond lengths of: 2.230(7) $\AA$, 2.684(2) $\AA$ and 2.476(2) $\AA$ (for 6); 2.234(11) $\AA$, 3.124(1) A and 2.610(1) Å (for 7). Compound 8 shows two crystallographically independent molecules in the asymmetric unit with Bi1-C1, Bi1-I1 and Bi1-I2 bond lengths of 2.247(5) A, 3.0274(5) A, 2.8353(5) $\AA$ and $\mathrm{Bi} 2-\mathrm{C} 21, \mathrm{Bi} 2-\mathrm{I} 3$ and $\mathrm{Bi} 2-\mathrm{I} 4$ bond lengths of

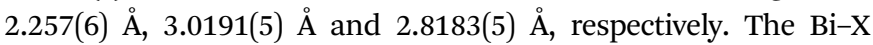
bond lengths are in accordance with those observed for primary and secondary $\mathrm{Bi}-\mathrm{X}$ bonds in other arylbismuth dihalides such as 
$\left(2-\mathrm{Ph}-\mathrm{C}_{6} \mathrm{H}_{4}\right)_{2} \mathrm{BiCl}(2 \mathrm{a})$

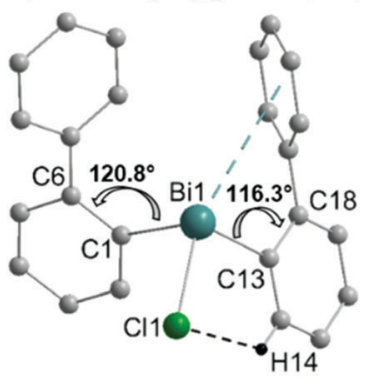

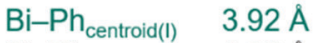

$\mathrm{Bi}-\mathrm{Ph}_{\text {centroid(II) }} \quad 4.25 \AA$

(2-Ph- $\left.\mathrm{C}_{6} \mathrm{H}_{4}\right)_{2} \mathrm{BiBr}(3)$

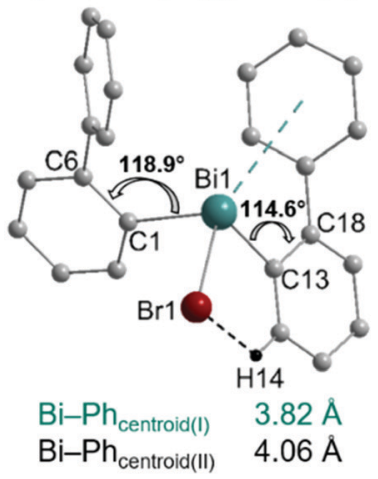

$\left(2-\mathrm{Ph}-\mathrm{C}_{6} \mathrm{H}_{4}\right)_{2} \mathrm{Bil}(4)$

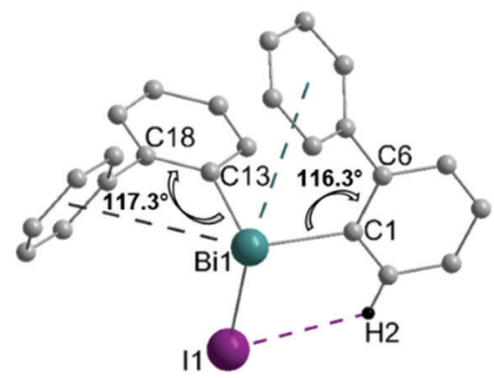

$\mathrm{Bi}-\mathrm{Ph}_{\text {centroid }(\mathrm{I})} 3.89 \AA$

$\mathrm{Bi}-\mathrm{Ph}_{\text {centroid(II) }} \quad 3.98 \AA$

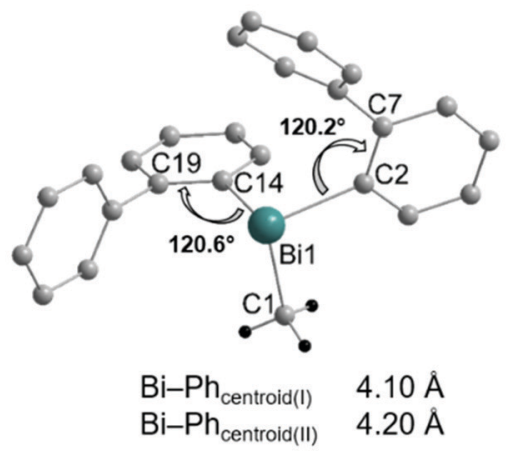

Fig. 6 Comparison of the intramolecular $\mathrm{Bi}$...Ph $\mathrm{Ph}_{\text {centroid }}$ distances and the $\mathrm{Bi}-\mathrm{C}-\mathrm{C}$ bond angles in the monomers of $\mathbf{2 a}, \mathbf{3}, \mathbf{4}$ and $\mathbf{5 a}$ as observed in the solid state.

$\left[\mathrm{PhBiX}_{2}(\mathrm{thf})\right](\mathrm{X}=\mathrm{Cl}, \mathrm{Br}, \mathrm{I}){ }^{43,44}$ The crystal structure analyses of 6 and 7 reveal long $\mathrm{Bi} \cdots \mathrm{Ph}_{\text {centroid }}$ distances $\left(\mathrm{Bi} 1 \cdots \mathrm{Ph}_{\text {centroid }} 3.94 \AA\right.$ for 6, Fig. 7(i) and Bi1 $\cdots \mathrm{Ph}_{\text {centroid }} 3.86 \AA$ for 7, Fig. 8(i)). For the independent molecules of compound $\mathbf{8}$ the intramolecular $\mathrm{Bi} \cdot \mathrm{Ph}_{\text {centroid }}$ distances amount to $4.044 \AA$ for molecule 8a and $3.911 \AA$ for molecule $\mathbf{8 b}$ (Fig. 9(i)). An indication for the intramolecular dispersion type $\mathrm{Bi} \cdots \pi$ arene interaction are the Bi1-C1-C6 bond angles $\left(6: 117.2(5)^{\circ}, 7: 117.1(8)^{\circ}, 8\right.$ 116.7(4) and
Bi2-C21-C26 118.3(4) ${ }^{\circ}$, which deviate from the ideal angle of $120^{\circ}$. Significant differences were not observed for the intramolecular $\mathrm{Bi} \cdots \mathrm{Ph}_{\text {centroid }}$ distances in 6-8; they are slightly larger than those observed for compounds 2-4. However, a clear trend on the intramolecular $\mathrm{Bi} \cdots \mathrm{Ph}_{\text {centroid }}$ distances related to the nature of $\mathrm{X}$ is not obvious.

The structures of the arylbismuth(III) dihalides show the formation of 1D ribbons which occurs through short intermolecular i)

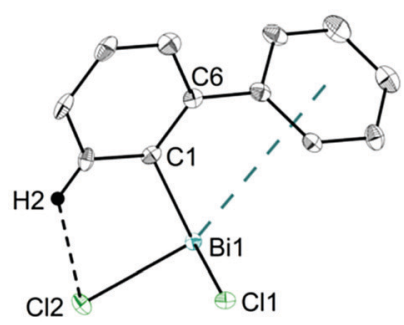

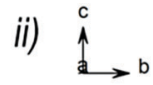

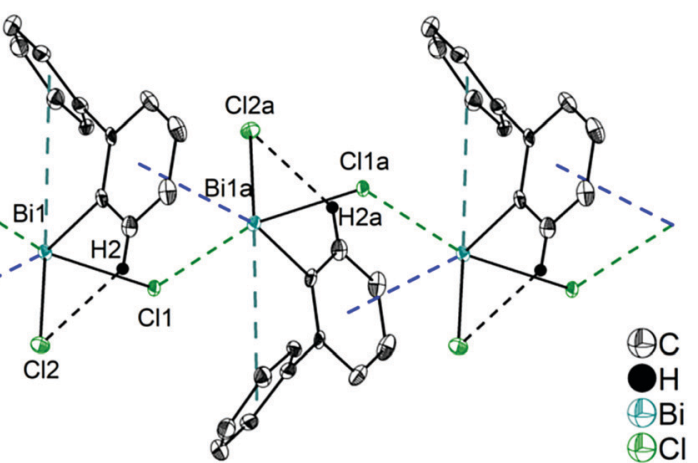

Fig. 7 (i) Thermal ellipsoid model of $\left(2-\mathrm{PhC}_{6} \mathrm{H}_{4}\right) \mathrm{BiCl}_{2}$ (6) at $50 \%$ probability level and (ii) 1D ribbon-like structure (view along the a-axis). Hydrogen atoms are omitted for clarity, except those involved showing intramolecular contacts. Selected bond lengths [Å]: Bi1-C1 2.230(7), Bi1-Cl1 2.684(2), Bi1-Cl2 2.476(2),

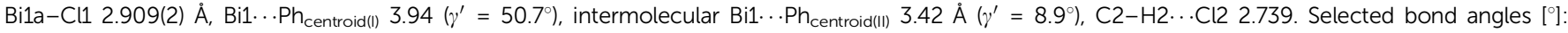
C1-Bi1-Cl1 85.2(2), C1-Bi1-Cl2 93.6(2), Cl1-Bi1-Cl2 91.8(6), Cl1-Bi1a-Cl1a 165.6(4), Cl1-Bi1a-Cl2a 95.3(6), Bi1-C1-C6 117.2(5), Bi1-Cl1-Bi1a 109.8(1). Symmetry transformations: $a=2-x, 1 / 2+y, 1 / 2-z$. 

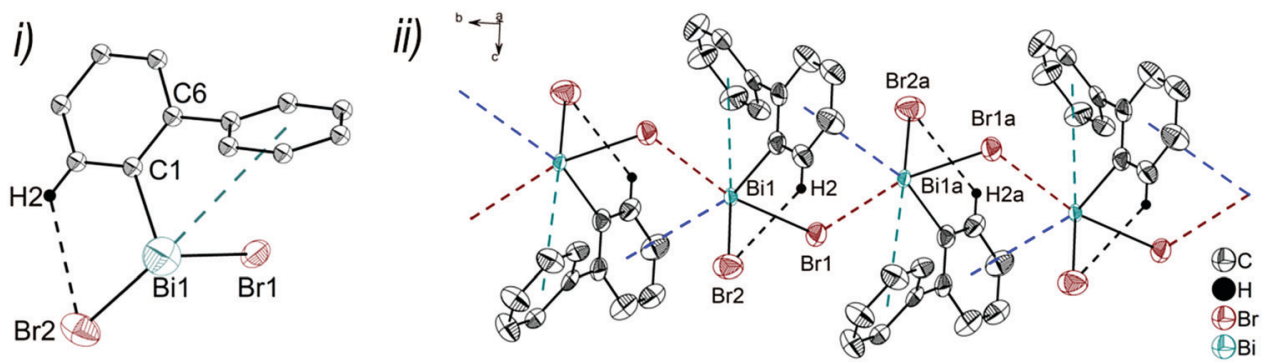

Fig. 8 (i) Thermal ellipsoid model of $\left(2-\mathrm{PhC}_{6} \mathrm{H}_{4}\right) \mathrm{BiBr}_{2}$ (7) at $50 \%$ probability level and (ii) 1D ribbon-like structure (view along the a-axis). Hydrogen atoms are omitted for clarity, except $\mathrm{H} 2$ involved in intramolecular interaction with a bromine atom. Selected bond lengths [Å]: Bi1-C1 2.234(11),

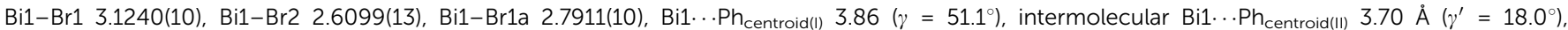
$\mathrm{C} 2-\mathrm{H} 2 \cdots \mathrm{Br} 2$ 2.991. Selected bond angles [']: C1-Bi1-Br1 79.9(7), C1-Bi1-Br2 96.9(7), C1-Bi1-Br1a 90.3(7), Br1-Bi1-Br2 95.3(3), Br1-Bi1a-Br1a 167.59(2), Br2-Bi1-Br1a 93.4(3), Bi1-Br1-Bi1a 105.23(3) Bi1-C1-C6 117.1(8), symmetry transformations: $a=-x, 1 / 2+y, 1 / 2-z$.
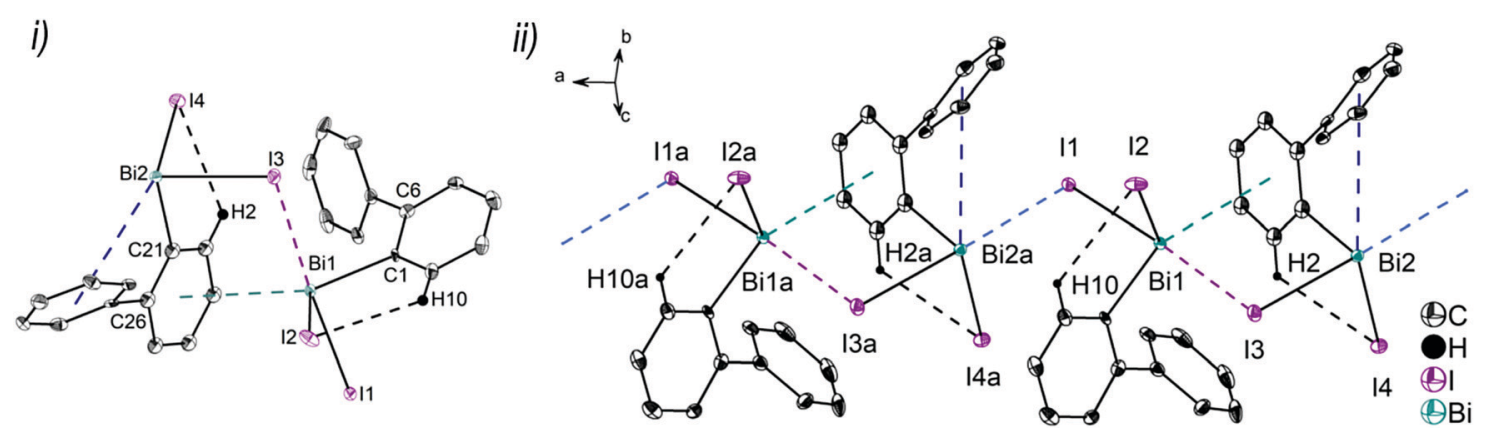

Fig. 9 (i) Thermal ellipsoid model of $\left(2-\mathrm{PhC}_{6} \mathrm{H}_{4}\right) \mathrm{Bil}_{2}$ (8) at $50 \%$ probability level showing dimer association of molecules $\mathbf{8 a}$ and $\mathbf{8 b}$ and (ii) $1 \mathrm{D}$ ribbon like structure. Hydrogen atoms are omitted for clarity, except $\mathrm{H} 2$ and $\mathrm{H} 10$ involved in intramolecular interaction with the iodine atoms. Selected bond lengths [Å]: Bi1-C1 2.247(5), Bi1-I1 3.0274(5), Bi1-I2 2.8353(5), Bi2a-I1 3.2091(5) A, Bi1-I3 3.2205(5) Å, Bi1 ...Ph centroid(I) 4.04, Bi2-C21 2.257(6), Bi2-I3 3.0191(5),

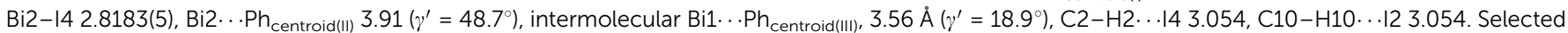
bond angles [']: C1-Bi1-I1 92.88(14), C1-Bi1-I2 96.25(15), C1-Bi1-I3 84.07(14), C21-Bi2-I3 90.34(17), C21-Bi2-14 94.45(16), C21-Bi2-I1 90.34(14), I1-Bi1-I2 94.078(13), I1-Bi1-I3 176.289(12), I2-Bi1-I3 88.367(13), I3-Bi2-I4 92.031(13), I3a-Bi2a-I1 177.743(12), Bi1-I3-Bi2 98.170(14), Bi1-I1-Bi2a 100.114(14), Bi1-C1-C6 116.7(4), Bi2-C21-C26 118.3(4). (ii) Symmetry transformations: $a=1+x, y, z ; b=-x, 1-y, 1-z$.

$\mathrm{Bi} \cdots \mathrm{X}$ interactions approximately trans to the opposite halogen atom from the neighbouring molecule (6: Cl1a-Bi1a...Cl1

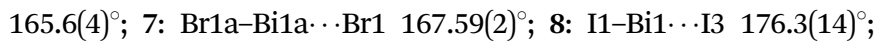
I3a-Bi2a $\cdots$ I1 $\left.177.7(14)^{\circ}\right)$. The secondary bridging $\mathrm{Bi} \cdots \mathrm{X}$ distances are as follows; 6: Bi1a...Cl1 2.909(2) $\AA$, (cf. $\sum r_{\mathrm{vdw}}(\mathrm{Bi}, \mathrm{Cl})$

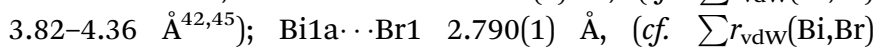

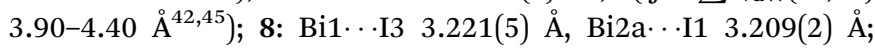
$\left(\sum r_{\mathrm{vdw}}(\mathrm{Bi}, \mathrm{I}) 4.05-4.58 \AA^{42,45}\right)$. The primary Bi-X distances in the $\mathrm{X}-\mathrm{Bi} \cdots \mathrm{X}$ bridges are, as expected, shorter (6: Bi1-Cl1 2.684(2) A; 7: Bi1-Br1 3.1240(10) Å; 8: Bi1-I1 3.027(5) Å, Bi2a-I3a 3.019(5) ̊). In addition to these donor-acceptor $\mathrm{Bi} \cdot \mathrm{X}$ bonds for the dihalides 6-8, intermolecular $\mathrm{Bi} \cdots \pi$ arene interactions between the bismuth atom and the phenyl ring of the neighbouring molecule are present. In combination they lead to the formation of zig-zag chains along one crystallographic axis (1D ribbons in Fig. 7(ii)-9(ii)). The $\mathrm{Bi} \cdot \mathrm{Ph}_{\text {centroid }}$ distances amount to $3.42 \AA$ (for 6), 3.70 $\AA$ (for 7), $3.56 \AA$ (for 8) and are comparable to those observed in $\left[\mathrm{PhBiX}_{2}(\right.$ thf $\left.)\right],\left(\mathrm{X}=\mathrm{Cl}, \mathrm{Br}, \mathrm{I} ; \mathrm{Bi} \cdots \mathrm{Ph}_{\text {centroid }}\right.$ distances in the range between $3.43 \AA$ and $3.54 \AA$ ). ${ }^{43,44}$ The competition between donor-acceptor and dispersion interaction is commonly observed for this type of $\mathrm{ArBiX}_{2}$ compounds. The crystal structures 6 and 7 show very similar features, even though they are not isostructural. The environment at the bismuth atom for $\mathbf{6}$ and 7 becomes distorted octahedral based on the core $\left[\left(2-\mathrm{PhC}_{6} \mathrm{H}_{4}\right) \mathrm{BiX}_{3}\left(\mathrm{Ph}_{\text {centroid }}\right)_{2}\right]$, with the $\mathrm{C} 1$ atom of the biphenyl ligand, the $\mathrm{X}_{\text {bridging }}$ atoms and the intermolecular $\mathrm{Ph}_{\text {centroid }}$ occupying the equatorial positions. The $\mathrm{Ph}_{\text {centroid }}$ involved in intramolecular interaction and the terminal halogen atom are placed in the axial positions with $\mathrm{Ph}_{\text {centroid }}-\mathrm{Bi} 1-\mathrm{Cl} 2159.2^{\circ}$ (for 6 ) and $\mathrm{Ph}_{\text {centroid }}-\mathrm{Bi} 1-\mathrm{Br} 2162.3^{\circ}$ (for 7 ). In 8 the $\mathrm{Bi} 2$ atom adopts a distorted square pyramidal geometry with the carbon atom of the biphenyl ligand in apical position and the vector of the intramolecular $\mathrm{Bi} \cdot \mathrm{Ph}_{\text {centroid }}$ contact placed trans to the terminal iodide atom I4. This is reflected in the bond angles of $\mathrm{Ph}_{\text {cen- }}$

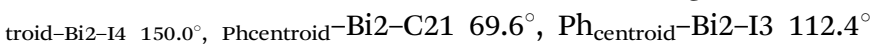
and C21-Bi2-I3 90.34(17) ${ }^{\circ}$. A distorted square pyramidal environment was observed for the Bi1 atom, with the basal plane formed by the carbon atom $\mathrm{C} 1$ of the biphenyl ligand, two $\mathrm{I}_{\text {bridging }}$ atoms

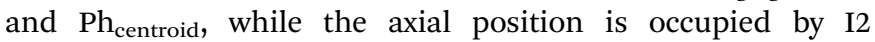
(cf. corresponding bond angles $\mathrm{Ph}_{\text {centroid-Bi1-C1 }} 150.2^{\circ}$, I1-Bi1-I3 $176.3^{\circ}$, I2-Bi1-C1 96.3 ${ }^{\circ}$, I2-Bi1-I1 95.1 ${ }^{\circ}$, I2-Bi3-I1 $88.4^{\circ}, \mathrm{I} 2-\mathrm{Bi}^{-}-\mathrm{Ph}_{\text {centroid }} 112.4^{\circ}$ ).

Furthermore, a 2D network is formed based on short intermolecular $\mathrm{C}-\mathrm{H} \cdots \mathrm{Cl}$ bonds (for 6 ) and $\mathrm{C}-\mathrm{H}_{\text {arene }} \cdots \mathrm{Ph}$ contacts (for 7 and 8) between parallel 1D layers connected through

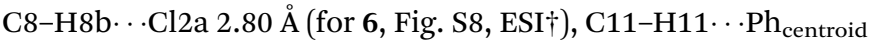


$2.84 \AA\left(\gamma=13.1^{\circ}\right.$, for 7, Fig. S9, ESI $\left.\dagger\right)$ and C10-H1A $\cdots \mathrm{Ph}_{\text {centroid }}$ $2.87 \AA\left(\gamma=17.1^{\circ}\right.$, for 8, Fig. S10, ESI $\left.\dagger\right)$.

\section{Computational study of diarylbismuth halides 2-4 and the diarylmethlybismuthine 5}

As one of the aims of this study is to rationalize intramolecular $\mathrm{Bi} \cdots \pi$ arene interactions using a library of flexible ligands, the crystallographic analyses are supplemented by computational studies. While in most of the presented compounds intermolecular interactions are dominating in the crystal structure, in compounds 2-5 intramolecular $\mathrm{Bi} \cdots \pi$ arene interactions seem to dominate. Hence, we start by discussing whether the trends

\begin{tabular}{|c|c|c|c|}
\hline & & $\frac{I_{4}}{(11.6)}$ & \\
\hline & $I_{4}$ & $\mathbf{I}_{\mathbf{3}}$ & $\mathbf{I}_{4}$ \\
\hline $\mathbf{I}_{4}$ & (7.4) & (7.6) & (7.6) \\
\hline$\overline{(4.5)}$ & & & \\
\hline$I_{3}$ & $I_{3}$ & & $\mathbf{I}_{\mathbf{3}}$ \\
\hline$(3.2)$ & $(\mathbf{3 . 0})$ & & (4.6) \\
\hline$I_{2}$ & $\mathbf{I}_{2}$ & $\mathbf{I}_{2}$ & $\mathbf{I}_{2}$ \\
\hline (2.4) & (2.2) & (2.7) & (3.4) \\
\hline$I_{1}$ & $\mathbf{I}_{1}$ & $I_{1}$ & $I_{1}$ \\
\hline$(0.0)$ & $(0.0)$ & $(0.0)$ & (0.0) \\
\hline (a) & (b) & (c) & (d) \\
\hline
\end{tabular}

Fig. 10 Schematic representation of the four lowest energy conformers $I_{n}$ for each compound (a) $\mathrm{R}_{2} \mathrm{BiCH}_{3}$ (2), (b) $\mathrm{R}_{2} \mathrm{BiCl}$ (3), (c) $\mathrm{R}_{2} \mathrm{BiBr}$ (4), and (d) $\mathrm{R}_{2} \mathrm{Bil}(\mathbf{5})\left(\mathrm{R}=2-\mathrm{PhC}_{6} \mathrm{H}_{4}\right)$. The lowest energy geometries of each compound are set to zero (energy in $\mathrm{kJ} \mathrm{mol}^{-1}$, structures see Fig. 11 and 12). observed in the crystal structures are purely due to intramolecular interactions, or whether crystal packing effects play a major role.

In order to assess the molecular structures of compounds $\mathbf{2 - 5}$, one has to take into account that this particular system has several "soft" degrees of freedom leading to a rich variety of possible conformers. In order to compare and assess the structures found by the crystallographic analysis, first of all, an overview over the most important low energy conformers has to be obtained. For this purpose, a conformational sampling approach recently published by Grimme et al. was carried out. ${ }^{46}$ In this scheme, a multistep multilevel procedure is used to screen a large part of the conformational space, select the lowest energy conformers and refine them at a higher level of theory.

The relative energies of the lowest energy conformations of 2-5 after a final optimization at the PBE-D3/def2-TZVP level of theory are shown in Fig. 10. Note that previous studies have shown that this level of theory provides a good balance between computational effort and accuracy in comparison to high-level methods. ${ }^{34,35}$ The structural parameters, i.e. the computed $\mathrm{Bi} \cdot \mathrm{Ph}_{\text {centroid }}$ distances and the $\mathrm{Bi}-\mathrm{C}-\mathrm{C}$ angle, are displayed in Fig. 11. For all compounds the same structural motif with one close $\mathrm{Bi} \cdots \mathrm{Ph}$ contact is found as the lowest energy structure. Given the crystal structures discussed in the previous sections, the results for the fully relaxed structures are quite remarkable. From methyl to iodide, the bismuth-to-phenyl centroid distance and the two $\mathrm{Bi}-\mathrm{C}-\mathrm{C}$ angles with the organic substituents monotonously decrease from 4.11 to $3.76 \AA$ and from $120.6^{\circ}$ to $116.0^{\circ}$, respectively, as might be expected for an increasing strength of the intramolecular $\mathrm{Bi} \cdots \pi$ arene interaction.

The question is why the structures observed in the crystal do not show the expected trends. Fig. 12 includes the structures found in the conformational search and in addition the minimum
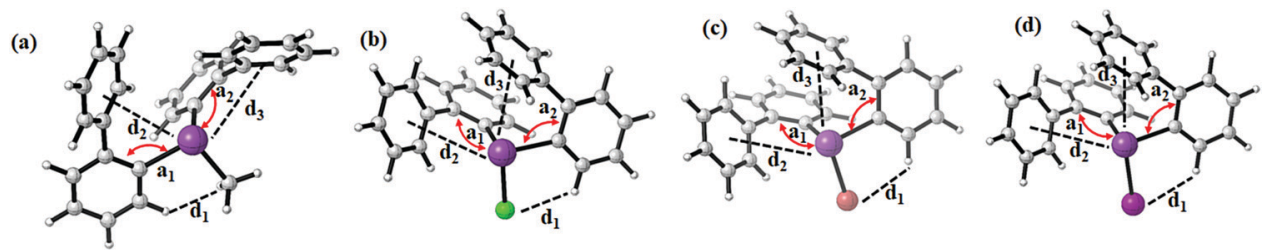

\begin{tabular}{|c|c|c|c|c|c|}
\hline Compound & $d_{1(X \cdots H)}$ & $d_{2(B i \cdots P h)}$ & $d_{3(B i \cdots P h)}$ & $a_{1(B i-C-C)}$ & $a_{2(B i-C-C)}$ \\
\hline (a) $\mathrm{R}_{2} \mathrm{BiCH}_{3}(2)$ & $2.68 \AA$ & $4.05 \AA$ & $4.11 \AA$ & $119.4^{\circ}$ & $120.6^{\circ}$ \\
\hline (b) $\mathrm{R}_{2} \mathrm{BiCl}$ (3) & $2.82 \AA$ & $4.05 \AA$ & $3.79 \AA$ & $119.6^{\circ}$ & $117.1^{\circ}$ \\
\hline (c) $\mathrm{R}_{2} \mathrm{BiBr}(4)$ & $2.93 \AA$ & $4.04 \AA$ & $3.77 \AA$ & $119.3^{\circ}$ & $116.5^{\circ}$ \\
\hline (d) $\mathrm{R}_{2} \mathrm{Bil}$ (5) & $3.06 \AA$ & $4.04 \AA$ & $3.76 \AA$ & $119.2^{\circ}$ & $116.0^{\circ}$ \\
\hline
\end{tabular}

Fig. 11 Lowest energy structures of (a) $\mathrm{R}_{2} \mathrm{BiCH}_{3}$ (2), (b) $\mathrm{R}_{2} \mathrm{BiCl}$ (3), (c) $\mathrm{R}_{2} \mathrm{BiBr}$ (4), and (d) $\mathrm{R}_{2} \mathrm{Bil}(\mathbf{5})\left(\mathrm{R}=2-\mathrm{PhC}_{6} \mathrm{H}_{4}\right)$ calculated at the PBE-D3/def2-TZVP level of theory. Closest $\mathrm{Bi} \ldots \mathrm{Ph}_{\text {centroid }}$ distances and shortest halide-hydrogen bond lengths are given. 


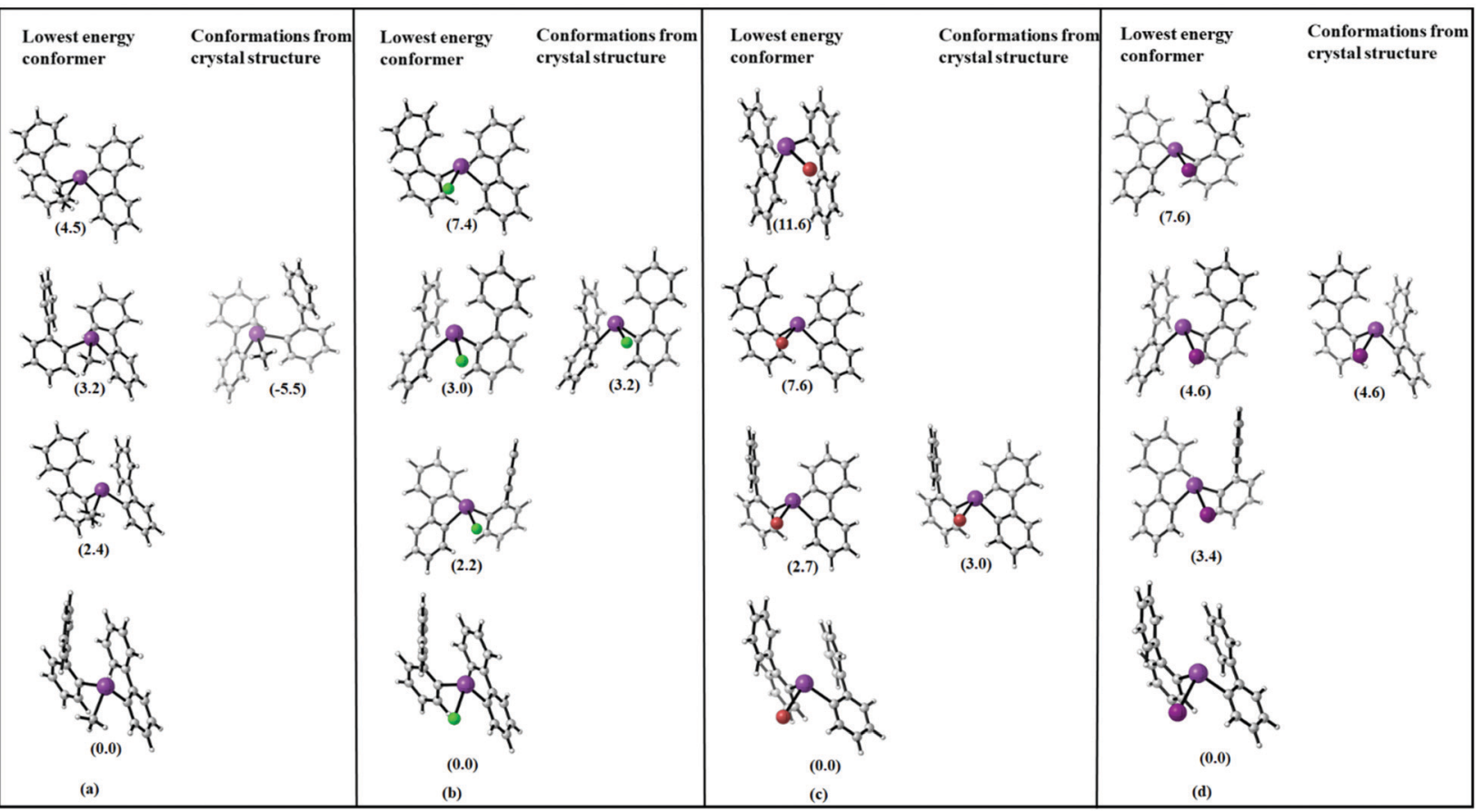

Fig. 12 Molecular structures of the four lowest energy conformations of (a) $\mathrm{R}_{2} \mathrm{BiCH}_{3}$ (2), (b) $\mathrm{R}_{2} \mathrm{BiCl}(\mathbf{3})$, (c) $\mathrm{R}_{2} \mathrm{BiBr}(\mathbf{4})$, and (d) $\mathrm{R}_{2} \mathrm{Bil}(\mathbf{5})\left(\mathrm{R}=2\right.$ - $\left.\mathrm{PhC} \mathrm{H}_{4}\right)$ $\mathrm{R}=\left(2-\mathrm{PhC}_{6} \mathrm{H}_{4}\right)$ (in kJ mol$\left.{ }^{-1}\right)$, and comparison with geometries as obtained by optimization of the molecules geometries in the solid state. Note that the small energy differences between equivalent structures are due to the numerics of the geometry optimizations.

geometries obtained by optimising the molecular structures as obtained from the single crystal X-ray structure analysis.

Obviously, none of the conformers found in the crystal structure represents the most stable conformer but the molecular structures derived from $\mathbf{5}$, the chloride $\mathbf{3}$ and iodide $\mathbf{5}$ resemble each other.

In Table 1, the energy differences between molecules as present in the crystal (with optimized hydrogen positions) and the fully optimized geometries along with the energy difference to the lowest conformer are given. This energy difference arises at least partially from packing effects but also includes the error of DFT in computing equilibrium geometries. While these two effects might be difficult to disentangle, the size of the observed effect with around $10-70 \mathrm{~kJ} \mathrm{~mol}^{-1}$ already allows to estimate that packing effects - especially due to $\mathrm{CH} \cdots \pi$ and $\pi \cdots \pi$ interactions in the crystal play a significant role for these structures. This has also been observed in previous work on the crystal

Table 1 Relaxation energies (in $\mathrm{kJ} \mathrm{mol}^{-1}$ ) from the experimental crystal structure geometries (with pre-optimized hydrogen atom positions) to the fully optimized conformer (middle column) and comparison to the lowest energy conformer from the GFN-XTB simulation (right column). All structures are optimized at PBE-D3/def2-TZVP level of theory $\mathrm{R}=\left(2-\mathrm{PhC}_{6} \mathrm{H}_{4}\right)$

\begin{tabular}{lll}
\hline & $\begin{array}{l}\text { Energy difference of } \\
\text { H-optimized crystal structure } \\
\text { and fully relaxed molecular } \\
\text { structure }\end{array}$ & $\begin{array}{l}\text { Energy difference of } \\
\text { fully relaxed structure } \\
\text { to the lowest energy } \\
\text { conformer }\end{array}$ \\
Structure & -60.3 & -5.5 \\
$\mathrm{R}_{2} \mathrm{BiCH}{ }_{3}(2)$ & -11.0 & -3.2 \\
$\mathrm{R}_{2} \mathrm{BiCl}(3)$ & -28.1 & -3.0 \\
$\mathrm{R}_{2} \mathrm{BiBr}(4)$ & -56.1 & -4.6 \\
$\mathrm{R}_{2} \mathrm{BiI}(5)$ & &
\end{tabular}

structures of arylbismuth(III) compounds in which computational methods have been applied to quantify the effects of intermolecular interactions in crystal structures. Here, it was found that typical $\mathrm{Bi} \cdots \pi$ arene interactions for $\mathrm{BiPh}_{3}$ range in the order of $30-40 \mathrm{~kJ} \mathrm{~mol}^{-1}$ while intermolecular $\mathrm{CH} \cdots \pi$ and $\pi \cdots \pi$ interactions yield interaction energies of similar strength, which results in a rich polymorphism observed in single crystal $\mathrm{X}$-ray structure analysis. ${ }^{20}$

\section{Solution NMR studies of compounds 1-9}

Compounds 1-9 were investigated by solution ${ }^{1} \mathrm{H}$ and ${ }^{13} \mathrm{C}\left\{{ }^{1} \mathrm{H}\right\}$ NMR spectroscopy at ambient temperature in $\mathrm{CDCl}_{3}$ solution. The assignment of resonance signals is based on 2D NMR (COSY, Fig. S14-S22, ESI; $\dagger$ HSQC and HMBC) correlation spectra, according to the numbering shown in Scheme 4.

The ${ }^{1} \mathrm{H}$ NMR spectra of compounds 1-9 show the expected resonance signals corresponding to the aromatic protons of the 2-biphenyl ligand (Fig. 15 and 16). For the diarylbismuth(III) halides 2-4 and the heteroleptic diaryl(methyl)bismuth(III) compound 5 the ${ }^{1} \mathrm{H}$ NMR spectra show only one set of signals indicating the equivalence of the organic ligands. A very large downfield shift is observed for the resonance signals that belong to the H-6 proton placed in the ortho position to the bismuth atom. The shift depends on the nature of $\mathrm{X}$ and increases following the order 2- $\mathrm{PhC}_{6} \mathrm{H}_{4}<\mathrm{Me}<\mathrm{Cl}<\mathrm{Br}<\mathrm{I}$ (Fig. 13). Characteristic shifts to $\delta=8.86 \mathrm{ppm}$ for $2(\mathrm{X}=\mathrm{Cl})$, $8.96 \mathrm{ppm}$ for $3(\mathrm{X}=\mathrm{Br})$ and $9.11 \mathrm{ppm}$ for $\mathbf{4}(\mathrm{X}=\mathrm{I})$ are observed, while the triorganobismuth(III) compounds $\mathbf{1}$ and $\mathbf{5}$ show resonance signals at $\delta=7.91 \mathrm{ppm}$ and $\delta=7.97 \mathrm{ppm}$, respectively. For comparison the corresponding triarylantimony(III) 


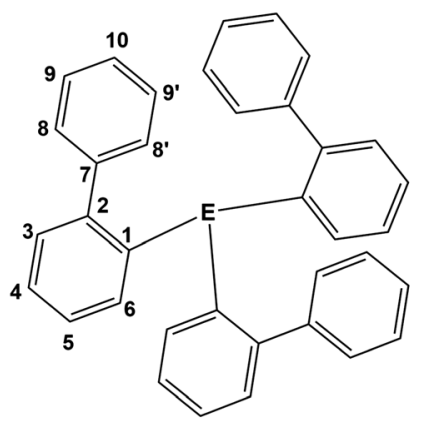<smiles>[X]c1ccccc1-c1ccccc1[B]c1ccccc1-c1ccccc1</smiles>

$\mathrm{X}=\mathrm{Cl}(\mathbf{2}), \mathrm{Br}(\mathbf{3}), \mathrm{I}(4), \mathrm{Me}(\mathbf{5})$

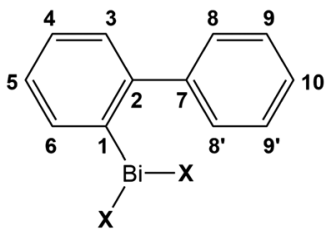

$\mathbf{X}=\mathrm{Cl}(\mathbf{6}), \mathrm{Br}(\mathbf{7}), \mathrm{I}(\mathbf{8})$

$\mathrm{E}=\mathrm{Bi}(\mathbf{1}), \mathrm{Sb}(\mathbf{9})$

Scheme 4 Compounds 1-9 and numbering scheme for NMR assignments.

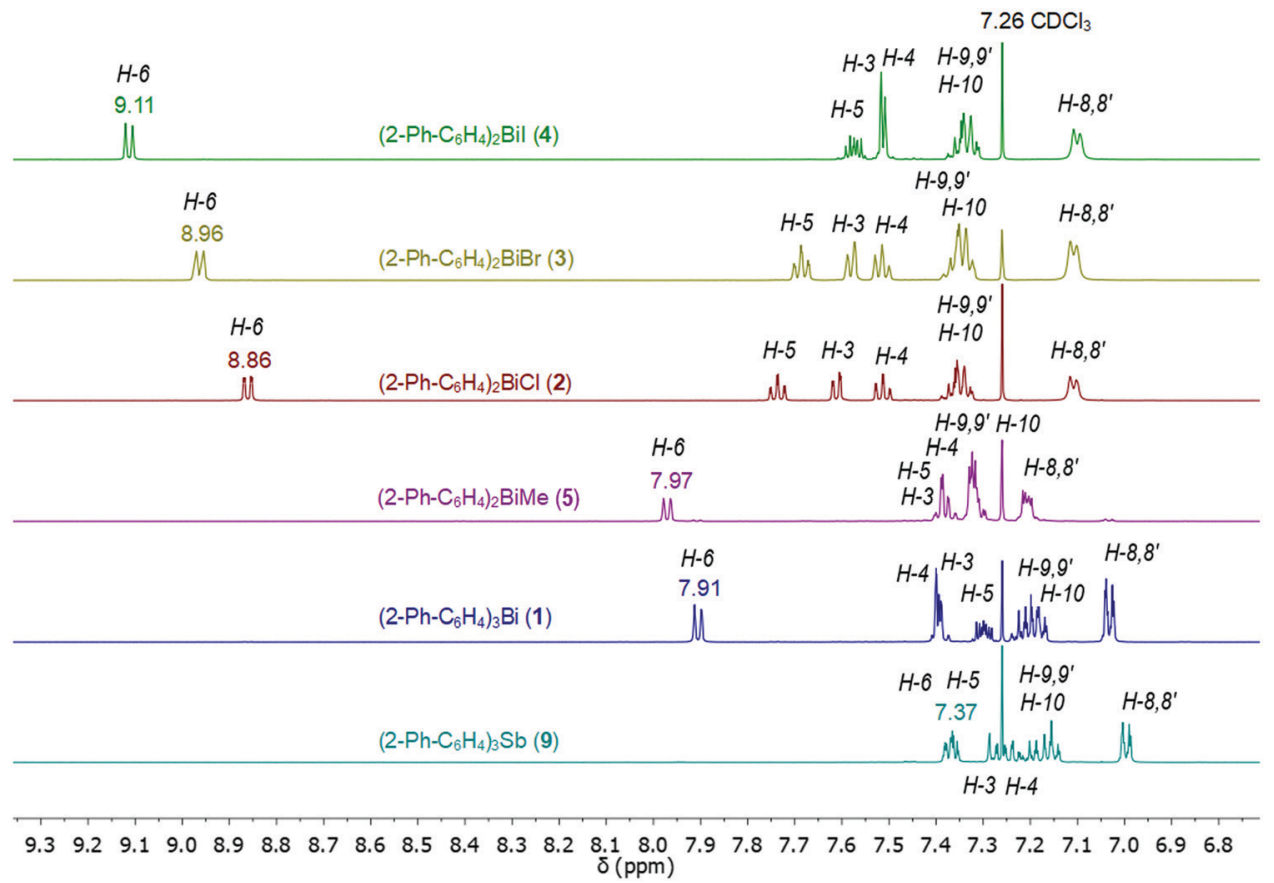

Fig. 13 Comparison of ${ }^{1} \mathrm{H}$ NMR spectra (aromatic region) in $\mathrm{CDCl}_{3}$ of compounds $\mathbf{1 - 5}$ and $\mathbf{9}$ showing a large downfield shifts for the resonance signals belonging to $\mathrm{H}-6$ placed in ortho position to the bismuth atom.

compound 9 was prepared, which shows a resonance signal for the $\mathrm{H}-6$ proton at $\delta=7.37 \mathrm{ppm}$. Even more pronounced downfield shifts were observed in the case of the monoarylbismuth(III) dihalides 6-8 showing a similar dependence (vide infra) on the nature of the substituent $\mathrm{X}$ attached to the bismuth atom $(\mathrm{Cl}<$ $\mathrm{Br}<\mathrm{I}$, Fig. 14). The corresponding resonance signals for $\mathrm{H}-6$ are observed at $\delta=9.78 \mathrm{ppm}$ for $6(\mathrm{X}=\mathrm{Cl}), 10.04 \mathrm{ppm}$ for 7 $(\mathrm{X}=\mathrm{Br})$ and $10.42 \mathrm{ppm}$ for $8(\mathrm{X}=\mathrm{I})$. In the literature, a similar trend of the chemical shifts with regard to the halide was described for arylbismuth(III) and arylantimony(III) halides for the signal belonging to the H-6 proton placed in the ortho position to the metal atom. For example, in the series of compounds $\mathrm{Ar}_{2} \mathrm{EX}$ and $\mathrm{ArEX}_{2}\left(\mathrm{E}=\mathrm{Sb}, \mathrm{Ar}=2-\left(\mathrm{Me}_{2} \mathrm{NCH}_{2}\right) \mathrm{C}_{6} \mathrm{H}_{4}\right.$, $\mathrm{X}=\mathrm{Ar}, \mathrm{Cl}, \mathrm{Br}, \mathrm{I}),{ }^{47,48}\left(\mathrm{E}=\mathrm{Bi}, \mathrm{Ar}=2-\left(\mathrm{Et}_{2} \mathrm{NCH}_{2}\right) \mathrm{C}_{6} \mathrm{H}_{4}, \mathrm{X}=\mathrm{Ar}, \mathrm{Cl}, \mathrm{Br}\right.$, I) ${ }^{49}$ the chemical shift depends on both the metal atom and on the nature of $\mathrm{X}$, but similar trends with regard to the nature of
$\mathrm{X}$ are observed (Table 2). There is a small difference between the chemical shifts in compounds of the type $\operatorname{ArBiX}_{2}(\Delta=$ $0.10 \mathrm{ppm}$ for $\mathrm{Cl}<\mathrm{Br}$ and $\mathrm{Br}<\mathrm{I}$ each, $\left.\mathrm{Ar}=2-\left(\mathrm{Et}_{2} \mathrm{NCH}_{2}\right) \mathrm{C}_{6} \mathrm{H}_{4}\right),{ }^{49}$ which is in good agreement with the corresponding values for 2-4 $(\Delta=0.10 \mathrm{ppm}$ for $\mathrm{Cl}<\mathrm{Br}$ and $\Delta=0.15 \mathrm{ppm}$ for $\mathrm{Br}<\mathrm{I})$. In the case of the reported dihalides $\left(\left(\mathrm{Et}_{2} \mathrm{NCH}_{2}\right) \mathrm{C}_{6} \mathrm{H}_{4}\right) \mathrm{BiX}_{2}{ }^{49}$ the differences of the chemical shifts of $\Delta=0.14 \mathrm{ppm}$ for $\mathrm{Cl}<\mathrm{Br}$ and $\Delta=0.28 \mathrm{ppm}$ for $\mathrm{Br}<\mathrm{I}$ are significantly smaller than those found in the compounds 6-8 $(\Delta=0.26 \mathrm{ppm}$ for $\mathrm{Cl}<\mathrm{Br}$ and $\Delta=0.38 \mathrm{ppm}$ for $\mathrm{Br}<\mathrm{I}$ ). To the best of knowledge the chemical shift of $\delta=10.42 \mathrm{ppm}$ for $\mathrm{H}-6$ in $\left(2-\mathrm{PhC}_{6} \mathrm{H}_{4}\right) \mathrm{BiI}_{2}$ is exceptional for arylbismuth(III) halides.

An explanation for the large downfield shift of the hydrogen atom in ortho position to the bismuth atom was given by Suzuki and coworkers. Firstly, they point at the participation of H-6 in hydrogen bonds, i.e. the presence of a weak $\mathrm{H} \cdots$ halogen 


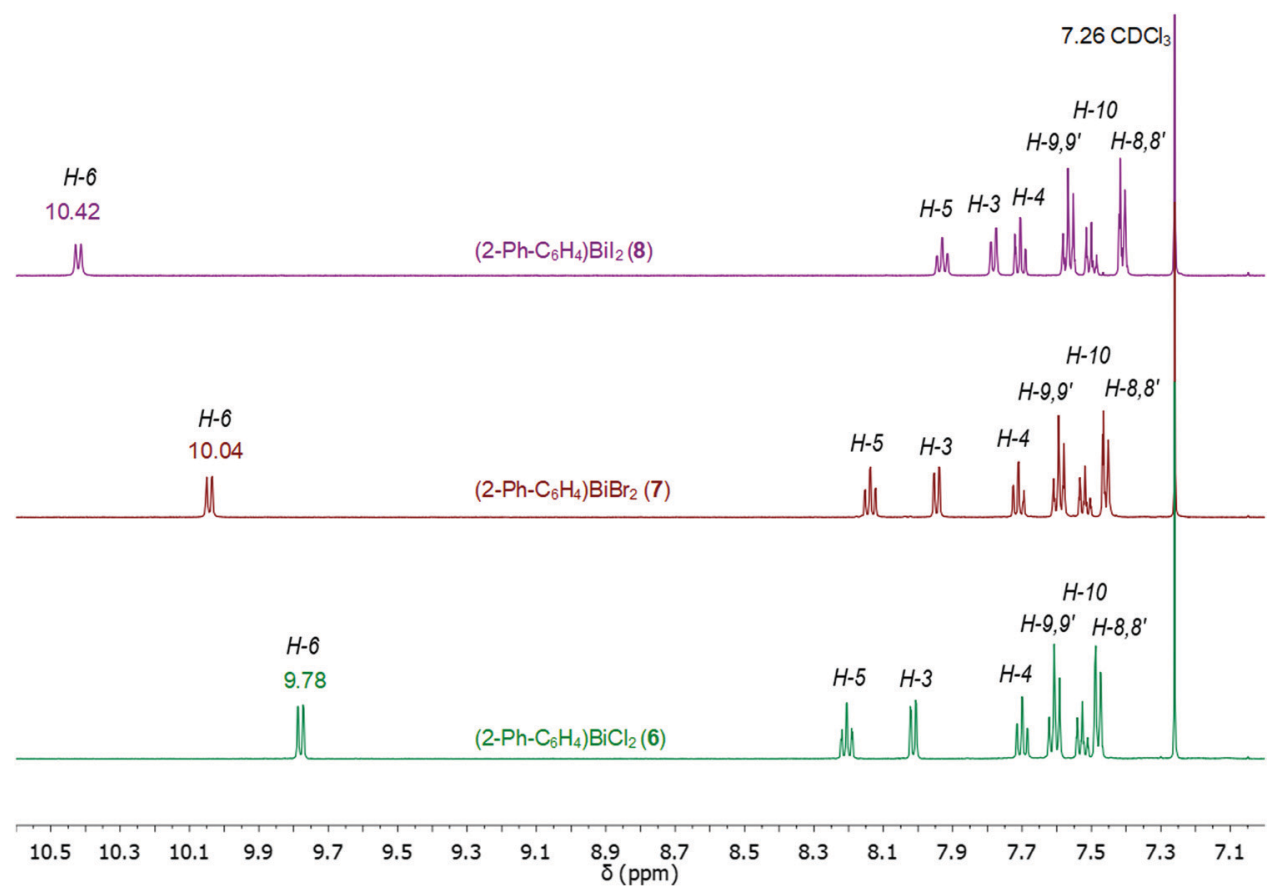

Fig. 14 Comparison of ${ }^{1} \mathrm{H}$ NMR spectra (aromatic region) in $\mathrm{CDCl}_{3}$ of compounds $\mathbf{6 - 8}$ showing a large downfield shift for the resonance signals belonging to $\mathrm{H}-6$ placed in ortho position to the bismuth atom.

interaction, and secondly to the anisotropic deshielding effect due to the proximity of the hydrogen atom to the $\mathrm{Bi}-\mathrm{X}$ bond as discussed for the chiral bismuthines $\left[2-\left(\mathrm{Me}_{2} \mathrm{NCH}_{2}\right) \mathrm{C}_{6} \mathrm{H}_{4}\right]-$ $\left[4-\mathrm{MeC}_{6} \mathrm{H}_{4}\right] \mathrm{BiX}(\mathrm{X}=\text { para-tolyl, } \mathrm{F}, \mathrm{Cl}, \mathrm{Br}, \mathrm{I})^{50}$ and $\left[2-\left({ }^{t} \mathrm{BuSO}_{2}\right)-\right.$ $\left.\mathrm{C}_{6} \mathrm{H}_{4}\right]\left[4-\mathrm{MeC}_{6} \mathrm{H}_{4}\right] \mathrm{BiX}(\mathrm{X}=\mathrm{Cl}, \mathrm{Br}) .{ }^{51}$ Note that our preliminary calculations of the ${ }^{1} \mathrm{H}$ NMR chemical shifts indicate that the downfield shift is not reproduced using a nonrelativistic approach. It seems likely that the increasing downfield shift is mainly due to the so-called Inverse Halogen Dependence (IHD) which is caused by spin orbit coupling on the heavy halogen atom and its effect on the ${ }^{1} \mathrm{H}$ NMR shift. Similar effects for through space interactions and an IHD have been reported for iodo alkyl and aryl compounds by Kaupp et al. and for ion pairs by Ariai et al..$^{52,53}$

The ${ }^{13} \mathrm{C}\left\{{ }^{1} \mathrm{H}\right\}$ NMR spectra of the di- and monoarylbismuth(III) halides also exhibit a downfield shift for the C-6 carbon resonance signals, which follows the order $\mathrm{Cl}<\mathrm{Br}<\mathrm{I}$ (2: $\delta=138.24 \mathrm{ppm}$, 3: $\delta=139.77 \mathrm{ppm}$, 4: $\delta=142.75$ ppm, Fig. S11, ESI, $\dagger$ 6: $\delta=$ $138.02 \mathrm{ppm}, \mathbf{8 :} \delta=140.70 \mathrm{ppm}$, 9: $\delta=146.35 \mathrm{ppm}$, Fig. S12, ESI $\dagger$ ).

In the ${ }^{1} \mathrm{H}$ NMR spectra of compounds $2-4$ significant broadening of the NMR signals at ambient temperature is observed, which is indicative for a dynamic process in solution. In order to study the dynamic behavior, variable temperature ${ }^{1} \mathrm{H}$ NMR spectra were recorded in $\mathrm{CD}_{2} \mathrm{Cl}_{2}$ for compounds 3 (Fig. 15) and $\mathbf{4}$ (Fig. S13, $\mathrm{ESI} \dagger$ ), in the temperature range of $293 \mathrm{~K}$ to $178 \mathrm{~K}$. At ambient temperature the ${ }^{1} \mathrm{H}$ NMR spectra of 3 and 4 show characteristic resonance signals at $\delta=7.11 \mathrm{ppm}$ and $\delta=7.10 \mathrm{ppm}$, respectively, which belong to the $\mathrm{H}-8$ and $\mathrm{H}-\mathrm{8}^{\prime}$ protons of the biphenyl ligand. This might be interpreted as a result of a dynamic interaction of dispersion type between bismuth and the aryl ligand.

As the temperature was lowered, the resonances belonging to the $\mathrm{H}-8$ and $\mathrm{H}-\mathrm{8}^{\prime}$ protons further coalesced, with a coalescence temperature $\left(T_{\mathrm{c}}\right)$ of $233 \mathrm{~K}$. The corresponding free energies of activation $\Delta G^{\ddagger}$ are $42.8 \mathrm{~kJ} \mathrm{~mol}^{-1}$ for 3 and $43.3 \mathrm{~kJ} \mathrm{~mol}^{-1}$ for 4 . For the signal assigned to the $\mathrm{H}-9$ and $\mathrm{H}-\mathrm{9}^{\prime}$ protons a broadening is observed above $243 \mathrm{~K}$. By subsequent cooling of the solution to $178 \mathrm{~K}$, the ${ }^{1} \mathrm{H}$ NMR spectra show two sets of doublet resonances (integral ratio of $1: 1$ ), i.e. at $\delta=6.51$ for $\mathrm{H}-8$ and at $\delta=7.47$ for $\mathrm{H}-8^{\prime}$ in 3 , at $\delta=6.66$ for $\mathrm{H}-8$ and $\delta=7.44$ for $\mathrm{H}-8^{\prime}$ in 4 and two sets of triplet resonances (integral ratio of $1: 1$ ), i.e. at $\delta=7.25$ for $\mathrm{H}-9$ and $\delta=7.41$ for $\mathrm{H}-9^{\prime}$ in 3 , and at $\delta=7.26$ for $\mathrm{H}-9$ and at $\delta=7.39$ for $\mathrm{H}-9^{\prime}$ in 4 . This assignment is supported by a COSY NMR spectrum of compound 3 at $178 \mathrm{~K}$ (Fig. 16). For the aryl protons (H-3-H-6) belonging to the aromatic ring $\mathrm{C}_{6} \mathrm{H}_{4}$ changes are not observed, being indicative for a fast flip of the aryl ligand. These results indicate that at $293 \mathrm{~K}$ the aryl groups attached to the bismuth atom are equivalent and free rotation of the phenyl rings around the $\mathrm{C}-\mathrm{C}$ bond is allowed, while at low temperature the dynamic process becomes slower, being consistent with the nonequivalence of $\mathrm{H}-8$ and $\mathrm{H}-\mathrm{8}^{\prime}$ as well as $\mathrm{H}-9$ and $\mathrm{H}-\mathrm{9}^{\prime}$ protons. Thus, in solution the rotation of the phenyl group is frozen, but the $\mathrm{Bi} \cdots \pi$ arene interaction does not freeze. The 2-biphenylbismuth dibromide 7 shows a small upfield shift of its ${ }^{1} \mathrm{H}$ NMR signals $\left(\mathrm{CD}_{2} \mathrm{Cl}_{2}\right)$ at $178 \mathrm{~K}$, but no significant changes in comparison to the spectrum measured at $293 \mathrm{~K}$ are observed, which indicates the equivalence of $\mathrm{H}-8$ and $\mathrm{H}-8^{\prime}$ as well as $\mathrm{H}-9$ and $\mathrm{H}-\mathbf{9}^{\prime}$ in the 2-biphenyl ligand even at low temperature.

\section{Computational study of the structural dynamics}

In order to study the internal degrees of freedom that contribute to the structural dynamics in these systems we have first computed potential energy surfaces for the structurally simplest 
Table $2{ }^{1} \mathrm{H}$ NMR chemical shifts and selected distances and angles of compounds $\mathbf{1 - 4}$ and $\mathbf{6 - 8}$ and compounds of the general formulas $\mathrm{Ar}_{2} \mathrm{EX}$ and $\mathrm{ArEX}_{2}$

\begin{tabular}{|c|c|c|c|c|c|c|}
\hline Compounds & Substituent X & Chemical shift $\delta(\mathrm{ppm})$ & H. X distance $(\AA)$ & $\mathrm{C} \cdot \mathrm{X}$ distance $(\AA)$ & $\mathrm{C}-\mathrm{H} \cdots \mathrm{X}$ angle $\left(^{\circ}\right)$ & Lit. \\
\hline \multirow[t]{5}{*}{$\mathrm{Ar}_{2} \mathbf{B i X ~ A r}=2-\mathrm{PhC}_{6} \mathrm{H}_{4}$} & $\operatorname{Ar}(\mathbf{1})$ & 7.91 & - & & - & This work \\
\hline & $\mathrm{Cl}(2)$ & 8.86 & 2.808 & 3.458 & 126.4 & This work \\
\hline & $\mathrm{Br}(3)$ & 8.96 & 2.943 & 3.560 & 125.1 & This work \\
\hline & I (4) & 9.11 & 3.034 & 3.727 & 130.9 & This work \\
\hline & $\operatorname{Me}(5)$ & 7.97 & - & - & - & This work \\
\hline \multirow[t]{3}{*}{$\mathbf{A r}_{2} \mathbf{B i X ~ A r}=\mathrm{Ph}$} & $\mathrm{Cl}$ & 8.30 & - & - & - & 44 \\
\hline & $\mathrm{Br}$ & 8.36 & 2.820 & 3.505 & 129.0 & \\
\hline & I & 8.41 & - & - & - & \\
\hline \multirow[t]{4}{*}{$\mathrm{Ar}_{2} \mathrm{BiX} \mathrm{Ar}=2-\left(\mathrm{Et}_{2} \mathrm{NCH}_{2}\right) \mathrm{C}_{6} \mathrm{H}_{4}$} & $\mathrm{Ar}$ & 7.70 & - & & - & 49 \\
\hline & $\mathrm{Cl}$ & 8.55 & 2.815 & 3.436 & 125.1 & 49 \\
\hline & $\mathrm{Br}$ & 8.65 & 2.925 & 3.547 & 125.5 & 49 \\
\hline & I & 8.75 & 3.128 & 3.814 & 132.1 & 49 \\
\hline \multirow[t]{4}{*}{$\mathbf{A r}_{2} \mathbf{S b X ~ A r}=2-\left(\mathrm{Me}_{2} \mathrm{NCH}_{2}\right) \mathrm{C}_{6} \mathrm{H}_{4}$} & $\mathrm{Ar}$ & 7.53 & - & & - & 47 \\
\hline & $\mathrm{Cl}$ & 7.86 & 2.724 & 3.360 & 126.3 & 48 \\
\hline & $\mathrm{Br}$ & 7.90 & 2.838 & 3.481 & 125.8 & 48 \\
\hline & I & 7.96 & 3.104 & 3.769 & 129.9 & 48 \\
\hline \multirow[t]{3}{*}{$\operatorname{ArBiX}_{2} \mathrm{Ar}=2-\mathrm{PhC}_{6} \mathrm{H}_{4}$} & $\mathrm{Cl}(6)$ & 9.78 & 2.739 & 3.727 & 130.9 & This work \\
\hline & $\mathrm{Br}(7)$ & 10.04 & 2.991 & 3.392 & 126.5 & This work \\
\hline & $\mathrm{I}(\mathbf{8})$ & 10.42 & 3.054 & 3.682 & 125.1 & This work \\
\hline \multirow[t]{3}{*}{$\operatorname{ArBiX}_{2} \mathrm{Ar}=\mathrm{Ph}$} & $\mathrm{Cl}$ & 8.97 & 2.732 & 3.400 & 129.5 & 44 \\
\hline & $\mathrm{Br}$ & 9.12 & 2.774 & 3.496 & 132.6 & 43 \\
\hline & I & 9.22 & $2.948,2955$ & $3.677,3.694$ & $133.0,135.6$ & 43 \\
\hline \multirow[t]{3}{*}{$\operatorname{ArBiX}_{2} \mathrm{Ar}=2-\left(\mathrm{Et}_{2} \mathrm{NCH}_{2}\right) \mathrm{C}_{6} \mathrm{H}_{4}$} & $\mathrm{Cl}$ & 9.17 & - & - & - & 49 \\
\hline & $\mathrm{Br}$ & 9.31 & - & - & - & 49 \\
\hline & I & 9.59 & 3.077 & 3.757 & 129.9 & 49 \\
\hline \multirow[t]{3}{*}{$\operatorname{ArSbX}_{2} \mathrm{Ar}=2-\left(\mathrm{Me}_{2} \mathrm{NCH}_{2}\right) \mathrm{C}_{6} \mathrm{H}_{4}$} & $\mathrm{Cl}$ & 8.28 & 2.764 & 3.346 & 120.4 & 48 \\
\hline & $\mathrm{Br}$ & 8.58 & 2.818 & 3.473 & 126.9 & 48 \\
\hline & I & 8.68 & 3.073 & 3.738 & 129.9 & 48 \\
\hline
\end{tabular}

compounds 6-8, by varying the dihedral angle alpha (see Fig. 17 and Table 3) and beta (see Fig. 18 and Table 4) separately and relaxing all other degrees of freedom at the PBE-D3/def2-TZVP level of theory. The resulting curves are displayed in Fig. 17 and 18 and show that already for only one substituent there are several minima connected by transition states with barriers ranging between a few and $40 \mathrm{~kJ} \mathrm{~mol}^{-1}$.

From the results given in Fig. 17 it is concluded that the $\mathrm{BiX}_{2}$ moieties are able to undergo a pseudo rotation with very low barrier, switching between two hydrogen bonded motifs. A full rotation is hindered by the organic substituent (barrier height of more than $30 \mathrm{~kJ} \mathrm{~mol}^{-1}$ ) and the halide $\cdots \pi$ interaction leads to a local minimum high in energy (see Table 3 ). Note that the barrier for rotation around the central $\mathrm{C}-\mathrm{C}$ bond in biphenyl itself has been reported as $8-10 \mathrm{~kJ} \mathrm{~mol}^{-1} .^{54}$

Fig. 18 depicts the corresponding potential energy surfaces from the rotation of the phenyl moiety which exhibit a low barrier for a $90^{\circ}$ tilt connecting two minima with short Bi1 $\cdots \mathrm{Ph}_{\text {centroid }}$ distances. The full rotation, however, is hindered by repulsion of the phenyl ring and the halide substituents as can be concluded from the bond distances and angles as given in Fig. 18 resulting in a barrier of more than $40 \mathrm{~kJ} \mathrm{~mol}^{-1}$ (Table 4).

In order to study and rationalize the effects that we observe for compound 3 in the temperature dependent NMR measurement (see Fig. 15), we have extended the study of the conformational degrees of freedom to include transition states between different conformers. While this system is considerably more complex than that of compounds 6-8, the minimum structures obtained from the conformational search already indicate which degrees of freedom are decisive for the observed temperature dependence of the NMR in solution.

Starting from the minimum energy conformer (Fig. 12), it can be seen that the protons $\mathrm{H}-6$ and $\mathrm{H}-6^{\prime}$ (see Fig. 15), for example, are not equivalent. However, if compared to its mirror image, the protons $\mathrm{H}-6$ and $\mathrm{H}-\mathrm{6}^{\prime}$ are exchanged, while protons $\mathrm{H}-8$ and $\mathrm{H}-8^{\prime}$ are still distinguishable. The barrier that we compute for this process is $22.5 \mathrm{~kJ} \mathrm{~mol}^{-1}$ (see Fig. 19), which is well above the estimated conversion barrier for the process observed above $178 \mathrm{~K}$. Hence, we conclude that a pseudorotation in which the phenyl rings slide across each other converting the structure to its mirror image and averaging the corresponding protons is the process present at low temperatures. This also allows us to assess that the strength of the $\mathrm{Bi} \cdots \pi$ arene interactions rather falls within this range (below $20 \mathrm{~kJ} \mathrm{~mol}^{-1}$ ), as the interaction is disrupted and re-established in this process.

Corresponding transition state searches between the different conformers (Fig. 19) exhibit barriers of more than $40 \mathrm{~kJ} \mathrm{~mol}^{-1}$ as 


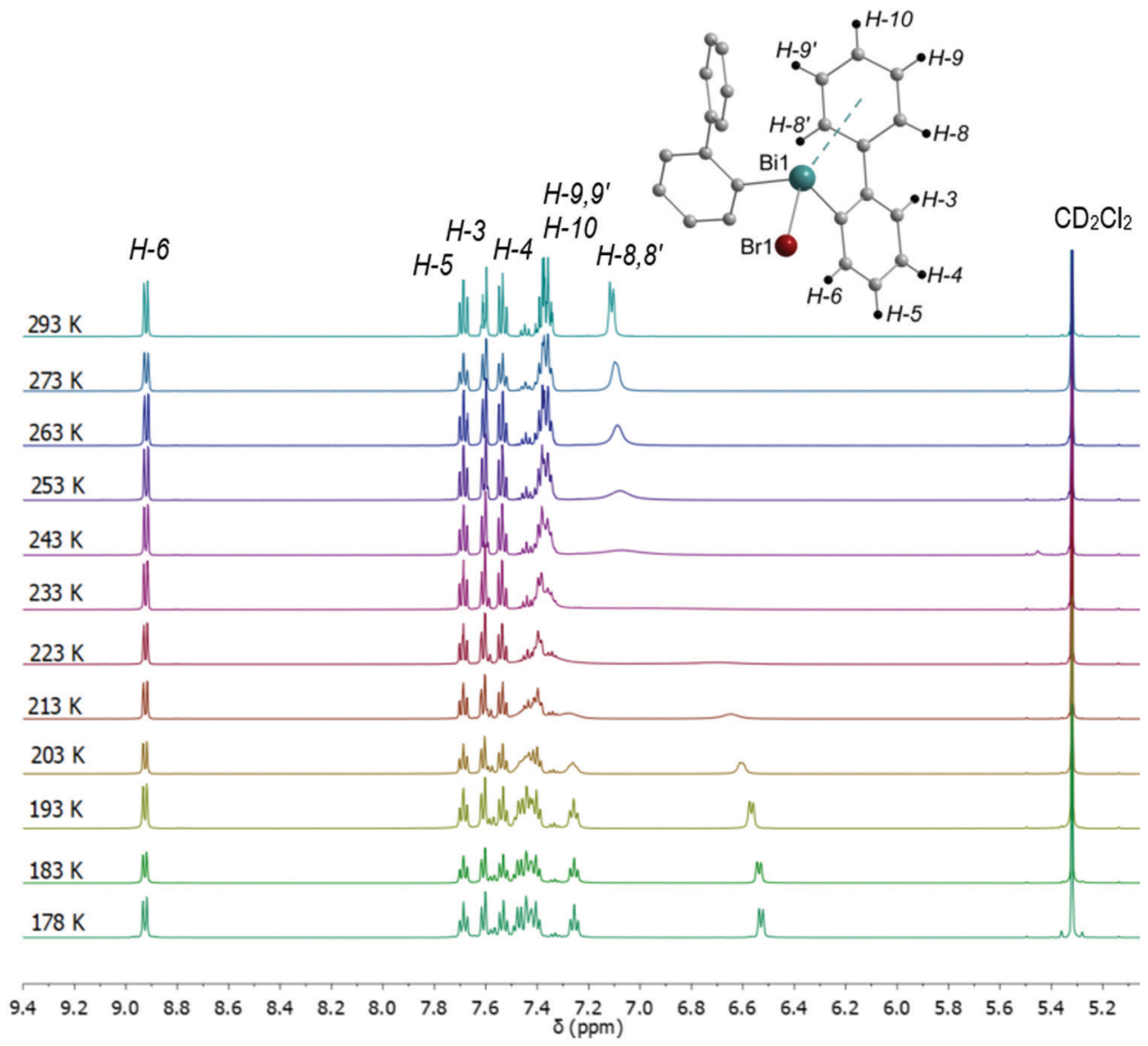

Fig. 15 Temperature dependent ${ }^{1} \mathrm{H}$ NMR spectra of $\left(2-\mathrm{PhC}_{6} \mathrm{H}_{4}\right)_{2} \mathrm{BiBr}(3)$ measured in $\mathrm{CD}_{2} \mathrm{Cl}_{2}$ showing the region for aromatic protons including the numbering scheme.

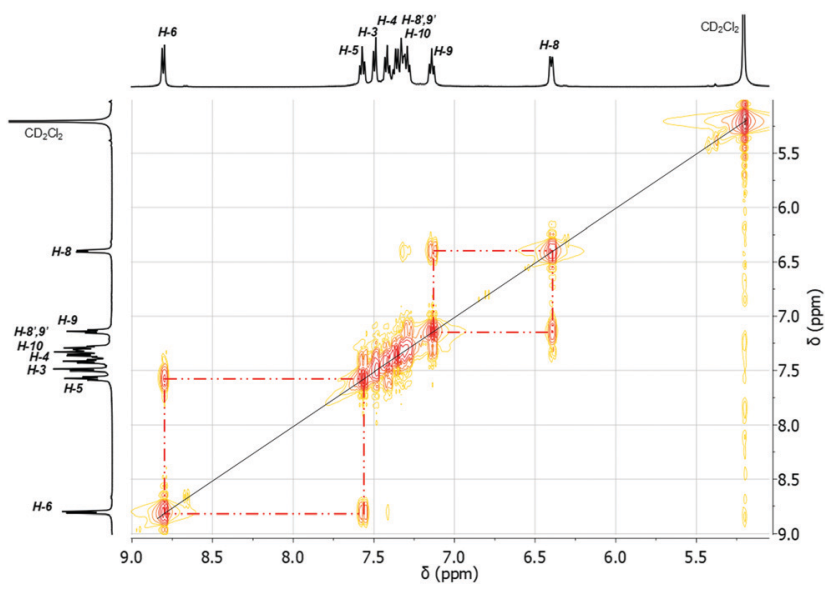

Fig. $16{ }^{1} \mathrm{H}-{ }^{1} \mathrm{H}$ COSY NMR spectrum $(500.30 \mathrm{MHz})$ of $\left(2-\mathrm{PhC}_{6} \mathrm{H}_{4}\right)_{2} \mathrm{BiBr}(3)$ recorded in $\mathrm{CD}_{2} \mathrm{Cl}_{2}$ at $178 \mathrm{~K}$.

soon as a full rotation of a phenyl moiety is considered, which is in agreement with the results obtained for the monosubstituted species discussed above. Hence, the averaging of protons $\mathrm{H}-8$ and $\mathrm{H}-8^{\prime}$, for example, which is observed above $230 \mathrm{~K}$ is likely to result from rotation around the central $\mathrm{C}-\mathrm{C}$ bond in the 2-biphenyl ligand occurring at higher temperatures, for which the major contribution likely comes from steric hindrance during the rotation.

Thus, we conclude that steric hindrance of the biphenyl ligands rather than a significantly strong dispersion interaction with bismuth is responsible for the trapped rotation of the biphenyl ligand observed in the temperature dependent NMR experiment between $180 \mathrm{~K}$ and $220 \mathrm{~K}$.

In order to quantify the $\mathrm{Bi} \cdots \pi$ arene interaction in these compounds in more detail, we have carried out further electronic structure calculations at the DLPNO-CCSD(T) level of theory applying the local energy decomposition (LED) for a molecular model system that allows to express the intermolecular interaction in terms of interactions between molecular fragments (see Fig. 20).

In previous studies it was found that for $\mathrm{Bi} \cdots \pi$ arene interactions a broad range of interaction energies can be observed due to the unique property of heavy main group elements to act as dispersion energy donors and as electron acceptors. For mostly dispersive $\mathrm{Bi} \cdots \pi$ arene interactions as observed in organobismuth compounds, interaction energies around $20 \mathrm{~kJ} \mathrm{~mol}^{-1}$ are found, while an additional donor/acceptor component increases the interaction strength to above $40 \mathrm{~kJ} \mathrm{~mol}^{-1}$. In conjunction with aromatic substituents that optimises the donor properties of the arene interaction energies of up to $70 \mathrm{~kJ} \mathrm{~mol}^{-1}$ can be obtained. ${ }^{35}$ 

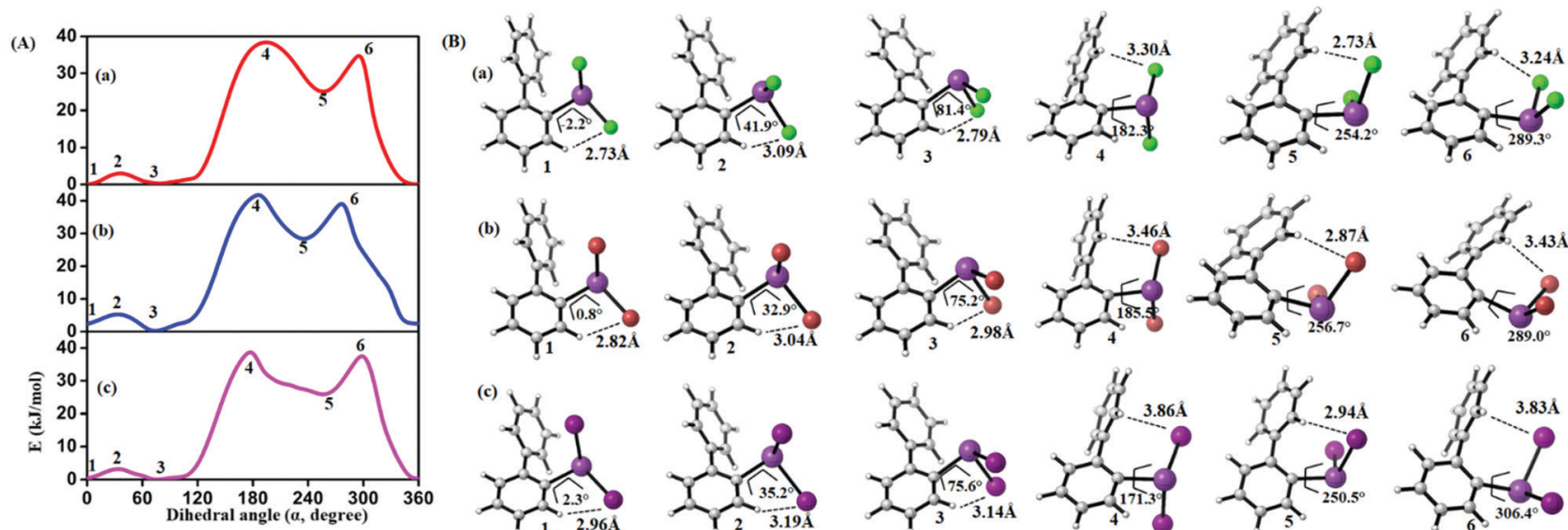

Fig. 17 (A) Computed potential energy surfaces (2-PhC $\left.6 \mathrm{H}_{4}\right) \mathrm{BiX}_{2}$; (a) $\mathrm{X}=\mathrm{Cl}$, (b) $\mathrm{X}=\mathrm{Br}$, (c) $\mathrm{X}=\mathrm{I}$, along with relaxed $\mathrm{C}-\mathrm{C}-\mathrm{Bi}-\mathrm{X}$ dihedral $(\alpha)$ scan at $\mathrm{PBE}-\mathrm{D} 3$ / def2-TZVPP level of theory. (B) Selected conformers of $\left(2-\mathrm{PhC}_{6} \mathrm{H}_{4}\right) \mathrm{BiX}_{2}$ taken from PES; (a) $\mathrm{X}=\mathrm{Cl}$, (b) $\mathrm{X}=\mathrm{Br}$, (c) $\mathrm{X}=1$. The respective dihedral angle and the shortest hydrogen bond between the nearest hydrogen atom and halogen are shown in each geometry $(1,3$, and $5(2,4$, and 6$))$ denotes the local minima (maxima) of the respective compound). For details on the dihedral definition see ESI. $\dagger$

Table 3 Computed relative energy (in $\mathrm{kJ} \mathrm{mol}^{-1}$ ) for the lowest energy conformations of $\left(2-\mathrm{PhC}_{6} \mathrm{H}_{4}\right) \mathrm{BiX}_{2}(\mathbf{6}-\mathbf{8})$ taken from potential energy surface geometries (see Fig. 17)

\begin{tabular}{lllllll}
\hline Compound & $\mathbf{1}$ & $\mathbf{2}$ & $\mathbf{3}$ & $\mathbf{4}$ & $\mathbf{5}$ & $\mathbf{6}$ \\
\hline$\left(2-\mathrm{PhC}_{6} \mathrm{H}_{4}\right) \mathrm{BiCl}_{2}(\mathbf{6})$ & 0.0 & 3.1 & 0.2 & 38.4 & 24.8 & 36.4 \\
$\left(2-\mathrm{PhC}_{6} \mathrm{H}_{4}\right) \mathrm{BiBr}_{2}(7)$ & 2.4 & 5.4 & 0.0 & 42.3 & 28.3 & 40.7 \\
$\left(2-\mathrm{PhC}_{6} \mathrm{H}_{4}\right) \mathrm{BiI}_{2}(\mathbf{8})$ & 0.4 & 3.3 & 0.0 & 39.9 & 25.7 & 39.03
\end{tabular}

In order to quantify and rationalize the $\mathrm{Bi} \cdots \pi$ arene interaction studied here, we focus on compound 3. For this purpose, a model structure was constructed that allows to interpret the intermolecular interaction at the DLPNO-CCSD(T) level of theory applying the local energy decomposition (LED). Fig. 20 displays the structure and the decomposition of the $\mathrm{Bi} \cdots \pi$ arene interaction strength computed for this model (Table 5).
Table 4 Computed relative energies (in $\mathrm{kJ} \mathrm{mol}^{-1}$ ) for the lowest energy conformations of $\left(2-\mathrm{PhC}_{6} \mathrm{H}_{4}\right) \mathrm{BiX}_{2}(\mathbf{6}-\mathbf{8})$ taken from the potential energy surface (see Fig. 18)

\begin{tabular}{lllll}
\hline Compound & $\mathbf{1}$ & $\mathbf{2}$ & $\mathbf{3}$ & $\mathbf{4}$ \\
\hline$\left(2-\mathrm{PhC}_{6} \mathrm{H}_{4}\right) \mathrm{BiCl}_{2}(\mathbf{6})$ & 3.6 & 7.5 & 0.0 & 45.9 \\
$\left(2-\mathrm{PhC}_{6} \mathrm{H}_{4}\right) \mathrm{BiBr}_{2}(7)$ & 2.9 & 6.9 & 0.0 & 46.0 \\
$\left(2-\mathrm{PhC}_{6} \mathrm{H}_{4}\right) \mathrm{BiI}_{2}(\mathbf{8})$ & 2.1 & 6.3 & 0.0 & 46.7
\end{tabular}

The results clearly indicate that the interaction of the moiety with the shortest $\mathrm{Bi} \cdots \pi$ arene contact is almost exclusively bound by dispersion. A repulsive Hartree-Fock contribution of $+43 \mathrm{~kJ} \mathrm{~mol}^{-1}$ and a very small attractive non-dispersive correlation contribution $\left(-1 \mathrm{~kJ} \mathrm{~mol}^{-1}\right)$ in the LED which are compensated by the dispersion contribution $\left(-54 \mathrm{~kJ} \mathrm{~mol}^{-1}\right)$ to yield an overall interaction of $-21 \mathrm{~kJ} \mathrm{~mol}^{-1}$ are typical features
(A)

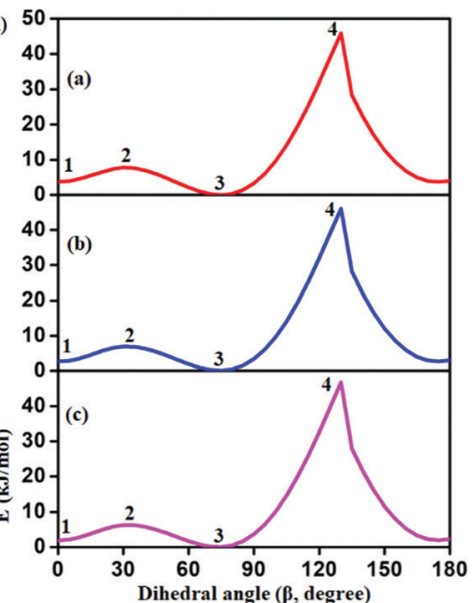

(B)

(a)

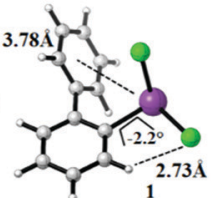

(b)

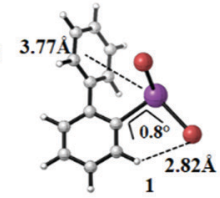

(c)

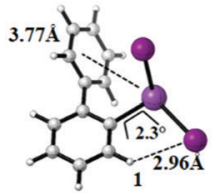

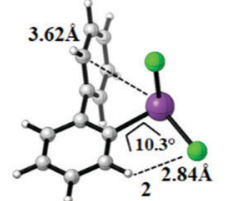
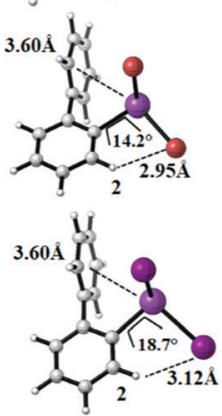
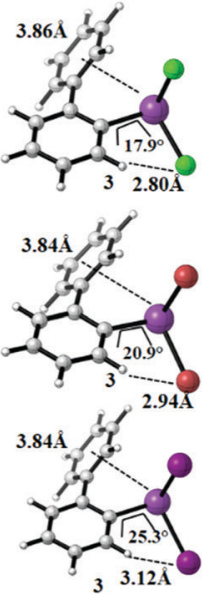
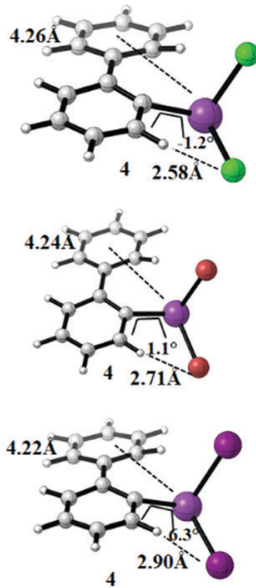

Fig. 18 (A) Computed potential energy surface of halogen $(\mathrm{X})$ substituted (2-PhC $\left.6 \mathrm{H}_{4}\right) \mathrm{BiX}_{2}$ along with $\mathrm{C}-\mathrm{C}-\mathrm{C}-\mathrm{C}$ dihedral $(\beta)$ rotation at PBE-D3/def2-TZVPP level of theory (1 and 3 (2 and 4)) denotes the local minima (maxima) of the respective compound). (B) Selected conformers of $\left(2-\mathrm{PhC}_{6} \mathrm{H}_{4}\right) \mathrm{BiX}_{2}$ taken from PES; (a) $X=C l$, (b) $X=B r$, (c) $X=1$. Respective dihedral angle, shortest hydrogen bond distance between the nearest hydrogen $(H)$ atom and halogen $(X)$, center-to-center distance between bismuth atoms and phenyl moieties are shown in each geometry. For details on the dihedral definition see ESI. $\dagger$ 
(a)

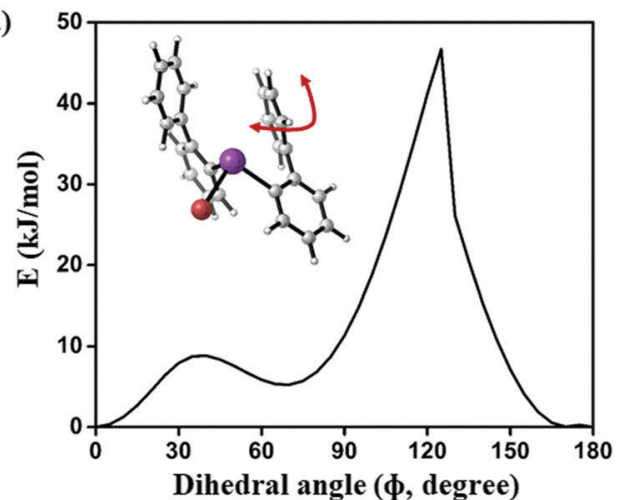

(b)

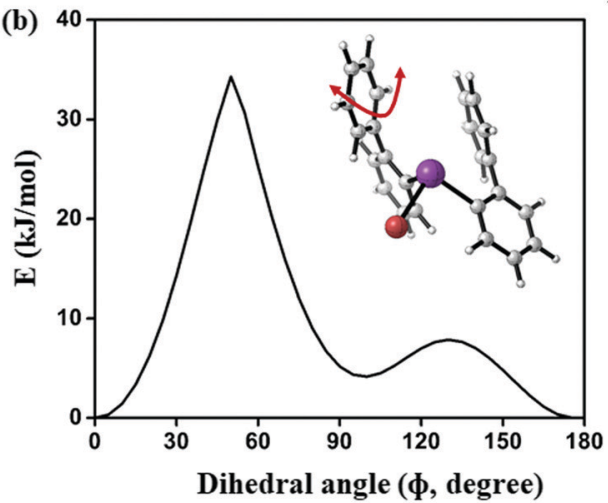

(c)

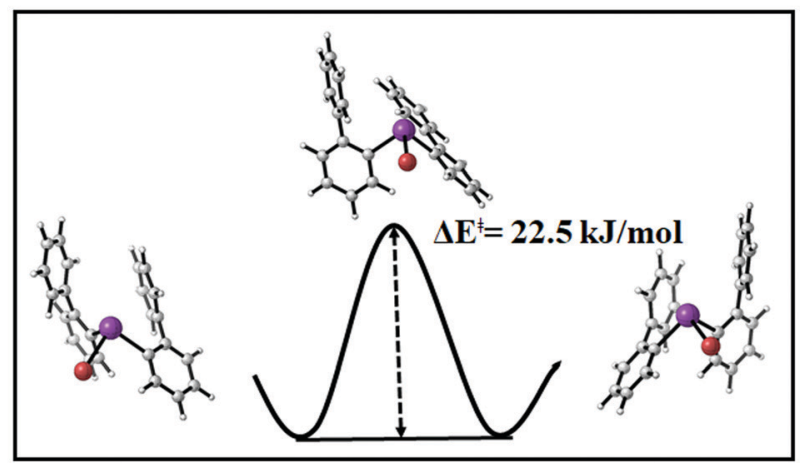

Fig. 19 (a and b) Computed potential energy surface of aryl ring rotation for $\left(2-\mathrm{PhC}_{6} \mathrm{H}_{4}\right)_{2} \mathrm{BiBr}(3)$ and (c) calculated barrier between equivalent conformations of $\mathbf{3}$ (PBE-D3/def2-TZVP) level of theory.

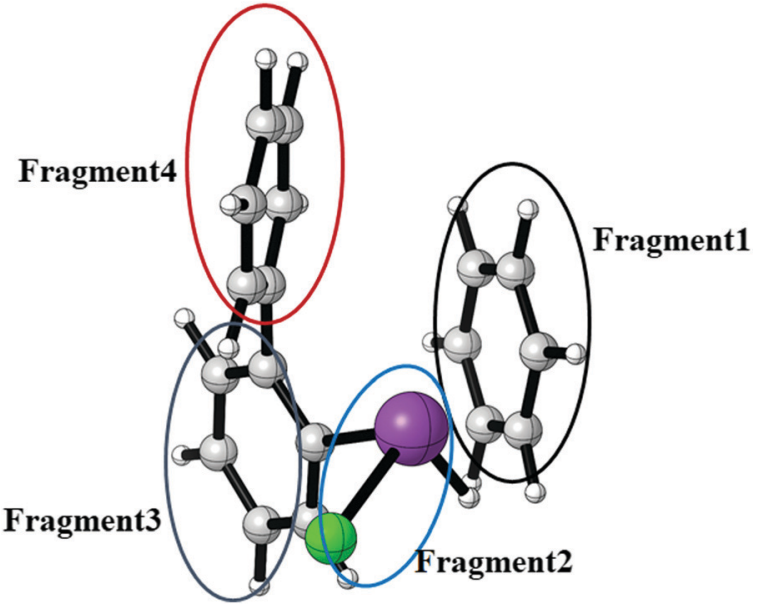

Fig. 20 Model system of compound 3 for the study of the $\mathrm{Bi} \cdots \pi$ arene interaction at the DLPNO-CCSD(T) level of theory using the LED scheme. The intramolecular interaction of compound $\mathbf{3}$ has been converted to an intermolecular interaction by substitution of the biphenyl ligand for $\mathrm{H}$ and $\mathrm{C}_{6} \mathrm{H}_{6}$ (deleting the bismuth bonded phenylene group) while keeping the rest of the structure fixed at the optimized structure of the lowest energy conformer of compound $\mathbf{3}$. This allows for a more detailed interpretation of the interactions between the different fragments.

of purely dispersive interactions. The $\mathrm{Bi} \cdots \pi$ interaction contributes roughly $-23 \mathrm{~kJ} \mathrm{~mol}^{-1}$ to the total dispersion interaction in comparison to -21 and $-10 \mathrm{~kJ} \mathrm{~mol}^{-1}$ for the interaction of this moiety with the biphenyl fragment (see Table 5).
At first glance it appears surprising that the nature of the interactions is almost purely dispersive, given the fact that one of the substituents on the bismuth is chlorine, which is known to increase the donor/acceptor character of $\mathrm{Bi} \cdots \pi$ arene interaction. However, the DLPNO-CCSD(T) quantification shows that the interaction strength is in line with what is computed for organobismuth compounds and also falls within the range of the weaker examples for these interactions.

Coming back to the results of the computational study of the barriers associated with the internal degrees of freedom discussed above, the energies in Table 5 also allow to assess how much of these are caused by the specific $\mathrm{Bi} \cdots \pi$ arene interaction. With an estimate of intramolecular $\pi-\pi$ interactions of $20-30 \mathrm{~kJ} \mathrm{~mol}{ }^{-1}$ and a $\mathrm{Bi} \cdots \pi$ arene interaction of about $20 \mathrm{~kJ} \mathrm{~mol}^{-1}$ it can be argued that while processes which disrupt several of these interactions - like for a rotation of a phenyl moiety (Fig. 19a and b) - necessarily exhibit barriers in the order of $40 \mathrm{~kJ} \mathrm{~mol}^{-1}$ while degrees of freedom in which only the $\mathrm{Bi} \cdots \pi$ interaction is disrupted will exhibit barriers around $20 \mathrm{~kJ} \mathrm{~mol}^{-1}$. Crystal packing effects, on the other hand, which we estimate to be quite a bit larger than that (around $40 \mathrm{~kJ} \mathrm{~mol}^{-1}$ ) will in sum dominate structure formation in this case. The analysis of the specific $\mathrm{Bi} \cdots \pi$ arene interaction in these systems is not only in line with the observations from the conformational study and the NMR experiments above, but also explains why crystal packing effects dominate the solid state structures, as $\mathrm{CH}-\pi$ and $\pi-\pi$ interactions of the same strength compete with this binding motif. 
Table 5 Local energy decomposition (LED) analysis and DLPNO-CCSD(T) correlation contributions to total interaction energies $\left(\mathrm{kJ} \mathrm{mol}^{-1}\right)$ of the model system of compound 3. Top part lists Contributions to the total interaction energy (total/int) which are Hatree-Fock interaction energy (HF/int), CCSD correlation contribution to the interaction energy (C-CCSD/ int) and triples contribution to the interaction energy (C-(T)/int). Middle section lists CCSD dispersive and non-dispersive contributions and bottom section lists the inter-fragment dispersion interactions (see Fig. 20) excluding multi-fragment contributions

Total interaction energy decomposition $\left(\Delta E_{\text {int }}^{\text {total }}\right)$

\begin{tabular}{llll}
\hline$\Delta E_{\mathrm{int}}^{\mathrm{HF}}$ & $\Delta E_{\mathrm{int}}^{\mathrm{C}-\mathrm{CCSD}}$ & $\Delta E_{\mathrm{int}}^{\mathrm{C}-\mathrm{C}(\mathrm{T})}$ & $\Delta E_{\mathrm{int}}^{\text {total }}$ \\
\hline 43.0 & -55.2 & -9.2 & -21.4 \\
\hline
\end{tabular}

Correlation energy decomposition $\left(\Delta E_{\mathrm{int}}^{\mathrm{C}-\mathrm{CCSD}}\right)$

\begin{tabular}{lcc}
\hline$\Delta E_{\text {disp }}^{\mathrm{C}-\mathrm{CCSD}}$ & $\Delta E_{\text {no-disp }}^{\mathrm{C}-\mathrm{CCSD}}$ & $\Delta E_{\mathrm{int}}^{\mathrm{C} \text {-CCSD }}$ \\
\hline-54.0 & -1.2 & -55.2
\end{tabular}

Inter-fragment dispersion contribution $\left(\Delta E_{\text {disp }}^{\mathrm{C}-\mathrm{CCSD}}\right)$

\begin{tabular}{cccc}
\hline $\mathbf{1} \leftrightarrow 2$ & $\mathbf{1} \leftrightarrow \mathbf{3}$ & $\mathbf{1} \leftrightarrow \mathbf{4}$ & $\Delta E_{\text {disp }}^{\text {C-CCSD }}$ \\
\hline-22.9 & -21.3 & -9.8 & -54.0
\end{tabular}

\section{Discussion and conclusion}

In this work we report on the synthesis and characterisation of a library of compounds of the type $\left(2-\mathrm{PhC}_{6} \mathrm{H}_{4}\right)_{3-n} \mathrm{BiX}_{n}[n=0$ (1); $n=1, \mathrm{X}=\mathrm{Cl}(2), \mathrm{Br}(3), \mathrm{I}(4), \mathrm{Me}(5) ; n=2, \mathrm{X}=\mathrm{Cl}$ (6), $\mathrm{Br}(7), \mathrm{I}(8)]$ and $\left(2-\mathrm{PhC}_{6} \mathrm{H}_{4}\right)_{3} \mathrm{Sb}(\mathbf{9})$, and study intra- and intermolecular London dispersion interactions. The focus of this work lies on the variation of the intramolecular $\mathrm{Bi} \cdots \pi$ arene interaction strength between the outer phenyl ring of the 2-biphenyl ligand and the bismuth atom upon variation of the ligand $\mathrm{X}$. The triorganobismuth(III) compound 1 shows an encapsulation of the metal atom due to the crowded ligands, but a pronounced dispersion interaction is not observed (bismuth $\left.\cdots \mathrm{Ph}_{\text {centroid }} \sim 4.0 \AA\right)$. In the less crowded monoarylbismuth compounds $\left(2-\mathrm{PhC}_{6} \mathrm{H}_{4}\right) \mathrm{BiX}_{2}(6-8)$, intramolecular $\mathrm{Bi} \cdots \pi$ arene interactions are present, but the structures are dominated by intermolecular donor-acceptor bonds between the bismuth and halide atoms. Thus, 1D ribbon-like structures are formed. Short intermolecular $\mathrm{Bi} \cdot \cdots \mathrm{Ph}_{\text {centroid }}$ distances are also observed in these structures, which are shorter than the intramolecular $\mathrm{Bi} \cdots \mathrm{Ph}_{\text {centroid }}$ distances and accompany the donor acceptor bonds. The diarylbismuth(III) compounds $\left(2-\mathrm{PhC}_{6} \mathrm{H}_{4}\right)_{2} \mathrm{BiX}$ $(2, \mathrm{X}=\mathrm{Cl}(2), \mathrm{X}=\mathrm{Br}(3), \mathrm{X}=\mathrm{I}(4), \mathrm{X}=\mathrm{Me}(5))$ do not show intermolecular donor-acceptor bonds but only intramolecular bismuth $\cdots \mathrm{Ph}$ contacts with one of the phenyl groups belonging to the 2-biphenyl ligand. It seems that in this case the moderate crowding leads to the monomeric structures even in the solid state. The single crystal X-ray diffraction analyses of these diorganobismuth(III) compounds revealed that the expectations of shorter $\mathrm{Bi} \cdots \mathrm{Ph}_{\text {centroid }}$ distances related to the nature of the halogen substituents and thus to a higher polarizability of the Bi-X moiety are not fulfilled. The shortest distance of $3.82 \AA$ is found for $\left(2-\mathrm{PhC}_{6} \mathrm{H}_{4}\right)_{2} \mathrm{BiBr}(3)$ which is slightly shorter than the longest distance of $3.92 \AA$ as observed for $\left(2-\mathrm{PhC}_{6} \mathrm{H}_{4}\right)_{2} \mathrm{BiCl}(2)$, and the corresponding distance of $3.89 \AA$ for $\left(2-\mathrm{PhC}_{6} \mathrm{H}_{4}\right)_{2} \mathrm{BiI}(4)$ is found in between. Thus, packing effects, e.g. resulting from $\mathrm{C}-\mathrm{H} \cdots \mathrm{Ph}$ contacts have to be considered and make it impossible to draw a meaningful conclusion only from the single crystal X-ray data. A conformational analysis exhibits that the structures found in the experimental crystallographic analysis actually do not correspond to the lowest energy conformers for the isolated molecules. Our results confirm that rather the intermolecular interactions than the intramolecular interactions determine the molecular structure in the solid state. An analysis of the lowest energy structures obtained by conformational search and geometry optimization, on the other hand, show the expected trends for the intramolecular $\mathrm{Bi} \cdots \mathrm{Ph}_{\text {centroid }}$ distances related to the nature of the ligand $\mathrm{X}$ in $\left(2-\mathrm{PhC}_{6} \mathrm{H}_{4}\right)_{2} \mathrm{BiX}$. While the acceptor character on the bismuth atom increases (as a result of the interaction with $\mathrm{X}$ ), the $\mathrm{Bi} \cdots \mathrm{Ph}_{\text {centroid }}$ distance decreases, inducing strain on the substituents which is also reflected in the corresponding $\mathrm{Bi}-\mathrm{C}-\mathrm{C}$ bond angles. In addition to the structural analysis in the solid state NMR spectra in solution were recorded, which reveal information about structural dynamics in solution. A pronounced downfield shift in the ${ }^{1} \mathrm{H}$ NMR spectra for the resonance signal assigned to the $\mathrm{H}$ derived from the experimental observations of the temperature dependence of the NMR chemical shifts and transition state calculations for the different conformers indicate that at high temperatures the phenyl moieties freely rotate. At temperatures below $200 \mathrm{~K}$ a process with a barrier of $40 \mathrm{~kJ} \mathrm{~mol}^{-1}$ is frozen, lifting the equivalence of several protons, while other pairs of hydrogen atoms, such as the ortho protons, still yield averaged signals. Based on the electronic structure calculations it can be suggested that the low temperature species is the lowest energy conformer, which converts with its mirror image via a process in which the $\mathrm{Bi} \cdots \pi$ arene interaction is broken and re-established and which has a barrier in the order of $20 \mathrm{~kJ} \mathrm{~mol}^{-1}$. Hence, the $\mathrm{Bi} \cdots \pi$ arene interaction can be estimated to be in the order of $20 \mathrm{~kJ} \mathrm{~mol}^{-1}$ or less. This is confirmed by a study of a model compound at the DLPNO$\operatorname{CCSD}(\mathrm{T})$ level of theory applying the local energy decomposition. Thus for the $\left(2-\mathrm{PhC}_{6} \mathrm{H}_{4}\right)_{2} \mathrm{BiCl}$ system, the specific interaction is suggested to be $23 \mathrm{~kJ} \mathrm{~mol}^{-1}$ and the analysis indicates that it is almost purely a dispersion interaction.

\section{Experimental}

\section{General procedure}

All procedures were carried out under anhydrous nitrogen or argon using standard Schlenk techniques. Solvents were freshly distilled over appropriate drying reagents immediately prior to use. Reagents such as 2-bromobiphenyl were purchased from commercial suppliers and used as received. ATR-FTIR spectra were recorded with a Bio Rad FTS-165 spectrometer (Bio-Rad) with a Golden Gate (SpectroMat) sample adapter. ${ }^{1} \mathrm{H}$ and ${ }^{13} \mathrm{C}\left\{{ }^{1} \mathrm{H}\right\}$ NMR spectra were recorded at ambient temperature in $\mathrm{CDCl}_{3}$ (dried over $4 \AA$ molecular sieve) with an Avance III 500 spectrometer (Bruker) at $500.30 \mathrm{MHz}$ and $125.81 \mathrm{MHz}$, respectively, and are referenced internally to the deuterated solvent relative to $\mathrm{Si}\left(\mathrm{CH}_{3}\right)_{4}(\delta=0.00 \mathrm{ppm})$. NMR signals are given in $\mathrm{ppm}$. The NMR spectra were processed using the software MestReNova 
(version 11.0.4-18998 ${ }^{55}$ ). The temperature dependent ${ }^{1} \mathrm{H}$ NMR spectra were recorded in $\mathrm{CD}_{2} \mathrm{Cl}_{2}$ at different temperatures from $268 \mathrm{~K}$ to $178 \mathrm{~K}$. Calculations of the rate constant $k$ were performed by full line shape analysis with the $D N M R$ program, which is implemented in the TopSpin 2.1 program package. The activation parameters were calculated by use of the Eyring equation $k=\frac{R T}{N_{\mathrm{A}}} \mathrm{e}^{\frac{-\Delta G^{\neq}}{R T}}$, where $R$ is the general gas constant, $T$ is the absolute temperature, $N_{\mathrm{A}}$ is the Avogadro constant, $h$ is the Planck constant and $\Delta G^{\neq}$is the activation Gibbs free energy. The CHN-analyses were performed with a FlashEA 1112 analyzer (Thermo Fisher Scientific). The melting points of compounds were determined with a Melting Point B-540 apparatus (Büchi) and are uncorrected. Powder X-ray diffractograms were measured at ambient temperature with a Stadi $\mathrm{P}$ diffractometer (STOE) using $\mathrm{Ge}(111)$-monochromatized $\mathrm{Cu}-\mathrm{K}_{\alpha}$ radiation $(40 \mathrm{kV}, 40 \mathrm{~mA})$. Figures and schemes were created with ChemDraw Prime ${ }^{\circledR}$ (version 17.1) ${ }^{56}$ and Origin ${ }^{\circledR}$ Pro 2017. ${ }^{57}$

\section{Crystallographic studies}

Crystal data, data collection and refinement parameters for compounds 1-5 and 6-9 are given in Tables S1 and S2 (ESI $\dagger$ ), respectively. Data were collected with either a Rigaku-Oxford Gemini S diffractometer (CrysAlisPro, Version 1.171.38.41l, Rigaku OD, 2015) at $120 \mathrm{~K}(1), 115.7 \mathrm{~K}(3), 100 \mathrm{~K}(5)$ and $293 \mathrm{~K}(7)$ or a Bruker Venture D8 diffractometer (APEX3 v2017.3-0, Bruker AXS) at $100 \mathrm{~K}(2,4,6,8$ and 9) using graphite-monochromatized $\mathrm{Cu}-\mathrm{K} \alpha$ radiation $(\lambda=1.54184 \AA$ for $1,2,5)$ and Mo-K $\alpha$ radiation $(\lambda=$ $0.71073 \AA$ for $3,4,6-9)$. Crystals of the compounds were embedded in an inert oil (Krytox ${ }^{\circledR}$, GPL107) and a suitable crystal was selected under an optical microscope and mounted on a CryoLoop (Hampton Research, type: 20 micron and 0.2-0.3 mm diameter), with the CryoLoop fixed on a tiny glass needle. The structures were solved by direct methods using SHELXS$2013^{58,59}$ and refined by full matrix least-squares procedures on $F^{2}$ using SHELXL-2013. ${ }^{60,61}$ All non-hydrogen atoms were refined anisotropically, while all hydrogen atoms were geometrically placed and refined isotropically in riding modes using default parameters. The crystallographic data for 1-9 have been deposited at the Cambridge Crystallographic Data Centre as supplementary publications CCDC 1948644 (1), 1948645 (2), 1950689 (3), 1948646 (4), 1948647 (5), 1948648 (6), 1950690 (7), 1948649 (8), 1948650 (9). $\dagger$ Visualization of the crystal structures was performed with Diamond (version $4.5^{62}$ ).

PXRD analyses were performed for compounds 1-9 and the diffraction patterns of the measured diffractograms are in good agreement with those simulated from the single crystal X-ray crystallographic data for 1-5, 7, 9 (see ESI, $\dagger$ Fig. S23-S27, S29 and S31). Only in the case of 6 and 8 a different pattern was observed when comparing to the ones simulated from the single crystal X-ray analyses, most probably due to the formation of polymorphs (see ESI, $\dagger$ Fig. S28 and S30). In case of 5 the crystals made available were all observed to be twinned into several different domains, with the major domains comprising about $50 \%$ of all reflections. Comparatively high $R$ factor for this kind of structure are assumed to be partial overlap of reflections, while measurements at higher detector distances did not help to get better data.

\section{Computational details}

All calculations were performed using the development version of the Orca 4.1 program. Initially, we have carried out conformational sampling using the GFN2-XTB program to get insight into the thermally accessible minimum energy structure of 2-5. Then, all conformers generated by GFN2-XTB ${ }^{63,64}$ are fully optimized using the $\mathrm{PBE}^{65,66}$ density functional in conjunction with the def2-TZVP ${ }^{67}$ basis set and the def2/J auxiliary basis set. $^{68}$ The default effective core potentials ${ }^{69,70}$ (def2-ECP) were used for iodine and bismuth. Fine integration grids (grid 4) were used for DFT optimizations. Stationary points were confirmed by analytical harmonic vibrational frequency calculations. Dispersion correction $^{71,72}$ (D3) with Becke-Johnson (BJ) damping ${ }^{73}$ was used for DFT calculations. Based on the relative energy ordering, we have identified the four lowest energy structures for each compound (2-5). Transition structure calculation are analysed by frequency calculations to identify only one imaginary frequency at same level of theory. The energies were refined at the DLPNO-CCSD $(\mathrm{T})^{74-80}$ level of theory employing the cc-pVQZ ${ }^{81}$ basis set for lighter elements $(\mathrm{H}, \mathrm{C}, \mathrm{Cl}$, and $\mathrm{Br})$. Additionally, the cc-pVQZ-PP ${ }^{70,82}$ and cc-pwCVQZ-PP ${ }^{83}$ basis sets combined with the SK-MCDHF-RSC effective core potential were used for iodine and bismuth, accordingly. Additionally, def2/JK, ${ }^{84} \operatorname{def} 2 / \mathrm{C}^{85}$ and cc-pwCVQZ-PP/C ${ }^{86}$ (for bismuth) auxiliary basis sets were used in DLPNO-CCSD(T) calculations. TightPNO ${ }^{87,88}$ settings were utilized in all DLPNO-CCSD(T) calculations. Additionally, local energy decomposition ${ }^{10,12}$ (LED) analysis was performed on different conformers of biphenyl compounds in order to analyse dispersion energy contributions in a particular molecule.

Nuclear magnetic shieldings were computed using M06L, ${ }^{89}$ TPSS, ${ }^{90}$ and double hybrid PBEP86 and utilized pcSseg- $3{ }^{91}$ basis set for lighter elements and all-electron Sapporo-DKH3-TZP$2012^{92}$ basis set for bismuth. AutoAux ${ }^{93}$ was used to generate auxiliary basis sets for bismuth. Fine integration grids were used (grid 6 for M06L and TPSS, and grid 4 for PBEP86). Resolution of the identity (RI) approximation ${ }^{94-102}$ with corresponding auxiliary basis sets were employed in all calculations.

Synthesis of $\left(2-\mathrm{PhC}_{6} \mathbf{H}_{4}\right)_{3} \mathbf{B i}$ (1). A solution of ${ }^{n} \mathrm{BuLi}$ in $n$-hexane (5.5 mL, 2.5 M, $13.75 \mathrm{mmol}$ ) was added dropwise at $-78{ }^{\circ} \mathrm{C}$ to a stirred solution of 2-bromobiphenyl (3.038 g, $13.21 \mathrm{mmol})$ in anhydrous $\mathrm{Et}_{2} \mathrm{O}(30 \mathrm{~mL})$. The reaction mixture was stirred for $2 \mathrm{~h}$ at $-78{ }^{\circ} \mathrm{C}$. After that the organolithium derivative was added dropwise to a solution of $\mathrm{BiCl}_{3}(2.036 \mathrm{~g}, 6.46 \mathrm{mmol})$ in $\mathrm{Et}_{2} \mathrm{O}$ $(30 \mathrm{~mL})$, the reaction mixture was kept at $-78{ }^{\circ} \mathrm{C}$ for $1 \mathrm{~h}$ and then stirred overnight at ambient temperature. The solvent was removed in vacuo and the oily residue was extracted with toluene $(3 \times 15 \mathrm{~mL})$, filtrated off and after removal of the solvent in vacuo, a colorless solid was isolated. Single crystals suitable for X-ray analysis were grown from a $n$-hexane solution. Yield: $2.925 \mathrm{~g}(68 \%)$. M.p. $=205-206{ }^{\circ} \mathrm{C}$. Elemental analysis calcd $(\%)$ for $\mathrm{C}_{36} \mathrm{H}_{27} \mathrm{Bi}$ (668.58 $\mathrm{g} \mathrm{mol}^{-1}$ ): C, 64.67; H, 4.07. Found: C, 64.28; H, 4.02. ATR FTIR (cm $\left.{ }^{-1}\right): 3054(\mathrm{~m}), 3033(\mathrm{~m}), 2364(\mathrm{~m}), 2330(\mathrm{~m}), 1889(\mathrm{w})$, 1856 (w), 1822 (w), 1756 (w), 1598 (w), 1573 (m), 1552 (w), 1452 (s), 
1440 (s), 1427 (s), 1382 (w), 1327 (w), 1311 (w), 1282 (w), 1261 (w), $1244(\mathrm{~m}), 1178(\mathrm{~m}), 1157(\mathrm{~m}), 1111(\mathrm{~m}), 1072(\mathrm{~m}), 1059(\mathrm{w})$, $1030(\mathrm{~m}), 1013(\mathrm{w}), 995(\mathrm{w}), 980(\mathrm{~m}), 965(\mathrm{w}), 946(\mathrm{~m}), 914(\mathrm{~m})$, 876 (w), 843 (m), 770 (s), 747 (vs), 726 (s), 697 (vs), 669 (w), 645 (m), 615 (s), 548 (s), 532 (s), 442 (s), 432 (s), 413 (w). ${ }^{1} \mathrm{H}$ NMR $\left(500.30 \mathrm{MHz}, \mathrm{CDCl}_{3}\right): \delta 7.03\left[\mathrm{~m}, 6 \mathrm{H}, \mathrm{H}-8,8^{\prime},\left(\mathrm{C}_{6} H_{5}\right)\right], 7.20[\mathrm{~m}, 9 \mathrm{H}$, $\left.\mathrm{H}-9,9^{\prime}, \mathrm{H}-10,\left(\mathrm{C}_{6} H_{5}\right)\right], 7.30\left[\mathrm{~m}, 3 \mathrm{H}, \mathrm{H}-5,\left(\mathrm{C}_{6} H_{4}\right)\right], 7.39[\mathrm{~m}, 6 \mathrm{H}, \mathrm{H}-3$, $\left.\mathrm{H}-4,\left(\mathrm{C}_{6} H_{4}\right)\right], 7.91$ (d, 3H, H-6, $\left.{ }^{3} \mathrm{~J}_{\mathrm{H}-\mathrm{H}}=7.2 \mathrm{~Hz}, \mathrm{C}_{6} H_{4}\right) .{ }^{13} \mathrm{C}\left\{{ }^{1} \mathrm{H}\right\} \mathrm{NMR}$ (125.81 MHz, $\mathrm{CDCl}_{3}$ ): $\delta 127.16$ (s, C-10), 127.67 (s, C-4), 128.20 (s, C-9,9'), 129.11 (s, C-8,8'), 129.62 (s, C-5), 130.04 (s, C-3), 139.53 (s, C-6), 144.96 (s, C-7), 149.57 (s, C-2), 160.33 (s, C-1).

Synthesis of $\left(2-\mathrm{PhC}_{6} \mathrm{H}_{4}\right)_{2} \mathrm{BiCl}(2)$. A mixture of $\left(2-\mathrm{PhC}_{6} \mathrm{H}_{4}\right)_{3} \mathrm{Bi}$ $(0.868 \mathrm{~g}, 1.29 \mathrm{mmol})$ and $\mathrm{BiCl}_{3}(0.205 \mathrm{~g}, 0.65 \mathrm{mmol})$ was melted and stirred in the absence of any solvent for 15 minutes at $130{ }^{\circ} \mathrm{C}$. After cooling to ambient temperature, the solid product was extracted with $\mathrm{Et}_{2} \mathrm{O}(300 \mathrm{~mL})$, the solution was filtered and the solvent was evacuated in vacuo to give a colorless solid, followed by extraction with $n$-hexane $(500 \mathrm{~mL})$. Single crystals suitable for X-ray analysis were grown from a saturated $n$-hexane solution. Yield: $0.689 \mathrm{~g}$ (64\%). M.p. $=132-134{ }^{\circ} \mathrm{C}$. Elemental analysis calcd (\%) for $\mathrm{C}_{24} \mathrm{H}_{18} \mathrm{BiCl}\left(550.84 \mathrm{~g} \mathrm{~mol}^{-1}\right)$ : $\mathrm{C}, 52.33$; $\mathrm{H}, 3.29$. Found: $\mathrm{C}, 52.27 ; \mathrm{H}, 3.25$. ATR FTIR $\left(\mathrm{cm}^{-1}\right): 3054(\mathrm{~m})$, $3036(\mathrm{~m}), 3021(\mathrm{~m}), 2998(\mathrm{w}), 2346(\mathrm{w}), 1894(\mathrm{w}), 1821(\mathrm{w})$, 1574 (w), 1493 (w), 1455 (m), 1443 (s), 1430 (m), 1391 (w), 1285 (w), $1242(\mathrm{w}), 1177(\mathrm{w}), 1158(\mathrm{w}), 1072(\mathrm{~m}), 1059(\mathrm{w}), 1026(\mathrm{w})$, $1005(\mathrm{~s}), 996(\mathrm{w}), 969(\mathrm{w}), 914(\mathrm{~m}), 868(\mathrm{w}), 847(\mathrm{w}), 774(\mathrm{~s})$, 743 (vs), 723 (m), 700 (vs), 646 (w), 632 (m), 550 (s), $525(\mathrm{~m})$, 436 (s). ${ }^{1} \mathrm{H}$ NMR (500.30 MHz, $\mathrm{CDCl}_{3}$ ): $\delta 7.11$ (d, 4H, H-8, ${ }^{\prime}$, $\mathrm{C}_{6} H_{5}$ ), 7.35 (m, 6H, H-9,9', H10, $\mathrm{C}_{6} H_{5}$ ), 7.51 (ddd, 2H, H-4, $\left.{ }^{3} J_{\mathrm{H}-\mathrm{H}}=7.5 \mathrm{~Hz},{ }^{4} J_{\mathrm{H}-\mathrm{H}}=1.3 \mathrm{~Hz}, \mathrm{C}_{6} H_{4}\right), 7.61\left(\mathrm{dd}, 2 \mathrm{H}, \mathrm{H}-3,{ }^{3} J_{\mathrm{H}-\mathrm{H}}=\right.$ $\left.7.6 \mathrm{~Hz},{ }^{4} J_{\mathrm{H}-\mathrm{H}}=1.3 \mathrm{~Hz}, \mathrm{C}_{6} H_{4}\right), 7.74\left(\mathrm{ddd}, 2 \mathrm{H}, \mathrm{H}-5,{ }^{3} J_{\mathrm{H}-\mathrm{H}}=7.4 \mathrm{~Hz}\right.$, $\left.{ }^{4} J_{\mathrm{H}-\mathrm{H}}=1.4 \mathrm{~Hz}, \mathrm{C}_{6} H_{4}\right), 8.86\left(\mathrm{dd}, 2 \mathrm{H}, \mathrm{H}-6,{ }^{3} J_{\mathrm{H}-\mathrm{H}}=7.6 \mathrm{~Hz},{ }^{4} J_{\mathrm{H}-\mathrm{H}}=\right.$ $\left.1.3 \mathrm{~Hz}, \mathrm{C}_{6} H_{4}\right) .{ }^{13} \mathrm{C}\left\{{ }^{1} \mathrm{H}\right\}$ NMR (125.81 MHz, $\left.\mathrm{CDCl}_{3}\right): \delta 128.21$ (s, C-10), 128.46 (s, C-8,8'), 128.76 (s, C-4), 129.40 (s, C-9,9'), 131.46 (s, C-3), 132.40 (s, C-5), 138.24 (s, C-6), 143.59 (s, C-7), 148.54 (s, C-2), 180.98 (s, C-1).

Synthesis of (2-PhC $\left.{ }_{6} \mathrm{H}_{4}\right)_{2} \mathrm{BiBr}$ (3). A solution of ${ }^{n} \mathrm{BuLi}$ in $n$-hexane $(2.25 \mathrm{~mL}, 2.5 \mathrm{M}, 5.62 \mathrm{mmol})$ was added dropwise at $-78{ }^{\circ} \mathrm{C}$ to a stirred solution of 2-bromobiphenyl (1.191 g, $5.10 \mathrm{mmol})$ in anhydrous $\mathrm{Et}_{2} \mathrm{O}(30 \mathrm{~mL})$. The reaction mixture was stirred for $1 \mathrm{~h}$ at $-78{ }^{\circ} \mathrm{C}$. After the organolithium derivative was added dropwise to a solution of $\mathrm{BiBr}_{3}(1.146 \mathrm{~g}, 2.55 \mathrm{mmol})$ in $\mathrm{Et}_{2} \mathrm{O}(40 \mathrm{~mL})$, the reaction mixture was kept at $-78{ }^{\circ} \mathrm{C}$ for $2 \mathrm{~h}$ and then stirred overnight at ambient temperature. The solvent was evacuated in vacuo and the oily residue was extracted with $\mathrm{CHCl}_{3}$, the solution filtered and after removal of the solvent in vacuo a colorless solid was isolated. Single crystals suitable for $\mathrm{X}$-ray analysis were grown from a $n$-hexane solution. Yield: 0.158 g (10\%). M.p. $=149-150{ }^{\circ} \mathrm{C}$. Elemental analysis calcd (\%) for $\mathrm{C}_{24} \mathrm{H}_{18} \mathrm{BiBr}\left(595.28 \mathrm{~g} \mathrm{~mol}^{-1}\right)$ : $\mathrm{C}, 48.42 ; \mathrm{H}, 3.05$. Found: C, 48.65; H, 3.00. ATR FTIR $\left(\mathrm{cm}^{-1}\right): 3037(\mathrm{~m}), 2992(\mathrm{w}), 2951(\mathrm{w})$, 2342 (w), 1598 (w), 1572 (m), 1552 (w), 1494 (m), 1448 (m), 1440 (s), $1427(\mathrm{~m}), 1307$ (w), $1282(\mathrm{w}), 1267(\mathrm{w}), 1240(\mathrm{~m})$, $1178(\mathrm{w}), 1157(\mathrm{w}), 1107(\mathrm{w}), 1074(\mathrm{~m}), 1057(\mathrm{w}), 1032(\mathrm{w})$, $1003(\mathrm{~s}), 994(\mathrm{~m}), 983(\mathrm{w}), 970(\mathrm{w}), 945(\mathrm{w}), 916(\mathrm{~m}), 874(\mathrm{w})$, 845 (m), 769 (s), 745 (vs), 724 (s), 695 (vs), 670 (s), 645 (s), 615 (s),
550 (s), 528 (s), 432 (s). ${ }^{1} \mathrm{H}$ NMR (500.30 MHz, $\mathrm{CDCl}_{3}$ ): $\delta 7.11$ (d, $\left.4 \mathrm{H}, \mathrm{H}-8,8^{\prime}, \mathrm{C}_{6} H_{5}\right), 7.35\left(\mathrm{~m}, 6 \mathrm{H}, \mathrm{H}-9,9^{\prime}, \mathrm{H}-10, \mathrm{C}_{6} H_{5}\right), 7.51$ (ddd, $1 \mathrm{H}, \mathrm{H}-4,{ }^{3} J_{\mathrm{H}-\mathrm{H}}=7.4 \mathrm{~Hz},{ }^{4} J_{\mathrm{H}-\mathrm{H}}=1.4 \mathrm{~Hz}, \mathrm{C}_{6} H_{4}$ ), 7.58 (dd, $\left.2 \mathrm{H}, \mathrm{H}-3,{ }^{3} J_{\mathrm{H}-\mathrm{H}}=7.5 \mathrm{~Hz},{ }^{4} J_{\mathrm{H}-\mathrm{H}}=1.6 \mathrm{~Hz}, \mathrm{C}_{6} H_{4}\right), 7.69(\mathrm{ddd}, 1 \mathrm{H}$, $\left.\mathrm{H}-5,{ }^{3} J_{\mathrm{H}-\mathrm{H}}=7.4 \mathrm{~Hz},{ }^{4} J_{\mathrm{H}-\mathrm{H}}=1.5 \mathrm{~Hz}, \mathrm{C}_{6} H_{4}\right), 8.96(\mathrm{dd}, 1 \mathrm{H}, \mathrm{H}-6$, $\left.{ }^{3} J_{\mathrm{H}-\mathrm{H}}=7.6 \mathrm{~Hz}, \mathrm{C}_{6} H_{4}\right) .{ }^{13} \mathrm{C}\left\{{ }^{1} \mathrm{H}\right\} \mathrm{NMR}\left(125.81 \mathrm{MHz}, \mathrm{CDCl}_{3}\right)$ : $\delta 128.22$ (s, C-10), 128.47 (s, C-8, 8') 128.73 (s, C-4), 129.32 (s, C-9,9'), 131.14 (s, C-3), 132.59 (s, C-5), 139.77 (s, C-6), 143.66 (s, C-7), 148.49 (s, C-2), 175.66 (s, C-1).

Synthesis of (2-PhC $\left.{ }_{6} \mathbf{H}_{4}\right)_{2} \mathbf{B i I}(4)$. Solid $\mathrm{KI}(0.064 \mathrm{~g}, 0.38 \mathrm{mmol})$ was added to a solution of $\left(2-\mathrm{PhC}_{6} \mathrm{H}_{4}\right)_{2} \mathrm{BiBr}(0.176 \mathrm{~g}, 0.29 \mathrm{mmol})$ in EtOH $(20 \mathrm{~mL})$. The color of the solution turned immediately yellow and the reaction mixture was stirred for two days at ambient temperature. After removal of the solvent in vacuo, the yellow powder was extracted with toluene $(3 \times 5 \mathrm{~mL})$, the solution filtered and the solvent was removed in vacuo to give a yellow powder. Yield: $0.116 \mathrm{~g},(61 \%)$. Single crystals suitable for X-ray analysis were grown from a $\mathrm{CHCl}_{3}$ solution. M.p. $=138-139{ }^{\circ} \mathrm{C}$. Elemental analysis calcd (\%) for $\mathrm{C}_{24} \mathrm{H}_{18} \mathrm{BiI}\left(642.28 \mathrm{~g} \mathrm{~mol}^{-1}\right)$ : C, 44.88; H, 2.82. Found: C, 44.70; H, 2.93. ATR FTIR $\left(\mathrm{cm}^{-1}\right)$ : 3053 (m), 3019 (m), 2965 (w), 2343 (w), 1574 (m), 1491 (m), 1454 (m), 1441 (s), 1425 (m), 1387 (w), 1333 (w), 1258 (s), 1242 (m), 1179 (m), 1154 (m), 1091 (s), 1071 (s), 1025 (s), 1004 (vs), 966 (m), 942 (w), $913(\mathrm{~m}), 867(\mathrm{~m}), 842(\mathrm{~m}), 796(\mathrm{~s}), 772(\mathrm{~s}), 742(\mathrm{vs}), 721(\mathrm{~s})$, 696 (vs), 642 (s), 613 (s), 547 (s), 525 (s), 484 (w), 434 (vs). ${ }^{1} \mathrm{H}$ NMR $\left(500.30 \mathrm{MHz}, \mathrm{CDCl}_{3}\right): \delta 7.10\left(\mathrm{~d}, 4 \mathrm{H}, \mathrm{H}-8,8^{\prime},{ }^{3} J_{\mathrm{H}-\mathrm{H}}=\right.$ $\left.6.5 \mathrm{~Hz}, \mathrm{C}_{6} H_{5}\right), 7.29-7.39\left(\mathrm{~m}, 6 \mathrm{H}, \mathrm{H}-9,9^{\prime}, \mathrm{H}-10, \mathrm{C}_{6} H_{5}\right), 7.51$ $\left(\mathrm{m}, 4 \mathrm{H}, \mathrm{H}-3+\mathrm{H}-4, \mathrm{C}_{6} H_{4}\right), 7.54-7.61\left(\mathrm{~m}, 2 \mathrm{H}, \mathrm{H}-5, \mathrm{C}_{6} H_{4}\right), 9.11$ (d, $\left.3 \mathrm{H}, \mathrm{H}-6,{ }^{3} J_{\mathrm{H}-\mathrm{H}}=7.4 \mathrm{~Hz}, \mathrm{C}_{6} H_{4}\right) .{ }^{13} \mathrm{C}\left\{{ }^{1} \mathrm{H}\right\}$ NMR $(125.81 \mathrm{MHz}$, $\mathrm{CDCl}_{3}$ ): $\delta 128.18$ (s, C-10), 128.39 (s, C-8,8 $8^{\prime}, 128.68$ (s, C-4), 129.16 (s, C-9,9'), 130.47 (s, C-3), 132.77 (s, C-5), 142.75 (s, C-6), 143.87 (s, C-7), 148.44 (s, C-2), 165.80 (s, C-1).

Synthesis of $\left(2-\mathrm{PhC}_{6} \mathrm{H}_{4}\right)_{2} \mathrm{BiMe}(5)$. A solution of $\mathrm{MeLi}$ in $\mathrm{Et}_{2} \mathrm{O}$ (0.65 mL, 1.6 M, $1.04 \mathrm{mmol}$ ) was added dropwise, via syringe to a stirred suspension of $\left(2-\mathrm{PhC}_{6} \mathrm{H}_{4}\right)_{2} \mathrm{BiCl}(3)(0.511 \mathrm{~g}, 0.93 \mathrm{mmol})$ in anhydrous $\mathrm{Et}_{2} \mathrm{O}(80 \mathrm{~mL})$ at $-78{ }^{\circ} \mathrm{C}$. The reaction mixture was kept at $-78{ }^{\circ} \mathrm{C}$ for $1 \mathrm{~h}$ and then stirred overnight at ambient temperature. The solvent was evacuated in vacuo and the light yellow isolated precipitate was extracted with $n$-pentane $(3 \times$ $30 \mathrm{~mL}$ ), the solution was filtered and after removal of the solvent in vacuo a colorless oil was isolated. Colorless single crystals suitable for X-ray analysis were grown from diffusion of $\mathrm{Et}_{2} \mathrm{O}$ into a $n$-pentane solution at $-28{ }^{\circ} \mathrm{C}$. Yield: $0.310 \mathrm{~g}(63 \%)$. M.p. $=83-$ $84{ }^{\circ} \mathrm{C}$. Elemental analysis calcd (\%) for $\mathrm{C}_{25} \mathrm{H}_{21} \mathrm{Bi}\left(530.42 \mathrm{~g} \mathrm{~mol}^{-1}\right)$ : C, 56.61; H, 3.99. Found: C, 56.91; H, 3.85. ATR FTIR $\left(\mathrm{cm}^{-1}\right)$ : 3056 (m), 3025 (m), 2919 (m), 2346 (w), 2284 (w), 1871 (w), $1752(\mathrm{w})$, 1599 (w), 1572 (w), 1499 (w), 1455 (w), 1443 (m), 1420 (w), $1389(\mathrm{w})$, $1244(\mathrm{w}), 1177$ (w), 1153 (w), 1111 (w), 1071 (m), 1030 (w), 1007 (m), $965(\mathrm{~m}), 913(\mathrm{~m}), 872(\mathrm{w}), 843(\mathrm{w}), 778(\mathrm{~m}), 747(\mathrm{vs}), 718(\mathrm{~s})$, 700 (vs), 666 (w), 642 (w), 552 (m), 523 (m), 450 (s), 438 (s). ${ }^{1} \mathrm{H}$ NMR $\left(500.30 \mathrm{MHz}, \mathrm{CDCl}_{3}\right): \delta 0.97\left(\mathrm{~s}, 3 \mathrm{H}, \mathrm{CH}_{3}\right), 7.21\left(\mathrm{~m}, 4 \mathrm{H}, \mathrm{H}-8,8^{\prime}\right.$, $\left.\mathrm{C}_{6} H_{5}\right), 7.32\left(\mathrm{~m}, 8 \mathrm{H}, \mathrm{H}-9,9^{\prime}, \mathrm{H} 10, \mathrm{C}_{6} H_{5}, \mathrm{H}-4, \mathrm{C}_{6} H_{4}\right), 7.38$ (m, 4H, H-3, $\left.\mathrm{H} 5, \mathrm{C}_{6} H_{4}\right), 7.97$ (d, 2H, H-6, $\left.{ }^{3} J_{\mathrm{H}-\mathrm{H}}=7.8 \mathrm{~Hz}, \mathrm{C}_{6} H_{4}\right) .{ }^{13} \mathrm{C}\left\{{ }^{1} \mathrm{H}\right\} \mathrm{NMR}$ (125.81 MHz, $\left.\mathrm{CDCl}_{3}\right): \delta 13.46\left(\mathrm{~s}, \mathrm{CH}_{3}\right), 127.26(\mathrm{~s}, \mathrm{C}-10), 127.62$ (s, C-4), 128.33 (s, C-9,9'), 129.11 (s, C-5), 129.15 (s, C-8, 8'), 129.41 (s, C-3), 138.26 (s, C-6), 145.18 (s, C-7), 149.50 (s, C-2), 151.03 (s, C-1). 
Synthesis of (2- $\left.\mathrm{PhC}_{6} \mathrm{H}_{4}\right) \mathbf{B i C l}_{2}(6)$. A mixture of $\left(2-\mathrm{PhC}_{6} \mathrm{H}_{4}\right)_{3} \mathrm{Bi}$ $(0.868 \mathrm{~g}, 1.29 \mathrm{mmol})$ and $\mathrm{BiCl}_{3}(0.205 \mathrm{~g}, 0.65 \mathrm{mmol})$ was melted and stirred for 10 minutes at $130{ }^{\circ} \mathrm{C}$, in the absence of any solvent. After cooling to ambient temperature, the solid product was extracted with $\mathrm{Et}_{2} \mathrm{O}(300 \mathrm{~mL})$, the solution filtered and the solvent was evacuated in vacuo to give a colorless solid, that was washed with $n$-hexane $(5 \times 10 \mathrm{~mL})$. Finally, the solid material was extracted with $\mathrm{CH}_{2} \mathrm{Cl}_{2}$ to give a colorless microcrystalline solid. Colorless single crystals suitable for X-ray analysis were grown from diffusion of $n$-pentane into a $\mathrm{Et}_{2} \mathrm{O}$ solution at $-28{ }^{\circ} \mathrm{C}$. Yield: $0.128 \mathrm{~g}(30 \%)$. M.p. $=181-183{ }^{\circ} \mathrm{C}$. Elemental analysis calcd (\%) for $\mathrm{C}_{12} \mathrm{H}_{9} \mathrm{BiCl}_{2}\left(433.08 \mathrm{~g} \mathrm{~mol}^{-1}\right)$ : C, 33.28; $\mathrm{H}$, 2.09. Found: C, 31.82; H, 2.09. ATR FTIR $\left(\mathrm{cm}^{-1}\right): 3054(\mathrm{~m})$, $3017(\mathrm{w}), 2347(\mathrm{w}), 2325(\mathrm{w}), 1983(\mathrm{w}), 1894(\mathrm{w}), 1830(\mathrm{w})$, $1574(\mathrm{w}), 1495$ (w), $1455(\mathrm{w}), 1443$ (s), $1432(\mathrm{~m}), 1420(\mathrm{~m})$, $1075(\mathrm{w}), 1059(\mathrm{w}), 1005(\mathrm{w}), 953(\mathrm{w}), 924(\mathrm{~m}), 860(\mathrm{w})$, $781(\mathrm{~m}), 741(\mathrm{vs}), 722(\mathrm{~s}), 704(\mathrm{vs}), 612(\mathrm{w}), 548(\mathrm{~m}), 521(\mathrm{~m})$, 432 (s). ${ }^{1} \mathrm{H}$ NMR $\left(500.30 \mathrm{MHz}, \mathrm{CDCl}_{3}\right): \delta 7.48\left(\mathrm{~m}, 2 \mathrm{H}, \mathrm{H}-8,8^{\prime}\right.$, $\left.\mathrm{C}_{6} H_{5}\right), 7.53\left(\mathrm{t}, 1 \mathrm{H}, \mathrm{H}-10, \mathrm{C}_{6} H_{5}\right), 7.61\left(\mathrm{~m}, 2 \mathrm{H}, \mathrm{H}-9,9^{\prime}, \mathrm{C}_{6} H_{5}\right)$, $7.71\left(\mathrm{ddd}, 1 \mathrm{H}, \mathrm{H}-4,{ }^{3} J_{\mathrm{H}-\mathrm{H}}=7.5 \mathrm{~Hz},{ }^{4} J_{\mathrm{H}-\mathrm{H}}=1.2 \mathrm{~Hz}, \mathrm{C}_{6} H_{4}\right), 8.01$ (dd, $\left.1 \mathrm{H}, \mathrm{H}-3,{ }^{3} J_{\mathrm{H}-\mathrm{H}}=7.6 \mathrm{~Hz},{ }^{4} J_{\mathrm{H}-\mathrm{H}}=1.3 \mathrm{~Hz}, \mathrm{C}_{6} H_{4}\right), 8.21$ (ddd, $1 \mathrm{H}$, $\left.\mathrm{H}-5,{ }^{3} J_{\mathrm{H}-\mathrm{H}}=7.5 \mathrm{~Hz},{ }^{4} J_{\mathrm{H}-\mathrm{H}}=1.3 \mathrm{~Hz}, \mathrm{C}_{6} H_{4}\right), 9.78(\mathrm{dd}, 1 \mathrm{H}, \mathrm{H}-6$, $\left.{ }^{3} J_{\mathrm{H}-\mathrm{H}}=7.8 \mathrm{~Hz},{ }^{4} J_{\mathrm{H}-\mathrm{H}}=1.2 \mathrm{~Hz}, \mathrm{C}_{6} H_{4}\right) .{ }^{13} \mathrm{C}\left\{{ }^{1} \mathrm{H}\right\} \operatorname{NMR}(125.81 \mathrm{MHz}$, $\left.\mathrm{CDCl}_{3}\right): \delta 128.51$ (s, C-8,8'), 129.44 (s, C-10), 130.04 (s, C-4), 130.72 (s, C-9,9'), 133.53 (s, C-3), 134.81 (s, C-5), 138.02 (s, C-6), 141.84 (s, C-7), 148.08 (s, C-2), C-1 could not be detected.

\section{Synthesis of $\left(2-\mathrm{PhC}_{6} \mathbf{H}_{4}\right) \mathbf{B i B r}_{2}(7)$}

Method A. A solution of ${ }^{n} \mathrm{BuLi}$ in $n$-hexane $(1.72 \mathrm{~mL}, 2.5 \mathrm{M}$, $4.29 \mathrm{mmol})$ was added dropwise at $-78{ }^{\circ} \mathrm{C}$ via a syringe, to a stirred solution of 2-bromobiphenyl $(1.000 \mathrm{~g}, 4.29 \mathrm{mmol})$ in anhydrous $\mathrm{Et}_{2} \mathrm{O}(50 \mathrm{~mL})$. The reaction mixture was stirred for $1 \mathrm{~h}$ at $-78{ }^{\circ} \mathrm{C}$. After that a solution of $\mathrm{BiBr}_{3}(1.925 \mathrm{~g}, 4.29 \mathrm{mmol})$ in $\mathrm{Et}_{2} \mathrm{O}(90 \mathrm{~mL})$ was added, the reaction mixture was kept at $-78{ }^{\circ} \mathrm{C}$ for $2 \mathrm{~h}$ and then stirred for four days at room temperature. The solvent was evacuated in vacuo and the oily residue was extracted with toluene and $\mathrm{CHCl}_{3}$, followed by filtration of the extract and removal of the solvent in vacuo to give an oily light brownish precipitate which was washed with $n$-hexane $(5 \times$ $10 \mathrm{~mL}$ ). Yield: $0.799 \mathrm{~g}(36 \%)$ yellow single crystals suitable for $\mathrm{X}$-ray analysis were grown from diffusion of $n$-hexane into $\mathrm{CHCl}_{3}$ solution (v/v 1:3).

Method B. A mixture of $\left(2-\mathrm{PhC}_{6} \mathrm{H}_{4}\right)_{3} \mathrm{Bi}(0.796 \mathrm{~g}, 1.19 \mathrm{mmol})$ and $\operatorname{BiBr}_{3}(1.068 \mathrm{~g}, 2.38 \mathrm{mmol})$ was melted and stirred for 15 minutes at $130{ }^{\circ} \mathrm{C}$ in the absence of any solvent. After cooling to ambient temperature the solid product was extracted with $\mathrm{Et}_{2} \mathrm{O}(20 \mathrm{~mL})$, the solution filtered and the solvent was evacuated in vacuo to give $0.280 \mathrm{~g} \mathrm{(45 \% )}$ of the title compound as light yellow powder. M.p. $=189-192{ }^{\circ} \mathrm{C}$. Elemental analysis calcd (\%) for $\mathrm{C}_{12} \mathrm{H}_{9} \mathrm{BiBr}_{2}\left(521.99 \mathrm{~g} \mathrm{~mol}^{-1}\right)$ : C, 27.61; H, 1.74. Found: C, 27.39; H, 1.55. ATR FTIR $\left(\mathrm{cm}^{-1}\right): 3058(\mathrm{w}), 3037(\mathrm{w}), 2346(\mathrm{w})$, $2136(\mathrm{w}), 1594(\mathrm{w}), 1573(\mathrm{~m}), 1548$ (w), $1494(\mathrm{~m}), 1481(\mathrm{w})$, 1452 (s), 1444 (s), 1415 (s), $1344(\mathrm{w}), 1311$ (m), 1285 (m), $1269(\mathrm{~m}), 1239(\mathrm{~m}), 1178(\mathrm{~m}), 1157$ (s), $1112(\mathrm{~m}), 1074(\mathrm{~s})$, $1053(\mathrm{~s}), 1003(\mathrm{w}), 974(\mathrm{~s}), 953(\mathrm{~m}), 920(\mathrm{~s}), 878(\mathrm{~m}), 849(\mathrm{~s})$, 778 (s), 750 (vs), 743 (vs), 719 (s), 706 (vs), 646 (m), 612 (m), $544(\mathrm{~s}), 517$ (s), 428 (s), $412(\mathrm{~m}) .{ }^{1} \mathrm{H}$ NMR (500.30 MHz, $\left.\mathrm{CDCl}_{3}\right)$ : $\delta 7.46\left(\mathrm{~m}, 2 \mathrm{H}, \mathrm{H}-8,8^{\prime}, \mathrm{C}_{6} H_{5}\right), 7.53\left(\mathrm{t}, 1 \mathrm{H}, \mathrm{H}-10,{ }^{3} \mathrm{~J}_{\mathrm{H}-\mathrm{H}}=7.5 \mathrm{~Hz}, \mathrm{C}_{6} H_{5}\right)$, $7.59\left(\mathrm{t}, 2 \mathrm{H}, \mathrm{H}-9,9^{\prime},{ }^{3} J_{\mathrm{H}-\mathrm{H}}=7.4 \mathrm{~Hz}, \mathrm{C}_{6} H_{5}\right), 7.71(\mathrm{ddd}, 1 \mathrm{H}, \mathrm{H}-4$, $\left.{ }^{3} J_{\mathrm{H}-\mathrm{H}}=7.5 \mathrm{~Hz},{ }^{4} J_{\mathrm{H}-\mathrm{H}}=1.2 \mathrm{~Hz}, \mathrm{C}_{6} H_{4}\right), 7.95\left(\mathrm{dd}, 1 \mathrm{H}, \mathrm{H}-3,{ }^{3} J_{\mathrm{H}-\mathrm{H}}=\right.$ $\left.7.6 \mathrm{~Hz},{ }^{4} J_{\mathrm{H}-\mathrm{H}}=1.3 \mathrm{~Hz}, \mathrm{C}_{6} H_{4}\right), 8.14\left(\mathrm{ddd}, 1 \mathrm{H}, \mathrm{H}-5,{ }^{3} J_{\mathrm{H}-\mathrm{H}}=7.5 \mathrm{~Hz}\right.$, $\left.{ }^{4} J_{\mathrm{H}-\mathrm{H}}=1.3 \mathrm{~Hz}, \mathrm{C}_{6} H_{4}\right), 10.04\left(\mathrm{dd}, 1 \mathrm{H}, \mathrm{H}-6,{ }^{3} J_{\mathrm{H}-\mathrm{H}}=7.7 \mathrm{~Hz},{ }^{4} J_{\mathrm{H}-\mathrm{H}}=\right.$ $\left.1.3 \mathrm{~Hz}, \mathrm{C}_{6} \mathrm{H}_{4}\right) \cdot{ }^{13} \mathrm{C}\left\{{ }^{1} \mathrm{H}\right\}$ NMR $\left(125.81 \mathrm{MHz}, \mathrm{CDCl}_{3}\right): \delta 128.27$ (s, C-8, 8'), 129.47 (s, C-10), 129.92 (s, C-4), 130.55 (s, C-9,9'), 132.95 (s, C-3), 135.37 (s, C-5), 140.70 (s, C-6), 142.13 (s, C-7), 147.84 (s, C-2), C-1 could not be detected.

Synthesis of (2-PhC $\left.{ }_{6} \mathbf{H}_{4}\right)$ BiI $_{2}$ (8). Solid KI $(0.154 \mathrm{~g}, 0.92 \mathrm{mmol})$ was added to a solution of $\left(2-\mathrm{PhC}_{6} \mathrm{H}_{4}\right) \mathrm{BiBr}_{2}$ (8) (0.202 g, $0.38 \mathrm{mmol})$ in EtOH $(20 \mathrm{~mL})$. The color of the solution turned immediately orange and the reaction mixture was stirred for three days at ambient temperature. After removal of solvent under vacuum, the orange powder was extracted with toluene $(3 \times 5 \mathrm{~mL})$, the solution filtered and the solvent was removed under vacuum to give an orange powder. Single crystals suitable for X-ray analysis were grown from a $\mathrm{CH}_{2} \mathrm{Cl}_{2}$ solution at ambient temperature. Yield: $0.095 \mathrm{~g},(40 \%)$. M.p. $=161-162{ }^{\circ} \mathrm{C}$. Elemental analysis calcd (\%) for $\mathrm{C}_{12} \mathrm{H}_{9} \mathrm{BiI}_{2}\left(615.99 \mathrm{~g} \mathrm{~mol}^{-1}\right)$ : C, $23.40 ; \mathrm{H}$, 1.47. Found: C, 22.93; H, 1.34. ATR FTIR $\left(\mathrm{cm}^{-1}\right): 3054(\mathrm{~m})$, $2359(\mathrm{w}), 2339(\mathrm{w}), 2326(\mathrm{w}), 1969(\mathrm{w}), 1947(\mathrm{w}), 1902(\mathrm{w})$, $1885(\mathrm{w}), 1860(\mathrm{w}), 1831(\mathrm{w}), 1815(\mathrm{w}), 1764$ (w), $1731(\mathrm{w})$, $1702(\mathrm{w}), 1656(\mathrm{w}), 1627(\mathrm{w}), 1594(\mathrm{~m}), 1573(\mathrm{~m}), 1548(\mathrm{~m})$, $1527(\mathrm{w}), 1490(\mathrm{~m}), 1452(\mathrm{~s}), 1440(\mathrm{~s}), 1423(\mathrm{~s}), 1411(\mathrm{~s}), 1390(\mathrm{~m})$, 1336 (w), 1315 (m), 1311 (m), 1286 (m), 1273 (m), $1240(\mathrm{~m})$, $1178(\mathrm{~s}), 1161$ (s), 1070 (s), 1057 (s), 1032 (m), 1015 (m), 1003 (s), $983(\mathrm{~s}), 970(\mathrm{~s}), 949(\mathrm{~s}), 920(\mathrm{~s}), 874(\mathrm{~m}), 849(\mathrm{~s}), 774(\mathrm{~s}), 745$ (vs), $716(\mathrm{~s}), 704(\mathrm{vs}), 666(\mathrm{w}), 642(\mathrm{~m}), 613(\mathrm{~s}), 550(\mathrm{~s}), 517(\mathrm{~s}), 425(\mathrm{~s})$, $408(\mathrm{~m}) .{ }^{1} \mathrm{H}$ NMR $\left(500.30 \mathrm{MHz}, \mathrm{CDCl}_{3}\right): \delta 7.41\left(\mathrm{~m}, 2 \mathrm{H}, \mathrm{H}-8,8^{\prime}\right.$, $\left.\mathrm{C}_{6} H_{5}\right), 7.50\left(\mathrm{t}, 1 \mathrm{H}, \mathrm{H}-10,{ }^{3} J_{\mathrm{H}-\mathrm{H}}=7.4 \mathrm{~Hz}, \mathrm{C}_{6} H_{5}\right), 7.57\left(\mathrm{t}, 2 \mathrm{H}, \mathrm{H}-9,9^{\prime}\right.$, $\left.{ }^{3} J_{\mathrm{H}-\mathrm{H}}=7.3 \mathrm{~Hz}, \mathrm{C}_{6} H_{5}\right), 7.70\left(\mathrm{ddd}, 1 \mathrm{H}, \mathrm{H}-4,{ }^{3} J_{\mathrm{H}-\mathrm{H}}=7.4 \mathrm{~Hz},{ }^{4} J_{\mathrm{H}-\mathrm{H}}=\right.$ $\left.1.2 \mathrm{~Hz}, \mathrm{C}_{6} H_{4}\right), 7.78\left(\mathrm{dd}, 1 \mathrm{H}, \mathrm{H}-3,{ }^{3} J_{\mathrm{H}-\mathrm{H}}=7.6 \mathrm{~Hz},{ }^{4} J_{\mathrm{H}-\mathrm{H}}=1.4 \mathrm{~Hz}\right.$, $\left.\mathrm{C}_{6} H_{4}\right), 7.93\left(\mathrm{ddd}, 1 \mathrm{H}, \mathrm{H}-5,{ }^{3} J_{\mathrm{H}-\mathrm{H}}=7.5 \mathrm{~Hz},{ }^{4} J_{\mathrm{H}-\mathrm{H}}=1.4 \mathrm{~Hz}, \mathrm{C}_{6} H_{4}\right)$, $10.42\left(\mathrm{~d}, 1 \mathrm{H}, \mathrm{H}-6,{ }^{3} J_{\mathrm{H}-\mathrm{H}}=7.7 \mathrm{~Hz}, \mathrm{C}_{6} H_{4}\right) .{ }^{13} \mathrm{C}\left\{{ }^{1} \mathrm{H}\right\} \mathrm{NMR}$ $\left(125.81 \mathrm{MHz}, \mathrm{CDCl}_{3}\right): \delta 127.68$ (s, C-8, $\left.8^{\prime}\right), 129.39$ (s, C-4), 129.70 (s, C-10), 130.23 (s, C-9,9'), 131.53 (s, C-3), 135.86 (s, C-5), 142.79 (s, C-7), 146.35 (s, C-6), 147.29 (s, C-2), C-1 could not be detected.

Synthesis of $\left(2-\mathrm{PhC}_{6} \mathrm{H}_{4}\right)_{3} \mathbf{S b}(\mathbf{9})$. A solution of ${ }^{n} \mathrm{BuLi}$ in $n$-hexane (2.33 mL, 2.5 M, $5.83 \mathrm{mmol}$ ) was added dropwise, at $-78{ }^{\circ} \mathrm{C}$, to a stirred solution of 2-bromobiphenyl $(1.130 \mathrm{~g}, 4.85 \mathrm{mmol})$ in anhydrous $\mathrm{Et}_{2} \mathrm{O}(35 \mathrm{~mL})$. The reaction mixture was stirred for $2 \mathrm{~h}$ at $-78^{\circ} \mathrm{C}$. After that the organolithium compound was added dropwise to a solution of $\mathrm{SbCl}_{3}(1.106 \mathrm{~g}, 4.85 \mathrm{mmol})$ in $\mathrm{Et}_{2} \mathrm{O}$ $(50 \mathrm{~mL})$, the reaction mixture was kept at $-78{ }^{\circ} \mathrm{C}$ for $2 \mathrm{~h}$ and then stirred overnight at ambient temperature. The solvent was evacuated in vacuo and the creamy precipitate was extracted with toluene $(3 \times 10 \mathrm{~mL})$, the solution filtrated and after removal of the solvent in vacuo, a colorless powder was isolated. Single crystals suitable for X-ray analysis were grown from a $\mathrm{CH}_{2} \mathrm{Cl}_{2}$ solution. Yield: $0.228 \mathrm{~g}(24 \%)$. M.p. $=214-215{ }^{\circ} \mathrm{C}$. Elemental analysis calcd (\%) for $\mathrm{C}_{36} \mathrm{H}_{27} \mathrm{Sb}\left(581.36 \mathrm{~g} \mathrm{~mol}^{-1}\right)$ : C, 74.38; H, 4.68. Found: C, 73.89; H, 4.62. ATR FTIR $\left(\mathrm{cm}^{-1}\right): 3054(\mathrm{~m})$, $3033(\mathrm{~m}), 2364(\mathrm{w}), 2322(\mathrm{w}), 1927(\mathrm{w}), 1822(\mathrm{w}), 1752(\mathrm{w})$, $1598(\mathrm{w}), 1577(\mathrm{~m}), 1559(\mathrm{w}), 1494(\mathrm{~m}), 1456(\mathrm{~s}), 1440(\mathrm{~s})$, 
1419 (s), 1382 (w), 1332 (w), 1282 (w), 1244 (m), 1178 (m), 1161 (m), $1111(\mathrm{~m}), 1074(\mathrm{~m}), 1032(\mathrm{w}), 1023(\mathrm{w}), 1008(\mathrm{~s}), 995(\mathrm{w})$, $983(\mathrm{w}), 966(\mathrm{w}), 949(\mathrm{~m}), 907(\mathrm{~m}), 874(\mathrm{w}), 841(\mathrm{~m}), 770(\mathrm{~s})$, 749 (vs), 730 (s), 697 (vs), 671 (m), 649 (m), 616 (s), 571 (w), 546 (s), 533 (s), 488 (w), 452 (s), 446 (s), 440 (s), 413 (w), 401 (w). ${ }^{1} \mathrm{H}$ NMR (500.30 MHz, $\left.\mathrm{CDCl}_{3}\right): \delta 6.97-7.02\left(\mathrm{~m}, 6 \mathrm{H}, \mathrm{H}-8,8^{\prime}, \mathrm{C}_{6} H_{5}\right), 7.13-7.21$ (m, 9H, H-9,9', H-10, $\left.\mathrm{C}_{6} H_{5}\right)$, 7.22-7.29 (m, 6H, H-3, H-4, $\mathrm{C}_{6} H_{4}$ ), 7.35-7.38 (m, 6H, H-5 and H-6, $\left.\mathrm{C}_{6} H_{4}\right) .{ }^{13} \mathrm{C}\left\{{ }^{1} \mathrm{H}\right\}$ NMR $(125.81 \mathrm{MHz}$, $\mathrm{CDCl}_{3}$ ): $\delta 127.19$ (s, C-10), 127.65 (s, C-4), 127.98 (s, C-9,9'), 128.43 (s, C-3), 129.21 (s, C-5), 129.30 (s, C-8,8'), 137.45 (s, C-6), 140.70 (s, C-1), 143.89 (s, C-7), 149.70 (s, C-2).

\section{Conflicts of interest}

There are no conflicts to declare.

\section{Acknowledgements}

We gratefully acknowledge financial support from the DFG SPP1807 "Control of London Dispersion Interactions in Molecular Chemistry". We thank Prof. S. Spange for access to the IR instrument. We are grateful to Anja Veit and Lutz Mertens for measuring the IR spectra and PXRD, respectively. We also thank Ute Stöß and Janine Freytag for performing the CHN analyses. We thank Sebastian Scharf und Sebastian Notz for measuring the temperature dependent NMR spectra. M. Korb thanks the Fonds der Chemischen Industrie for a PhD Chemiefonds fellowship. Ana Toma is grateful for financial support from the DAAD within the frame of the Eastern Europe Partnership program. Cristian Silvestru is grateful for financial support by TU Chemnitz of a short term scientific guest exchange. Anca Silvestru is thanked for ongoing fruitful cooperation in the field of organometallic synthesis. A. A. Auer, M. Krasowska and K. Bhattacharyya would like to acknowledge funding the Max Planck Society and the Max-Planck-Institut für Kohlenforschung. Open Access funding provided by the Max Planck Society.

\section{References}

1 C. Silvestru, H. J. Breunig and H. Althaus, Chem. Rev., 1999, 99, 3277-3328.

2 H. Schmidbaur and A. Schier, Organometallics, 2008, 27, 2361-2395.

3 V. M. Cangelosi, M. A. Pitt, W. J. Vickaryous, C. A. Allen, L. N. Zakharov and D. W. Johnson, Cryst. Growth Des., 2010, 10, 3531-3536.

4 J. Zukerman-Schpector and E. R. T. Tiekink, The Importance of Pi-Interactions in Crystal Engineering, John Wiley \& Sons, Ltd, 2012, pp. 275-299.

5 M. M. Watt, M. S. Collins and D. W. Johnson, Acc. Chem. Res., 2013, 46, 955-966.

6 I. Caracelli, I. Haiduc, J. Zukerman-Schpector and E. R. T. Tiekink, Coord. Chem. Rev., 2013, 257, 2863-2879.

7 I. Caracelli, J. Zukerman-Schpector, I. Haiduc and E. R. T. Tiekink, CrystEngComm, 2016, 18, 6960-6978.
8 E. R. T. Tiekink, Coord. Chem. Rev., 2017, 345, 209-228.

9 D. J. Liptrot and P. P. Power, Nat. Rev. Chem., 2017, 1, 0004.

10 W. B. Schneider, G. Bistoni, M. Sparta, M. Saitow, C. Riplinger, A. A. Auer and F. Neese, J. Chem. Theory Comput., 2016, 12, 4778-4792.

11 S. Grimme, A. Hansen, J. G. Brandenburg and C. Bannwarth, Chem. Rev., 2016, 116, 5105-5154.

12 G. Bistoni, A. A. Auer and F. Neese, Chem. - Eur. J., 2017, 23, 865-873.

13 R. Lo, P. Švec, Z. Růžičková, A. Růžička and P. Hobza, Chem. Commun., 2016, 52, 3500-3503.

14 A. Bauzá, D. Quiñonero, P. M. Deyà and A. Frontera, CrystEngComm, 2013, 15, 3137-3144.

15 A. Bauzá, D. Quiñonero, P. M. Deyà and A. Frontera, Phys. Chem. Chem. Phys., 2012, 14, 14061-14066.

16 A. A. Auer, D. Mansfeld, C. Nolde, W. Schneider, M. Schürmann and M. Mehring, Organometallics, 2009, 28, 5405-5411.

17 D. Mansfeld, M. Mehring and M. Schürmann, Z. Anorg. Allg. Chem., 2004, 630, 1795-1797.

18 A. M. Preda, W. B. Schneider, M. Rainer, T. Rüffer, D. Schaarschmidt, H. Lang and M. Mehring, Dalton Trans., 2017, 46, 8269-8278.

19 A. M. Toma, A. Pop, A. Silvestru, T. Rüffer, H. Lang and M. Mehring, Dalton Trans., 2017, 46, 3953-3962.

20 A. M. Preda, M. Krasowska, L. Wrobel, P. Kitschke, P. C. Andrews, J. G. MacLellan, L. Mertens, M. Korb, T. Rüffer, H. Lang, A. A. Auer and M. Mehring, Beilstein J. Org. Chem., 2018, 14, 2125-2145.

21 A. M. Preda, W. B. Schneider, D. Schaarschmidt, H. Lang, L. Mertens, A. A. Auer and M. Mehring, Dalton Trans., 2017, 46, 13492-13501.

22 L. Wrobel, T. Rüffer, M. Korb, H. Krautscheid, J. Meyer, P. C. Andrews, H. Lang and M. Mehring, Chem. - Eur. J., 2018, 24, 16630-16644.

23 K. Srinivas, P. Suresh, C. N. Babu, A. Sathyanarayana and G. Prabusankar, RSC Adv., 2015, 5, 15579-15590.

24 H. J. Breunig, N. Haddad, E. Lork, M. Mehring, C. Mügge, C. Nolde, C. I. Raţ and M. Schürmann, Organometallics, 2009, 28, 1202-1211.

25 C. Hering-Junghans, M. Thomas, A. Villinger and A. Schulz, Chem. - Eur. J., 2015, 21, 6713-6717.

26 C. Hering-Junghans, A. Schulz and A. Villinger, Chem. Commun., 2015, 51, 13834-13837.

27 C. Hering-Junghans, A. Schulz, M. Thomas and A. Villinger, Dalton Trans., 2016, 45, 6053-6059.

28 B. Twamley, C. D. Sofield, M. M. Olmstead and P. P. Power, J. Am. Chem. Soc., 1999, 121, 3357-3367.

29 J. Bresien, C. Hering-Junghans, A. Schulz, M. Thomas and A. Villinger, Organometallics, 2018, 37, 2571-2580.

30 R. J. Schwamm, C. M. Fitchett and M. P. Coles, Chem. Asian J., 2019, 14, 1204-1211.

31 A. Schulz, M. Thomas and A. Villinger, Z. Anorg. Allg. Chem., 2017, 643, 1406-1414.

32 J. Bresien, A. Schulz, M. Thomas and A. Villinger, Eur. J. Inorg. Chem., 2019, 1279-1287. 
33 J. Fanfrlik, R. Sedlak, A. Pecina, L. Rulisek, L. Dostal, J. Moncol, A. Ruzicka and P. Hobza, Dalton Trans., 2016, 45, 462-465.

34 M. Krasowska, W. B. Schneider, M. Mehring and A. A. Auer, Chem. - Eur. J., 2018, 24, 10238-10245.

35 M. Krasowska, A.-M. Fritzsche, M. Mehring and A. A. Auer, ChemPhysChem, 2019, 20, 2539-2552.

36 D. E. Worrall, J. Am. Chem. Soc., 1936, 58, 1820-1821.

37 D. E. Worrall, J. Am. Chem. Soc., 1940, 62, 2514-2515.

38 D. M. Hawley and G. Ferguson, J. Chem. Soc. A, 1968, 2059-2063.

39 P. G. Jones, A. Blaschette, D. Henschel and A. Weitze, Z. Kristallogr., 1995, 210, 377-378.

40 T. Ogawa, T. Ikegami, T. Hikasa, N. Ono and H. Suzuki, J. Chem. Soc., Perkin Trans. 1, 1994, 3479-3483.

41 V. Stavila, J. H. Thurston, D. Prieto-Centurión and K. H. Whitmire, Organometallics, 2007, 26, 6864-6866.

42 S. Alvarez, Dalton Trans., 2013, 42, 8617-8636.

43 W. Clegg, R. J. Errington, G. A. Fisher, D. C. R. Hockless, N. C. Norman, A. G. Orpen and S. E. Stratford, J. Chem. Soc., Dalton Trans., 1992, 1967-1974.

44 W. Clegg, R. J. Errington, G. A. Fisher, R. J. Flynn and N. C. Norman, J. Chem. Soc., Dalton Trans., 1993, 637-641.

45 M. Mantina, A. C. Chamberlin, R. Valero, C. J. Cramer and D. G. Truhlar, J. Phys. Chem. A, 2009, 113, 5806-5812.

46 S. Grimme, J. Chem. Theory Comput., 2019, 15, 2847-2862. 47 S. Kamepalli, C. J. Carmalt, R. D. Culp, A. H. Cowley, R. A. Jones and N. C. Norman, Inorg. Chem., 1996, 35, 6179-6183.

48 L. M. Opris, A. Silvestru, C. Silvestru, H. J. Breunig and E. Lork, Dalton Trans., 2003, 4367-4374.

49 A. Soran, H. J. Breunig, V. Lippolis, M. Arca and C. Silvestru, J. Organomet. Chem., 2010, 695, 850-862.

50 H. Suzuki, T. Murafuji, Y. Matano and N. Azuma, J. Chem. Soc., Perkin Trans. 1, 1993, 2969-2973.

51 H. Suzuki, T. Murafuji and N. Azuma, J. Chem. Soc., Perkin Trans. 1, 1993, 1169-1175.

52 M. Kaupp, O. L. Malkina, V. G. Malkin and P. Pyykkö, Chem. - Eur. J., 1998, 4, 118-126.

53 J. Ariai and G. Saielli, ChemPhysChem, 2019, 20, 108-115.

54 M. Rubio, M. Merchan and E. Orti, Theor. Chim. Acta, 1995, 91, 17-29.

55 MestReNova, (version 11.0.4-18998), Mestrelab Research S. L., Santiago de Compostela, 2017.

56 ChemDraw $^{\mathbb{R}}$ Prime (version 17.1), PerkinElmer Informatics, Waltham, MA, 2018.

57 Origin $^{\circledR}$ Pro 2017, OriginLab, Northampton, MA, 2017.

58 G. M. Sheldrick, SHELXS-2013, Program for Crystal Structures Solution, University of Göttingen, 2013.

59 G. M. Sheldrick, Acta Crystallogr., Sect. A: Found. Crystallogr., 2008, 64, 112-122.

60 G. M. Sheldrick, SHELXL-2013, Program for Crystal Structures Refinement, University of Göttingen, 2013.

61 G. M. Sheldrick, Acta Crystallogr., Sect. C: Struct. Chem., 2015, 71, 3-8.

62 K. Brandenburg and H. Putz, Diamond - Crystal and Molecular Structure Visualization (version 4.5), Bonn, 2018.

63 S. Grimme, C. Bannwarth and P. Shushkov, J. Chem. Theory Comput., 2017, 13, 1989-2009.
64 C. Bannwarth, S. Ehlert and S. Grimme, J. Chem. Theory Comput., 2019, 15, 1652-1671.

65 J. P. Perdew, K. Burke and M. Ernzerhof, Phys. Rev. Lett., 1996, 77, 3865-3868.

66 J. P. Perdew, K. Burke and M. Ernzerhof, Phys. Rev. Lett., 1997, 78, 1396.

67 F. Weigend and R. Ahlrichs, Phys. Chem. Chem. Phys., 2005, 7, 3297-3305.

68 F. Weigend, Phys. Chem. Chem. Phys., 2006, 8, 1057-1065.

69 B. Metz, H. Stoll and M. Dolg, J. Chem. Phys., 2000, 113, 2563-2569.

70 K. A. Peterson, D. Figgen, E. Goll, H. Stoll and M. Dolg, J. Chem. Phys., 2003, 119, 11113-11123.

71 S. Grimme, J. Antony, S. Ehrlich and H. Krieg, J. Chem. Phys., 2010, 132, 154104.

72 S. Grimme, S. Ehrlich and L. Goerigk, J. Comput. Chem., 2011, 32, 1456-1465.

73 A. D. Becke and E. R. Johnson, J. Chem. Phys., 2005, 123, 154101.

74 F. Neese, A. Hansen and D. G. Liakos, J. Chem. Phys., 2009, 131, 064103.

75 F. Neese, A. Hansen, F. Wennmohs and S. Grimme, Acc. Chem. Res., 2009, 42, 641-648.

76 A. Hansen, D. G. Liakos and F. Neese, J. Chem. Phys., 2011, 135, 214102.

77 D. G. Liakos, A. Hansen and F. Neese, J. Chem. Theory Comput., 2011, 7, 76-87.

78 C. Riplinger and F. Neese, J. Chem. Phys., 2013, 138, 034106.

79 C. Riplinger, B. Sandhoefer, A. Hansen and F. Neese, J. Chem. Phys., 2013, 139, 134101.

80 C. Riplinger, P. Pinski, U. Becker, E. F. Valeev and F. Neese, J. Chem. Phys., 2016, 144, 024109.

81 T. H. Dunning, J. Chem. Phys., 1989, 90, 1007-1023.

82 K. A. Peterson, J. Chem. Phys., 2003, 119, 11099-11112.

83 K. A. Peterson and K. E. Yousaf, J. Chem. Phys., 2010, 133, 174116.

84 F. Weigend, J. Comput. Chem., 2008, 29, 167-175.

85 F. Weigend, A. Kohn and C. Hattig, J. Chem. Phys., 2002, 116, 3175-3183.

86 C. Hättig, G. Schmitz and J. Koßmann, Phys. Chem. Chem. Phys., 2012, 14, 6549-6555.

87 D. G. Liakos and F. Neese, J. Chem. Theory Comput., 2015, 11, 4054-4063.

88 D. G. Liakos, M. Sparta, M. K. Kesharwani, J. M. L. Martin and F. Neese, J. Chem. Theory Comput., 2015, 11, 1525-1539.

89 Y. Zhao and D. G. Truhlar, J. Chem. Phys., 2006, 125, 194101.

90 J. Tao, J. P. Perdew, V. N. Staroverov and G. E. Scuseria, Phys. Rev. Lett., 2003, 91, 146401.

91 F. Jensen, J. Chem. Theory Comput., 2015, 11, 132-138.

92 T. Noro, M. Sekiya and T. Koga, Theor. Chem. Acc., 2013, 132, 1363.

93 G. L. Stoychev, A. A. Auer and F. Neese, J. Chem. Theory Comput., 2017, 13, 554-562.

94 E. J. Baerends, D. E. Ellis and P. Ros, Chem. Phys., 1973, 2, 41-51. 
95 J. L. Whitten, J. Chem. Phys., 1973, 58, 4496-4501.

96 B. I. Dunlap, J. W. D. Connolly and J. R. Sabin, J. Chem. Phys., 1979, 71, 3396-3402.

97 M. Feyereisen, G. Fitzgerald and A. Komornicki, Chem. Phys. Lett., 1993, 208, 359-363.

98 O. Vahtras, J. Almlöf and M. W. Feyereisen, Chem. Phys. Lett., 1993, 213, 514-518.
99 K. Eichkorn, O. Treutler, H. Öhm, M. Häser and R. Ahlrichs, Chem. Phys. Lett., 1995, 240, 283-290.

100 R. A. Kendall and H. A. Fruchtl, Theor. Chem. Acc., 1997, 97, 158-163.

101 F. Weigend and M. Haser, Theor. Chem. Acc., 1997, 97, 331-340. 102 F. Weigend, M. Häser, H. Patzelt and R. Ahlrichs, Chem. Phys. Lett., 1998, 294, 143-152. 